$$
\begin{aligned}
& \text { 震 }
\end{aligned}
$$

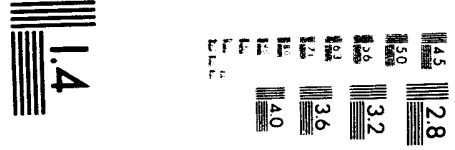

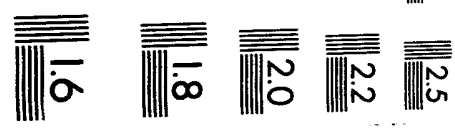



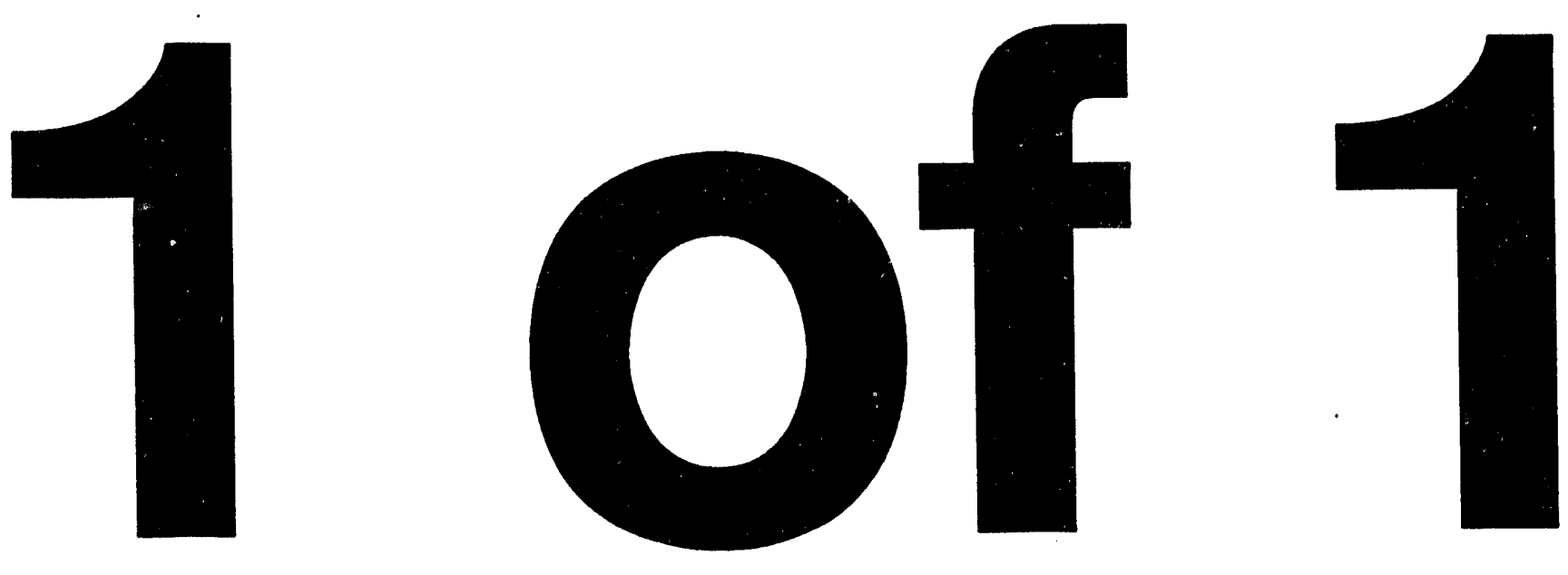


\section{ANL/CHM/PP.. 80545}

\section{Three Methods to Measure RH Bond Energies}

\author{
Joseph Berkowitz \\ Chemistry Division \\ Argonne National Laboratory \\ Argonne, IL 60439 \\ (708) $252-4086$ \\ (708) 252-9647 FAX
}

G. Barney Ellison

Department of Chemistry \& Biochemistry University of Colorado Boulder, CO 80309-0215

\author{
David Gutman \\ Department of Chemistry \\ Catholic University of America \\ Washington, DC 20064 \\ (202) 319-5383 (lab) \\ (202) 319-5381 (FAX)
}

\section{DISCLAIMER}

\footnotetext{
This report was prepared as an account of work sponsored by an agency of the United States Government. Neither the United States Government nor any agency thereof, nor any of their employees, makes any warranty, express or implied, or assumes any legal liability or responsibility for the accuracy, completeness, or usefulness of any information, apparatus, product, or process disclosed, or represents that its use would not infringe privately owned rights. Reference herein to any specific commercial product, process, or service by trade name, trademark, manufacturer, or otherwise does not necessarily constitute or imply its endorsement, recommendation, or favoring by the United States Government or any agency thereof. The views and opinions of authors expressed herein do not necessarily state or reflect those of the United States Government or any agency thereof.
} 
All chemists need to know bond energies. The energy changes associated with making and breaking bonds between atoms in a molecule are important practical concepts used everywhere in chemistry. In addition to being useful to synthetic chemists and material scientists, bond energies are also very good tests for empirical and ab initio theories of electronic structure. Accurate energies are essential for atmospheric and combustion modelling.

Bond dissociation energies (BDEs) offer an interesting window through which to view the stability of radicals. In contrast to closed shell species, the bond energies of radicals can sometimes be surprising. To wit, both the $\mathrm{C}-\mathrm{H}$ and $\mathrm{O}-\mathrm{H}$ bonds in methanol are roughly $100 \mathrm{kcal} / \mathrm{mol}$; in contrast recent studies[1] reveal that the corresponding bond strengths of the methoxy radical or the hydroxymethyl radical are much less (21 and 29 $\mathrm{kcal} / \mathrm{mol}$ ). Likewise, the first $\mathrm{C}-\mathrm{H}$ bond in benzene is approximately $110 \mathrm{kcal} / \mathrm{mol}$ which contrasts[2] to the energy of the $2^{\text {nd }} \mathrm{C}-\mathrm{H}$ bonds that lead to ortho-benzyne (79 i:cal/mol), or meta-benzyne $(89 \mathrm{kcal} / \mathrm{mol})$, or para-benzyne $(101 \mathrm{kcal} / \mathrm{mol})$.
$\mathrm{H}-\mathrm{CH}_{2} \mathrm{O}$
$\mathrm{CH}_{2} \mathrm{O}-\mathrm{H}$
$21 \mathrm{kcal} / \mathrm{mol}$
$29 \mathrm{kcal} / \mathrm{mol}$

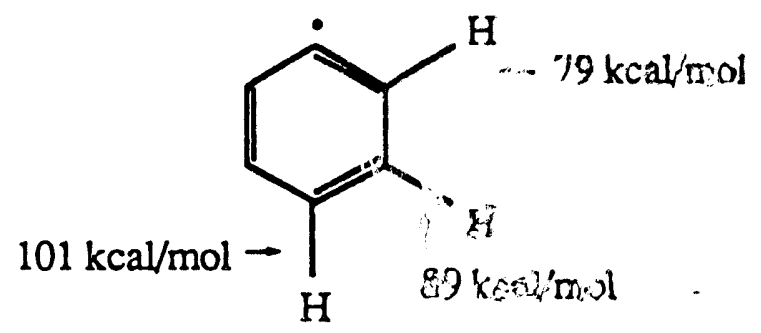

This is an essay which surives to compare and contrast three fowert 21 mashods for the experimental determination of polyatomic bond energies: radical kirits. prase acidity cycles, and photoionization mass spectroscopy.

Many techniques[3] have been used to measure a huge number of BDE's and it is not our purpose to survey this massive field. Instead, we will discuss three approaches that are commonly used to determine the $\mathrm{R}-\mathrm{H}$ bond energies of gas phase[4] polyatomic 
molecules: a) the study of radical kinetics, b) the use of negative ion thermochemical cycles, and c) photoionization mass spectroscopic techniques. It is essential to stress the complementarity of these three experimental methods; they are all inter-related. Our goal in this essay is to dissect each of our methods to describe how the measurements are carried out, what the limitations are, and to demonstrate by direct comparison that all give the same bond energies. An introduction to these three experimental programs is now in order.

\section{a) Radical Kinetics}

Suppose one measures the kinetics of equilibrium of a halogen atom, $\mathrm{X}$, with a substrate, RH.

$$
\mathrm{RH}+\mathrm{X}=\mathrm{R}+\mathrm{XH}
$$

By monitoring the time dependence of $[\mathrm{X}]$ and $[\mathrm{R}]$ after flash photolysis, by atomic fluorescence, and/or resonance lamp photoionization detection, one can determine the absolute rate constants $k_{1}$ and $k_{-1}$. These rate constants fix the equilibrium constant, $K_{\text {equi }}(1)$, which permits one to determine $\Delta G_{r x n}(1)$, from which the enthalpy, $\Delta H_{r \times n}(1)$, can be extracted. If the heats of formation $\left(\Delta \mathrm{H}_{\mathrm{f}}{ }^{\circ}(\mathrm{RH}), \Delta \mathrm{H}_{\mathrm{f}}{ }^{\circ}(\mathrm{X})\right.$, and $\left.\Delta \mathrm{H}_{\mathrm{f}}{ }^{\circ}(\mathrm{XH})\right)$ are known, $\Delta H_{r x n}(1)$ permits one to find $\Delta H_{f}{ }^{\circ}(R)$ which fixes the bond energy, $B D E(R-H)$.

\section{b) Negative len Cycles}

Ion chemistry can be used to deduce the gas phase acidity of a target molecule, RH. The acidity, $\Delta H_{\text {acid }}$, is the enthalpy for the proton abstraction reaction.

$$
\mathrm{RH} \rightarrow \mathrm{R}^{-}+\mathrm{H}^{+}
$$

This acidity is related to the bond dissociation energy and the electron affinity of the final radical by the following relationship:

$$
\Delta H_{\text {acid }}(\mathrm{R}-\mathrm{H})=\mathrm{BDE}(\mathrm{R}-\mathrm{H})+\mathrm{IP}(\mathrm{H})-\mathrm{EA}(\mathrm{R})
$$


One uses negative ion photoelectron spectroscopy to measure the EA(R) of the radical and combines it with the $\Delta H_{a c i d}(R-H)$ to extract values for $B D E(R-H)$.

\section{c) Photoionization Mass Spectroscopy}

By photoionization mass spectrometry (PIMS) one can measure the appearance energy $\left[E_{A P}(R-H)\right]$ of the dissociative process: $A P(R+, R H)$

$$
\mathrm{RH}+\mathrm{hv}_{\mathrm{AP}} \rightarrow \mathrm{R}^{+}+\mathrm{H}+\mathrm{e}^{-}
$$

This threshold can be related to the ionization energy of the radical and the bond strength.

$$
E_{A P}\left(R^{+}, R H\right)=B D E(R-H)+I P(R)
$$

PIMS and photoelectron spectroscopy are complementary methods to study the ionization energies of radicals. If the threshold for (4) can be accurately found, then the combination of $E_{A P}$ and IP permits one to extract $B D E(R-H)$. Alternatively, if $\Delta H_{f, 0 K}(R H)$ is known, $E_{A P}\left(R^{+}, R H\right)$ provides one with the heat of formation of the cation; $\Delta H_{f, 0 K}\left(R^{+}\right)=$ $\mathrm{E}_{\mathrm{AP}}\left(\mathrm{R}^{+}, \mathrm{RH}\right)+\Delta \mathrm{H}_{\mathrm{f}, 0 \mathrm{~K}}(\mathrm{RH})-\Delta \mathrm{H}_{\mathrm{f}, 0 \mathrm{~K}}(\mathrm{H})$.

These three techniques are all gas phase measurements which provide bond energies without having to deal with solvent effects. These methods can be used on a large number of species (hundreds) and have an accuracy between $\pm 3 \mathrm{kcal} / \mathrm{mol}$ and \pm 0.2 $\mathrm{kcal} / \mathrm{mol}[5]$. Our goal here is to compare these three experiments with each other and to demonstrate by direct comparison that they achieve consistent results.

We will not attempt to survey the computational literature. It is very important to recognize that $a b$ initio electronic structure calculations have developed to the point where they can provide significant assistance to the experimentalist. These elaborate computations require very large basis sets, careful attention to electron correlation, and can only be applied to molecules with a few heavy atoms. When the target molecule is small enough for 
these techniques to be applied, bond energies can be computed to an accuracy of roughly \pm $2 \mathrm{kcal} / \mathrm{mol}[6]$.

Before we begin to discuss bond energies, it is important to define terms. This may seem pedantic but not everyone means the same thing when referring to a BDE. Consider the dissociation of some polyatomic species (such as $\mathrm{H}_{2} \mathrm{O}, \mathrm{NH}_{3}, \mathrm{SiH}_{4}$ or $\mathrm{C}_{6} \mathrm{H}_{5} \mathrm{CH}_{2}-\mathrm{H}$ ):

$$
\mathrm{RH} \rightarrow \mathrm{R}+\mathrm{H}
$$

At $0 \mathrm{~K}$ the energy for process (6) is called the dissociation energy and is written[7] as $D_{0}(R$ H). This is the difference of the zero point energies:

$$
D_{0}(R-H) \equiv E_{0}(R)+E_{0}(H)-E_{0}(R H)
$$

If one considers dissociation (6) at some temperature $\mathrm{T}$ other than absolute zero, the proper function to consider is the enthalpy, $\mathrm{H}$, since the dissociation breaks one molecule into two and produces $\mathrm{pV}$ work.

$$
H=E+p V \equiv E+R T
$$

Thus dissociation at room temperature, where most experiments are done, is properly[8] a dissociation enthalpy (which is sometimes referred to as a bond enthalpy).

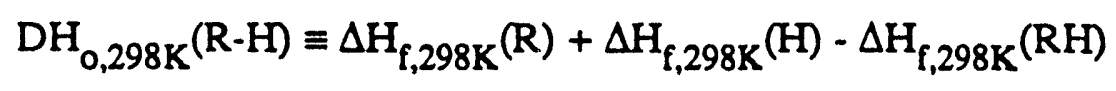

In order to relate $\mathrm{D}_{0}(\mathrm{R}-\mathrm{H})$ to $\mathrm{DH}_{0,298 \mathrm{~K}}(\mathrm{R}-\mathrm{H})$, one makes use[9] of the integrated heat capacity.

$$
\mathrm{DH}_{\mathrm{o} 298 \mathrm{~K}}(\mathrm{R}-\mathrm{H})=\mathrm{D}_{\mathrm{o}}(\mathrm{R}-\mathrm{H})+\int_{0}^{298} \mathrm{dT}\left[\mathrm{C}_{\mathrm{p}}(\mathrm{R})+\mathrm{C}_{\mathrm{p}}(\mathrm{H})-\mathrm{C}_{\mathrm{p}}(\mathrm{RH})\right]
$$

To dissociate $\mathrm{R}-\mathrm{H}$ at temperature $\mathrm{T}$, energy must be supplied to break the bond but it flows into all accessible degrees of freedom of the products as well. The molecule RH with its translations, rotations, and vibrations at temperature, $T$, shatters to produce fragments with different masses, rotational constants, and vibrational frequencies. The dissociation 
products, $H$ and $R$, will also be described by a Maxwell Boltzmann distribution. Equation (10) tells you that as $\mathrm{T} \rightarrow 0 \mathrm{~K}, \mathrm{DH}_{0, \mathrm{~T} \mathrm{~K}}(\mathrm{R}-\mathrm{H})-\mathrm{D}_{0}(\mathrm{R}-\mathrm{H})$.

\section{Experimental Probes of Bond Energies}

\section{A. Radical Kinetics}

Studies of the kinetics of equilibria involving the reactions of halogen atoms $\mathrm{X}=$ $\mathrm{Cl}, \mathrm{Br}, \mathrm{I}$ ) with organic molecules $\mathrm{R}-\mathrm{H}$ have been (for nearly 50 years) $[10,11,12,13,14,15,16,17,18,19]$, and continue to be, a rich source of thermochemical information on $\mathrm{R}-\mathrm{H}$ bonds broken in reactions such as eq.(1). Ideally, the forward and reverse reactions are isolated for direct study and rate constants $\left(k_{1}\right.$ and $\left.k_{-1}\right)$ measured. If $k_{1}$ and $k_{-1}$ can be measured accurately as a function of temperature, the Arrhenius activation energies $\left(E_{1}\right.$ and $\left.E_{-1}\right)$ are established, and $\Delta H_{r \times n}(1)$, obtained from $E_{1}-E_{-1}$, for the mid-temperature of the experiments is obtained directly. This is the Second Law method for obtaining $\Delta \mathrm{H}_{\mathrm{rxn}}$. If $\mathrm{k}_{1}$ and $\mathrm{k}_{-1}$ can be determined at only a single temperature (or over a very limited temperature range), $\Delta \mathrm{H}_{\mathrm{Ixn}}$ (1) can still be obtained. In this case, the more limited kinetic information provides $K_{\text {equi }}(1)=k_{1} / k_{-1}$ and hence $\Delta G_{r \times n}(1)$ at one temperature. $\Delta G_{r \times n}(1)$ may be combined with $\Delta S_{r \times n}(1)$ at the same temperature to obtain $\Delta \mathrm{H}_{\mathrm{rxn}}(1) . \Delta \mathrm{S}_{\mathrm{rxn}}(1)$ is obtained from calculated entropies of reactants and products using partition functions. This latter procedure for obtaining $\Delta H_{r \times n}(1)$ is referred to as the Third Law method. If $R$ is a relatively small radical ( $\leq 15$ atoms) its structure and vibrational frequencies are frequently known from experiment and/or $a b$ initio calculations, permitting more accurate calculation of radical entropies (and hence of reaction entropies) than is obtained from experiment (from a knowledge of $\Delta G_{\Gamma \times n}(1)$ and $\left.\Delta H_{\Gamma \times n}(1)\right)$. If this is the case, the Third Law method provides a somewhat more accurate radical heat of formation than does the Second Law method. 
Experimentally determined values of $\Delta \mathrm{H}_{\mathrm{rxn}}(1)$ and/or $\Delta \mathrm{G}_{\mathrm{rxn}}(1)$ are for a characteristic temperature of the experiments and are "corrected" to $298 \mathrm{~K}$ using tabulated or calculated heat capacities[20]. $\Delta C_{p, r \times n}(1)$ is usually so small that this correction rarely is over $0.2 \mathrm{kcal} / \mathrm{mol}$. Hence, if the Second Law method is used, $\Delta \mathrm{H}_{\Gamma \times n}(1)$ is obtained essentially directly from experiment without the need for other data or for assumptions. Since $\Delta \mathrm{H}_{\mathrm{f}}{ }^{\circ}(\mathrm{RH}), \Delta \mathrm{H}_{\mathrm{f}}{ }^{\circ}(\mathrm{X})$, and $\Delta \mathrm{H}_{\mathrm{f}}{ }^{\circ}(\mathrm{HX})$ are known, $\Delta \mathrm{H}_{\mathrm{f}}{ }^{\circ}(\mathrm{R})$ (and hence the $\mathrm{BDE}(\mathrm{R}$ $H)$ ) can be obtained from the experimental determination of $\Delta H_{\Gamma \times n}(1)$.

In recent years, the development of flash-photolysis techniques combined with sensitive detection methods has permitted isolating both forward and reverse reactions of equilibria involving the reactions of halogen atoms with organic substrates, reactions (1) and $(-1)$. Atomic fluorescence has been most valuable for monitoring the kinetics of the forward $X+R-H$ reactions $[17,21,22,23,24,25,26]$ and photoionization massspectrometry, which has been found to be extremely useful as a sensitive detector of polyatomic free radicals[27], $R$, has been used to study $R+H X$ reactions in time-resolved experiments under essentially isolated conditions.

Prior to 1988, it was typically necessary to combine kinetic information on the forward reactions with assumed information on the reverse reactions to obtain the desired thermochemical information on reaction $(1)[14,15,16]$. While there were many direct kinetic studies of $\mathrm{X}+\mathrm{R}-\mathrm{H}$ reactions reported, there were essentially none of the reverse reactions, $(-1)$, due to the greater difficulty of isolating reactions of polyatomic free radicals for kinetic study. Typically, in these older thermochemical studies, the measured activation energies of the forward reactions were combined with assumed activation energies of the reverse reactions to obtain $\Delta H_{\Gamma \times n}(1), \Delta H_{\Gamma \times n}(1)=E_{1}$ (measured) $-E_{-1}$ (assumed) $[14,15]$. From general knowledge that $\mathrm{R}+\mathrm{HX}$ reactions (involving $\mathrm{HBr}$ and $\mathrm{HI}$ ) are very rapid processes and from observations that $\mathrm{R}+\mathrm{HI}$ rate constants are larger than corresponding $\mathrm{R}$ 
+ $\mathrm{HBr}$ rate constants, it became the practice to use the following assumed "generic" activation energies for $R+H X$ reactions (which were presumed to be accurate to \pm 1 $\mathrm{kcal} / \mathrm{mol}$ ) to obtain $\Delta \mathrm{H}_{\mathrm{rxn}}$ (1) from the measured activation energies of $\mathrm{X}+\mathrm{R}-\mathrm{H}$ reactions: $2 \pm 1 \mathrm{kcal} / \mathrm{mol}$ for all $R+\mathrm{HBr}$ reactions and $1 \pm 1 \mathrm{kcal} / \mathrm{mol}$ for all $R+H I$ reactions. Reviews of these earlier studies, discussions of the thermochemical calculations and the assumptions used, and tables of radical heats of formation are provided by O'Neal and Benson[14] and by McMillen and Golden[15].

In the late-80's Gutman and coworkers developed a procedure to isolate $R+H X$ reactions for direct kinetic study. It involved the use of a heatable tubular reactor coupled to a very sensitive photoionization mass spectrometer. These relatively recent experiments and the technique used to isolate and study $\mathrm{R}+\mathrm{HX}$ reactions are described here. In these studies, it was discovered that virtually all the $\mathrm{R}+\mathrm{HBr}$ and $\mathrm{R}+\mathrm{HI}$ reactions investigated have negative activation energies, as low as $-2 \mathrm{kcal} / \mathrm{mol}$. Hence, new thermochemical calculations (since ' 88 ) based on measured activation energies for the $R+H X$ reactions have generally yielded higher heats of formation (and R-H bond energies). These revised values are typically $2-4 \mathrm{kcal} / \mathrm{mol}$ higher than those that were obtained from prior studies of the same equilibria, when "generic" activation energies for $R+H X$ reactions were used in thermochemical calculations.

The higher heats of formation (and $\mathrm{R}-\mathrm{H}$ bond energies) now being obtained from thermochemical studies of Reaction (1) are in complete accord with those obtained from studies of other equilibria involving neutral species, in particular studies of dissociationrecombination equilibria such as those involving several alkyl radicals which have been reviewed by Tsang:[28,29] R-H $=\mathrm{R}+\mathrm{H}$ and $\mathrm{R}-\mathrm{CH}_{3}=\mathrm{R}+\mathrm{CH}_{3}$. Former disparities between heats of formation derived from the two kinds of equilibria (i.e., $X+R H$ and dissociation-recombination equilibria) which had cast doubts on the veracity of the results obtained from both kinds of studies have completely disappeared[19,26]. 
The apparatus used by Gutman and coworkers[27] to study the kinetics of $R+H X$ reactions is shown in Fig. 1. Briefly, gas flowing through the heatable $1.05 \mathrm{~cm}$ or $2.20 \mathrm{~cm}$ i.d. Pyrex (or quartz) tubular reactor contains the radical precursor, $H X$ in varying amounts and an inert carrier gas in large excess ( $>99 \%$ helium at a pressure of roughly 5 Torr). Homogeneous reaction is initiated by pulsed unfocused radiation $(\cong 5 \mathrm{~Hz})$ from an excimer laser $\left(\lambda_{0}=193\right.$ or $\left.248 \mathrm{~nm}\right)$ directed along the axis of the tubular reactor, this burst of laser light photolyzes the radical precursor to generate the reactive species, $R$. The flow velocity ( 3 to $5 \mathrm{~m} \mathrm{~s}^{-1}$ ) is adequate to completely replace the gases in the reactor between laser pulses. Gas emerging from a small sampling orifice in the wall of the reactor is formed into a molecular beam and analyzed continuously using a photoionization mass spectrometer. The photoionizing light in the mass spectrometer is provided by simple high-intensity microwave-excited atomic resonance lamps[30,31]. By changing the gas flowing in the lamps, radiation of different ionizing energies is obtained in roughly $0.5 \mathrm{eV}$ steps between 7 and $11.6 \mathrm{eV}$. By using an ionizing photon with energy between the ionization potential of the radical of interest and the fragment onset of the precursor molecule, specious signals are suppressed and the radical, $R$, is detected by the appearance of the ion $\mathrm{R}^{+}$with essentially no background. For example, a hydrogen resonance lamp $(10.2 \mathrm{eV})$ is typically used to detect $\mathrm{CH}_{3}$ radicals which have an ionization potential of $9.8 \mathrm{eV}$.

The technique is sensitive enough to permit the use of initial concentrations of polyatomic free radicals in the range $10^{8}$ to $10^{11}$ radicals $\mathrm{cm}^{-3}$ in time-resolved kinetic experiments. Under these initial conditions, radical-radical recombination (a frequent competing process in kinetic studies involving polyatomic free radicals) has a negligible rate compared to that of the $\mathrm{R}+\mathrm{HX}$ reaction under study. The reaction of interest is essentially isolated for direct study in these experiments. 


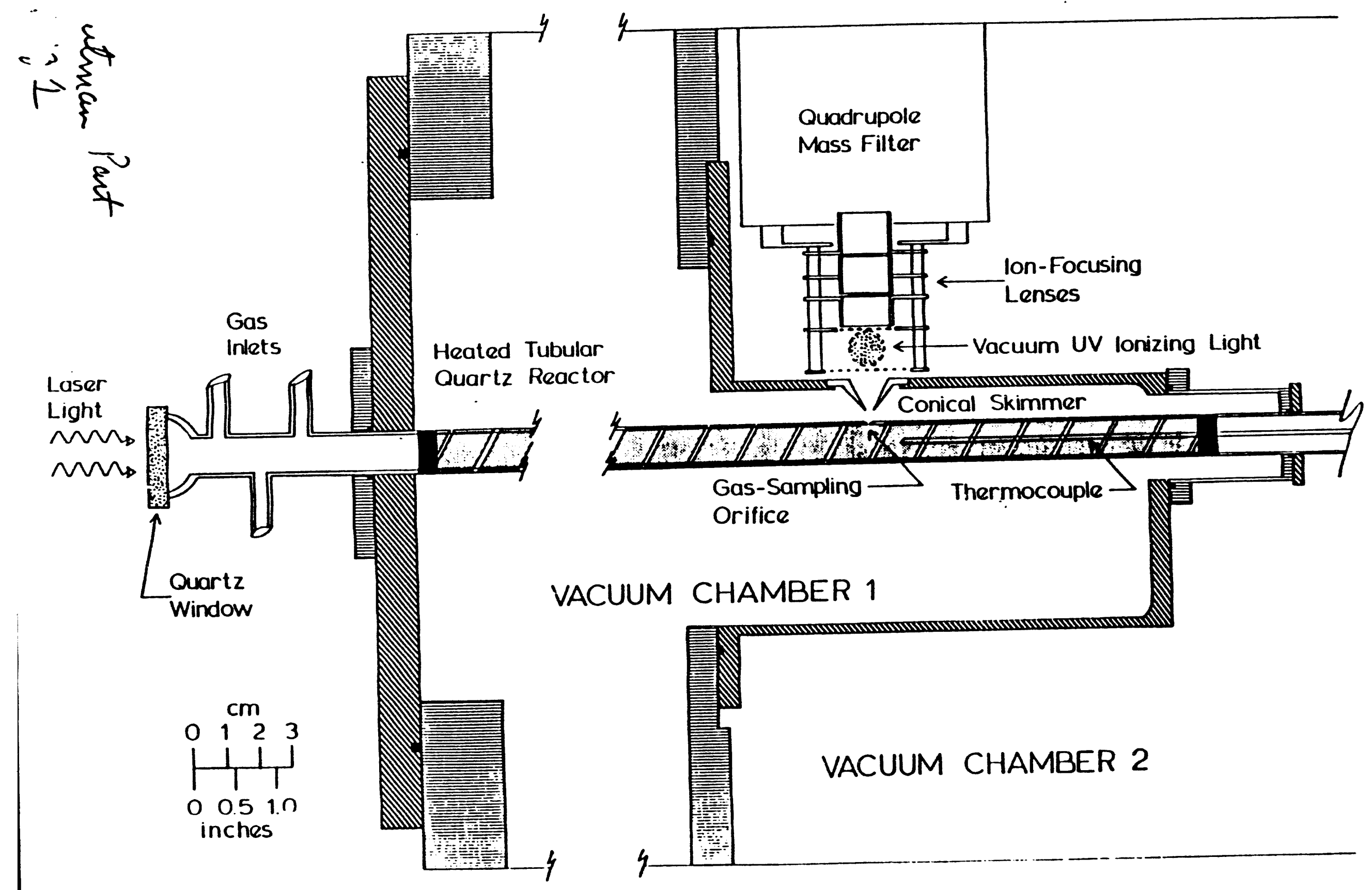


The use of atomic resonance fluorescence to monitor the kinetics of atom-molecule reactions is well documented. Wine and coworkers[22,24,26] as well as Pilling and coworkers $[21,23,25]$ have recently studied the kinetics of several $\mathrm{Br}+\mathrm{RH}$ reactions. The results of such studies have been used in the thermochemical calculations of radical heats of formation given in Table I. Both groups have extended the method to include monitoring $\mathrm{Br}$ formation in $\mathrm{R}+\mathrm{HBr}$ reactions and hence to obtain $\mathrm{R}+\mathrm{HBr}$ rate constants as well as $\mathrm{Br}+\mathrm{RH}$ constants. Agreement among the $\mathrm{R}+\mathrm{HBr}$ rate constants is excellent for the different diagnostic methods used. For the case of the $t-\mathrm{C}_{4} \mathrm{H}_{9}$ radical, recently reported rate constants for the $\mathrm{C}\left(\mathrm{CH}_{3}\right)_{3}+\mathrm{HBr}$ reaction are plotted in Fig. 2. They include values obtained by monitoring $\mathrm{Br}$-atom production using atomic fluorescence by Nicovich $e t$ al..[24] and by Seakins and Pilling[23] and from monitoring $\mathrm{C}\left(\mathrm{CH}_{3}\right)_{3}$ radical decay using photoionization mass spectrometry by Seakins et al.[25]. The activation energy of the line through the data of Seakins et al. is $-1.9 \mathrm{kcal} / \mathrm{mol}$. Particular attention is drawn to the close agreement below $500 \mathrm{~K}$ (i.e. $\frac{1000 \mathrm{~K}}{\mathrm{~T}}$ from 2 to 3.5). The two $t-\mathrm{C}_{4} \mathrm{H}_{9}+\mathrm{HB}$ r rate constants above $500 \mathrm{~K}$ were extracted from experiments in which the reaction did not go to completion but rather relaxed to an observable equilibrium which provides less accurate determinations of individual rate constants but direct determinations of $K_{\mathrm{rxn}}(1)$. The existence of negative activation energies in selected exothermic $R+H X$ reactic.is is now an established fact. 


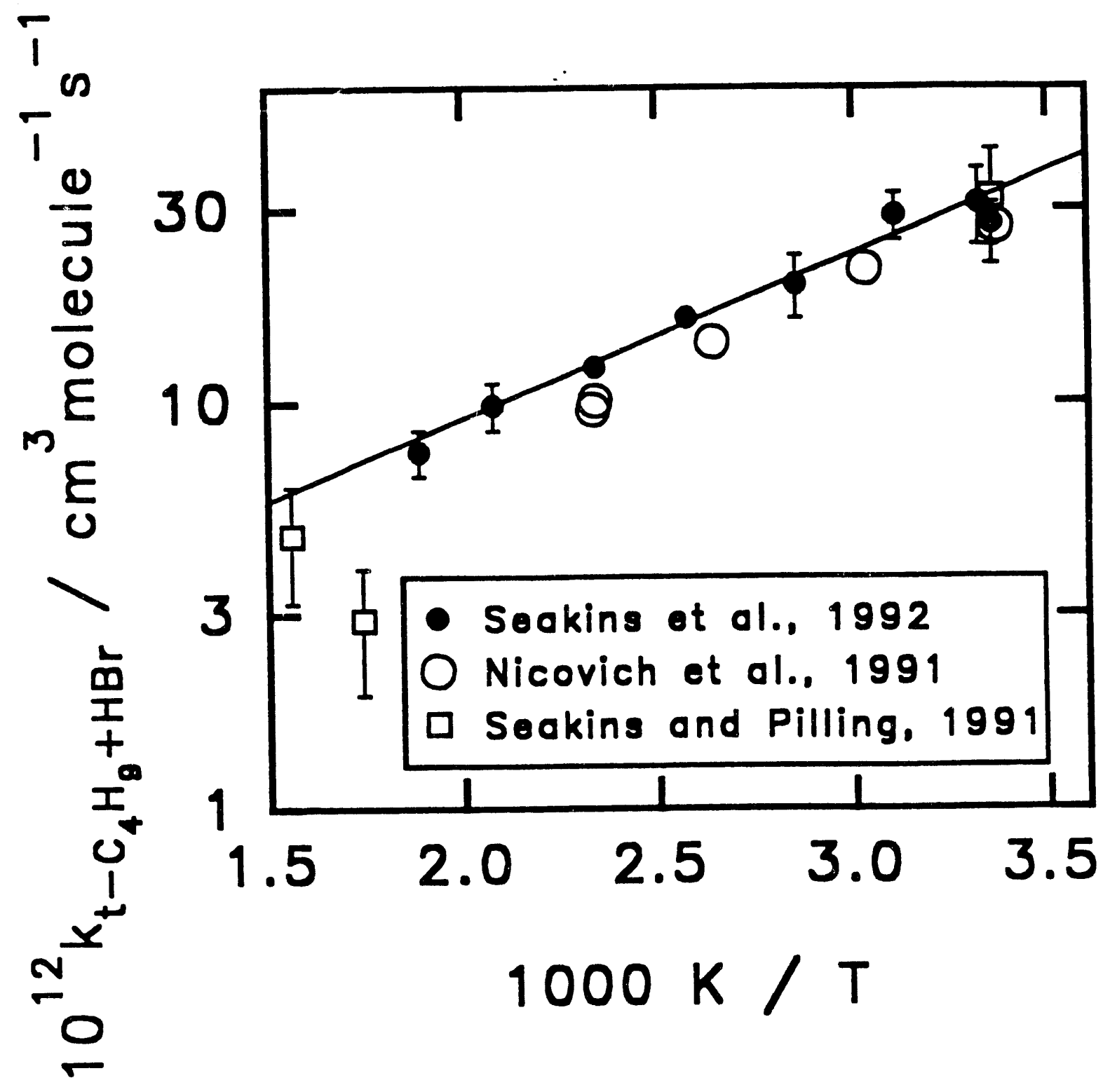

Entinan Part

Figure 2 
In the cases of many of the $\mathrm{X}+\mathrm{RH}$ equilibria studied (particularly invo:..ing bromine atoms), the reactions of interest are close to being thermoneutral. When this is the case, both the forward and reverse reactions are relatively fast, can be isolated for direct study, and absolute rate constants obtained for both reaction directions as a function of temperature. For a number of radicals, heats of formation were obtained from such studies with high accuracy using both the Second Law and Third Law methods. It should be pointed out that these two data-reduction methods are somewhat independent since the former uses only the temperature dependencies of the forward and reverse rate constants $\left(E_{1}-E_{-1}\right)$ to obtain $\Delta H_{r \times n}(1)$ (ignoring the magnitudes of $k_{1}$ and $k_{-1}$ ) whilst the latter uses only the magnitudes of the two rate constants at a particular temperature to obtain $K_{\mathrm{rxn}}(1)$ and $\Delta G_{5 \times n}(1)$ (in this case the temperature dependencies of $k_{1}$ and $k_{-1}$ are ignored). Results of both the Second and the Third Law determinations of radical heats of formation from such kinetic data for reaction 1 (where both the forward and reverse reactions were isolated for study) are presented in Table I. The close agreement between the values of the two radical heats of formation obtained from these two quite different properties of the measured rate constants (differences in $\Delta \mathrm{H}_{\mathrm{f}}{ }^{\circ}$ are typically under $0.3 \mathrm{kcal} / \mathrm{mol}$ ) provides strong support for the stated accuracies of the heats of formation derived from these kinetic studies (stated $1 \sigma$ accuracies of the radical heats of formation vary but are typically in the range 0.3 to $0.5 \mathrm{kcal} / \mathrm{mol}$ ).

The $I+R H$ reactions are quite endothermic (typically $\Delta H_{\mathrm{rxn}}(1)$ is $25-30$ $\mathrm{kcal} / \mathrm{mol}$ ) making direct study essentially impossible to date. However, a considerable body of $I+R H$ rate constants has been obtained from kinetic studies of complex iodination processes in which rate of the production or loss of stable species was monitored. These studies, reviewed and used by O'Neal and Benson and by McMillen and Golden in their evaluations of radical heats of formation and R-H bond energies, have resulted in many radical heats of formation (and R-H bond energies) which are too low by 2 to $4 \mathrm{kcal} / \mathrm{mol}$, 
again due largely to the use of the assumed "generic" activation energy for $\mathrm{R}+\mathrm{HI}$ reactions in the thermochemical calculations.

The kinetics of several $R+H I$ reactions, including those of five alkyl[19] radicals, the silyl radical[21], $\left(\mathrm{SiH}_{3}\right)$, and the hydroxymethyl[1] $\left(\mathrm{CH}_{2} \mathrm{OH}\right)$ have recently been directly studied using the photoionization mass spectrometric technique. When the rate constants measured in these studies are combined with the old I + RH rate constants obtained indirectly, radical heats of formation (and R-H bond energies) are obtained which are in very good agreement with those now obtained in direct studies of $\mathrm{Br}+\mathrm{RH}$ equilibria (and with dissociation-recombination equilibria).

A few studies have obtained radical thermochemistry from direct investigations of the kinetics of $(\mathrm{Cl}+\mathrm{RH})$ equilibria, in particular the near thermoneutral $(\mathrm{Cl}+$ $\left.\mathrm{CH}_{4}\right)$ [32,33], $\left(\mathrm{Cl}+\mathrm{C}_{2} \mathrm{H}_{4}\right)[34,35]$, and $\left(\mathrm{Cl}+\mathrm{CH}_{3} \mathrm{OH}\right)$ systems[36]. Again, results are in very good agreement with those obtained from the $\mathrm{Br}$-atom and I-atom equilibria and other methods as well, with the exception of the determination of the $\mathrm{C}_{2} \mathrm{H}_{3}$ heat of formation from the study of the $\mathrm{Cl}+\mathrm{C}_{2} \mathrm{H}_{4}$ equilibrium which is in conflict with values obtained using other methods such as with negative ion cycles[37]. The forward $\mathrm{Cl}+\mathrm{C}_{2} \mathrm{H}_{4}$ reaction is the elementary reaction involved in these three systems that was not studied directly[33], i.e. not isolated for direct investigation. It was studied using a very-low-pressure well-stirred reactor in which $\mathrm{Cl}$-atom loss during the residence time in the reactor was monitored. Interpretation of these experiments is not completely straightforward since secondary reactions and heterogeneous effects can be important in the data interpretation[38]. There is a real need for a more direct kinetic study of the $\mathrm{Cl}+\mathrm{C}_{2} \mathrm{H}_{4}$ reaction at elevated temperatures where the abstraction reaction can be observed without competition from the addition mechanism and under conditions where secondary reactions are unimportant. It is to be hoped that such a study will resolve the one significant remaining disparity between the radical heats of formation obtained from kinetic studies of both the forward and reverse 
reactions involved in $\mathrm{X}+\mathrm{R}-\mathrm{H}$ equilibria and from other methods such as negative and positive ion cycles.

Dobe[36], studying $\mathrm{Cl}+\mathrm{CH}_{3} \mathrm{OH}$, obtained $\Delta \mathrm{H}_{\mathrm{f298}}{ }^{\circ}\left(\mathrm{CH}_{2} \mathrm{OH}\right)=-2.1 \pm 1.0 \mathrm{kcal} / \mathrm{mol}$ ( $2^{\text {nd }}$ law) and $-3.3 \pm 0.5 \mathrm{kcal} / \mathrm{mol}$ (3rd law). Seetula and Gutman[1] obtained $-2.2 \pm 0.4$ $\mathrm{kcal} / \mathrm{mol}\left(\mathrm{Br}+\mathrm{CH}_{3} \mathrm{OH}, 3^{\text {rd law }}\right),-2.1 \pm 1.8 \mathrm{kcal} / \mathrm{mol}\left(\mathrm{I}+\mathrm{CH}_{3} \mathrm{OH}, 2^{\text {nd }}\right.$ law $)$ and $-1.9 \pm$ $1.9 \mathrm{kcal} / \mathrm{mol}\left(\mathrm{I}+\mathrm{CH}_{3} \mathrm{OH}\right), 3^{\text {rd }}$ law). The results appear to be in close agreement. However, Dobe used a different value for $\mathrm{S}_{298}\left(\ddot{\mathrm{CH}}_{2} \mathrm{OH}\right)$ than did Seetula and Gutman. The latter selected $\mathrm{S}_{300}\left(\mathrm{CH}_{2} \mathrm{OH}\right)=61.08 \mathrm{cal} / \mathrm{mol} \cdot d e g$ given by $T$ sang[39], and based upon free rotation about the $\mathrm{C}-\mathrm{O}$ bond. The value used by Dobe is based on expressions given by Burcat[40], which assume hindered rotation. From these expressions, we calculate $\mathrm{S}_{298}\left(\mathrm{CH}_{2} \mathrm{OH}\right)=57.88 \mathrm{cal} / \mathrm{mol} \cdot \mathrm{deg}$. Since there is strong evidence that $\mathrm{CH}_{2} \mathrm{OH}$ is a hindered rotor, the entropy used by Dobe is expected to be more nearly correct. (We calculate $\mathrm{S}_{298}\left(\mathrm{CH}_{2} \mathrm{OH}\right)=58.71 \mathrm{cal} / \mathrm{mol} \cdot \mathrm{deg}$, using the most recently available information [41] on the structure, vibrational frequencies and barrier to rotation of $\mathrm{CH}_{2} \mathrm{OH}$ ). When we

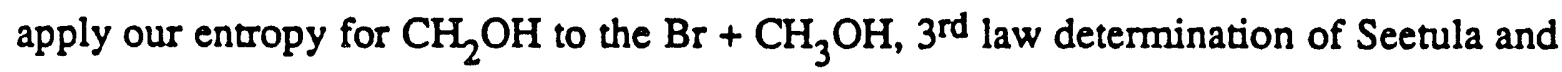
Gutman, we obtain $\Delta \mathrm{H}_{\mathrm{f} 298}{ }^{\circ}\left(\mathrm{CH}_{2} \mathrm{OH}\right)=-2.9 \pm 0.4 \mathrm{kcal} / \mathrm{mol}$, close to the $3^{\text {rd }}$ law result for the $\mathrm{Cl}+\mathrm{CH}_{3} \mathrm{OH}$ reaction, $-3.3 \pm 0.5 \mathrm{kcal} / \mathrm{mol}$. From these latter values, we can deduce $\mathrm{DH}_{0,298 \mathrm{~K}}\left(\mathrm{H} \cdot \mathrm{CH}_{2} \mathrm{OH}\right)=97.2 \pm 0.4 \mathrm{kcal} / \mathrm{mol}$ (Seetula and Gutman), and $96.8 \pm 0.5$ $\mathrm{kcal} / \mathrm{mol}$ (Dobe), in good agreement with the AP/IP combination of $\mathrm{D}_{0}\left(\mathrm{H}-\mathrm{CH}_{2} \mathrm{OH}\right)=95.0$ $\pm 0.7 \mathrm{kcal} / \mathrm{mol}$ obtained from PIMS (see §C below).

\section{B. Negative Ion Cycles}

Rather than attempt the direct measurement of a bond energy, $D_{0}(R-H)$, an altemative method is to embed the BDE in a negative ion thermochemical cycle. This cycle, eq. (3), involves the acidity of $R H\left[\Delta H_{a c i d}(R-H)\right]$, the electron affinity of $R,[E A(R)]$ and the ionization potential[42] of $\mathrm{H}$ atom $[\mathrm{IP}(\mathrm{H})]$. The strategy is to measure $\Delta \mathrm{H}_{\mathrm{acid}}(\mathrm{R}-\mathrm{H})$ and 
$E A(R)$ and then invert (3) to extract the bond energy, BDE. Care is needed to do this. As eq. (3) shows, any errors in $\Delta H_{a c i d}(R-H)$ or $E A(R)$ will propagate into $B D E(R-H)$. Use of the acidity/EA cycle is only useful if $\Delta H_{\text {acid }}(R-H)$ and $E A(R)$ can be cleanly measured in separate experiments.

The energetics of deprotonation in eq. (2) is formally described by expression (3). To be precise, one needs to pay attention to teraperatures in eq. (3). Gas phase acidities are generally based on experiments carried out at $298 \mathrm{~K}$ while electron affinities and ionization potentials are $0 \mathrm{~K}$ measurements. Rather than eq. (3), the proper relation[43] to connect the acidity to the bond dissociation energy and the electron affinity of the final radical is:

$$
\Delta \mathrm{H}_{\mathrm{acid}}(\mathrm{R}-\mathrm{H})=\mathrm{DH}_{\mathrm{0}, 298 \mathrm{~K}}(\mathrm{R}-\mathrm{H})+\mathrm{IP}_{0 \mathrm{~K}}(\mathrm{H})-\mathrm{EA}_{0 \mathrm{~K}}(\mathrm{R}) \text { - thermal correction }
$$

The thermal correction is simply the proper integrated heat capacities.

$$
\text { Thermal corr'n }=\int_{0}^{298} d T\left[C_{p}(R)-C_{p}\left(R^{-}\right)+C_{p}(H)-C_{p}\left(H^{+}\right)\right]
$$

The correction in eq. (12) is always smaller than $0.3 \mathrm{kcal} / \mathrm{mol}$ and most times is computed to be about $0.05 \mathrm{kcal} / \mathrm{mol}$. This correction is commonly ignored[44]; consequently it is standard procedure in (11) to simply equate $\Delta \mathrm{H}_{\mathrm{acid}}(\mathrm{R}-\mathrm{H})$ with $\left\{\mathrm{DH}_{0,298 \mathrm{~K}}(\mathrm{R}-\mathrm{H})+\mathrm{IP}(\mathrm{H})\right.$ $\mathrm{EA}(\mathrm{R})\}$.

Expression (11) indicates that the acidity is a large number. If a typical bond enthalpy is about $100 \mathrm{kcal} / \mathrm{mol}$ and a common EA is roughly $1 \mathrm{eV}$, one uses the ionization energy of $\mathrm{H}$ atom ( $313 \mathrm{kcal} / \mathrm{mol})$ to arrive at an approximate acidity, $\Delta \mathrm{H}_{\text {acid }}(\mathrm{R}-\mathrm{H}) \cong 100+$ 313 - 23 or $390 \mathrm{kcal} / \mathrm{mol}$. For example some representative acidities (out of several hundred examples)[45] are: 
Molecule $\quad \Delta \mathrm{H}_{\text {acid }}(\mathrm{kcal} / \mathrm{mol})$

$\begin{array}{cll}\uparrow & \mathrm{CH}_{4} & 416 \\ \text { less acidic } & \mathrm{NH}_{3} & 404 \\ & \mathrm{H}_{2} \mathrm{O} & 391 \\ \text { more acidic } & \mathrm{HF} & 371 \\ \downarrow & \mathrm{HI} & 314\end{array}$

In order to use expression (11) to compute $\mathrm{DH}_{0,298 \mathrm{~K}}(\mathrm{R}-\mathrm{H})$, one needs separate measurements of (1) the acidity and (2) the electron affinity.

\section{Gas Phase Acidities}

The acidity [46], $\Delta \mathrm{H}_{\mathrm{acid}}$, is the enthalpy for the proton abstraction reaction, eq (2) and most often is measured in ICR spectrometers[47] or flowing afterglow devices[48]. We will discuss several ways to find $\Delta H_{\text {acid }}(R-H)$ : (a) Thermochemically, (b) Equilibrium measurements, (c) Bracketing measurements, (d) Photoion PairFormation, and, most recently, (e) Collision Induced Dissociation (CID) of cluster ions. Another experimental approach to molecular acidities is high pressure mass spectrometry but we simply do not have space to cover this technique here.[49]

(a) For a set of molecules $\left\{\mathrm{H}_{2}, \mathrm{HF}, \mathrm{HCl}, \mathrm{HBr}, \mathrm{HI}, \mathrm{H}_{2} \mathrm{O}, \mathrm{CH}_{2} \mathrm{O}, \mathrm{NH}_{3}\right.$, and $\left.\mathrm{CH}_{4}\right\}$, one knows the bond dissociation energies and electron affinities much more precisely[50] than any acidity measurements; some of these are collected together in Table $\Pi$. Consequently the acidities for these species are computed with eqs. (11) and (12) using $E A(R)$ and $D_{0,0 K}(R-H)$. Table II flags these acidities with the $\equiv$ sign. The halogen acids, HX, together with water and ammonia are useful anchoring compounds with which to reference other acidities.

(b) There are two equilibrium ways to find $\Delta \mathrm{H}_{\mathrm{acid}}$; temperature-dependent and temperature-independent measurements. Suppose one has an unknown acid, HU. A 
common measurement of $\Delta \mathrm{H}_{\mathrm{acid}}(\mathrm{H}-\mathrm{U})$ is to study the proton transfer reaction with reference acids, $\mathrm{HA}_{1}, \mathrm{HA}_{2}, \ldots$. These are constant temperature measurements which can yield $\mathrm{K}_{\text {equi }}(13)$ at $\mathrm{T}=298 \mathrm{~K}$.

$$
\mathrm{U}^{-}+\mathrm{HA}-\mathrm{HU}+\mathrm{A}^{-}
$$

Now the equilibrium constant for (13) can be found from the ion-molecule rate constants or the concentrations. Flowing afterglow instruments usually report separate measurements of the rate constants, $k_{13}$ and $k_{-13}$, while ICR spectrometers directly measure the equilibrium ratios, $\left(\left[\mathrm{A}^{-}\right][\mathrm{HU}] /\left[\mathrm{U}^{-}\right][\mathrm{HA}]\right)$.

$$
K_{13}=\frac{k_{13}}{k_{.13}}=\frac{\left[A^{-}\right][\mathrm{HU}]}{\left[\mathrm{U}^{-}\right][\mathrm{HA}]}=e^{\frac{-\Delta G_{\text {exid }}}{R T}}
$$

Let us see how a flowing afterglow device can provide ion chemistry that is of use in (14); we will consider the determination of the acidity of HCC-H as an example.

Fig. 3 is a schematic diagram of a tandem Flowing Afterglow/Selected Ion Flow Tube[51] which can be used to study proton transfer kinetics. Consider an acidity measurement which connects the acidity of HCC-H to that of HF. From the definition (2), $\Delta G_{\mathrm{rxn} 298 \mathrm{~K}}(15)$ is the difference $\left[\Delta \mathrm{G}_{\text {acid298K }}(\mathrm{HCCH})-\Delta \mathrm{G}_{\mathrm{acid} 298 \mathrm{~K}}(\mathrm{HF})\right]$.

$$
\mathrm{F}^{-}+\mathrm{HCCH} \Rightarrow \mathrm{HF}+\mathrm{HCC}^{-}
$$

The acidity of HCCH was studied[37] by using a SIFT device to measure both the (a) rate constant of proton abstraction $\left(k_{15}\right)$ of $\mathrm{F}^{-}$with $\mathrm{HCCH}$ and $(b)$ rate constant of proton abstraction $\left(\mathrm{k}_{-15}\right)$ of $\mathrm{HCC}^{-}$with HF. To do this, $\mathrm{F}^{-}$was prepared in the ion source of the SIFT by electron bombardment of $\mathrm{NF}_{3}$. 


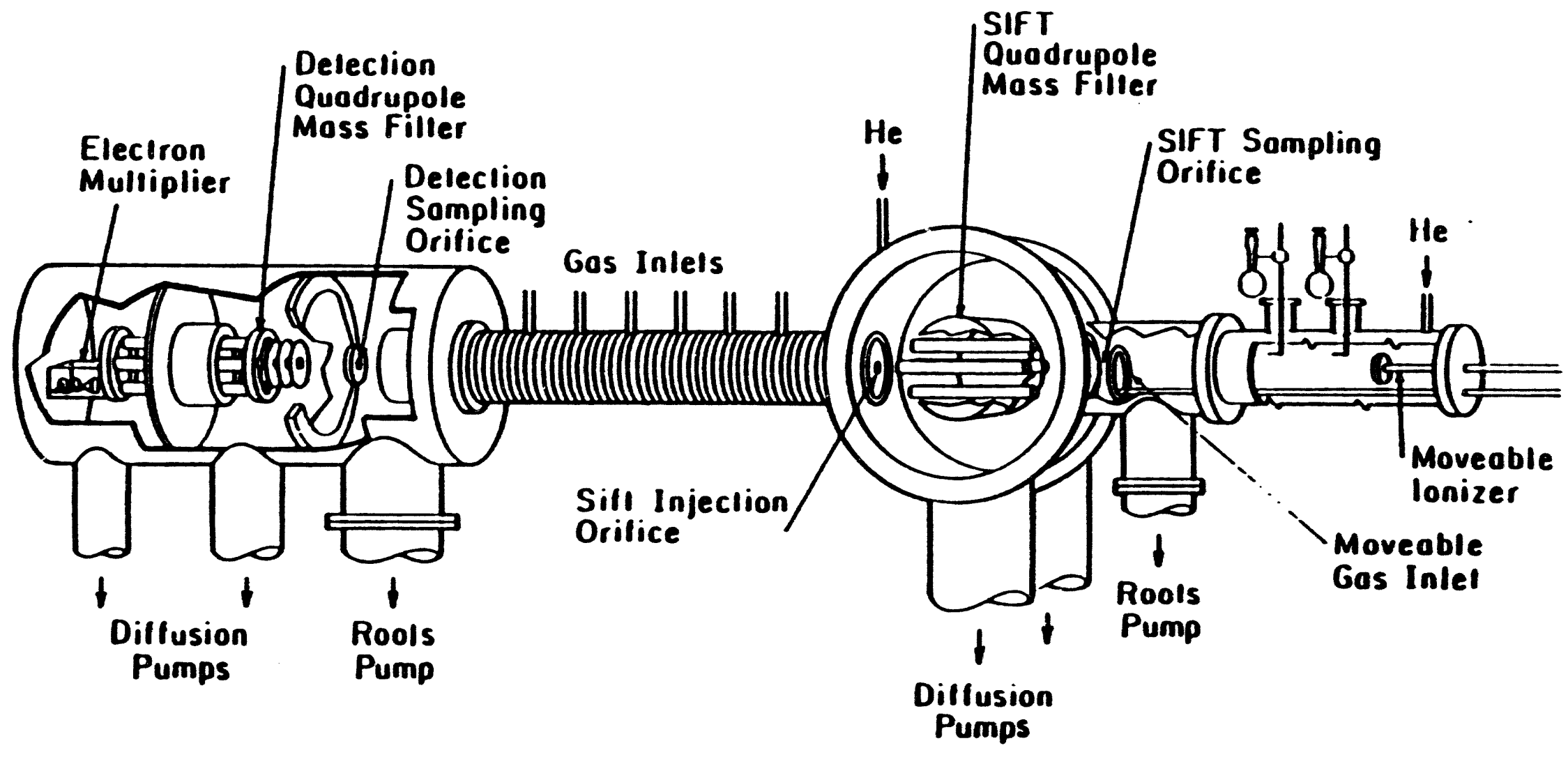


Ions were extracted from the resultant plasma through the SIFT sampling orifice and the SIFT quadrupole used to select the $\mathrm{F}^{-}$ions which were injected into the reaction flow tube. HCCH was added downstream via the fixed gas inlets, and the decay of $\mathrm{F}^{-}$(at $\mathrm{m} / \mathrm{e}$ 19) was monitored as a function of distance from the detection quadrupole mass filter. The buffer gas has a laminar flow through the afterglow in Fig. 3 and this permits a simple determination of the ion-molecule kinetic rate constant.

The resulting bimolecular rate constants were found to be $k_{15}=1.0( \pm 0.3) \times 10^{-12}$ $\mathrm{cm}^{3} \mathrm{sec}^{-1}$ and $\mathrm{k}_{.15}=1.3( \pm 0.2) \times 10^{-9} \mathrm{~cm}^{3} \mathrm{sec}^{-1}$. The ratio of these rate constants is the equilibrium constant, $K_{\text {equi }}(15)=k_{15} / k_{.15}$ or $0.0008 \pm 0.0003$. The equilibrium constant yields the free energy, $\Delta G_{r \times n 298 \mathrm{~K}}(15)=4.2 \pm 0.2 \mathrm{kcal} / \mathrm{mol}$. The free energy change for (15) can be expressed in terms of the gas phase acidities: $\Delta G_{r \times n 298 \mathrm{~K}}(15)=$ $\Delta \mathrm{G}_{\text {acid298K }}(\mathrm{HCCH})-\Delta \mathrm{G}_{\text {acid298K }}(\mathrm{HF})$. So if the acidity of $\mathrm{HF}$ can be established as an anchor, $\mathrm{K}_{\text {equi }}(15)$ will yield the acidity of $\mathrm{HCCH}, \Delta \mathrm{G}_{\text {acid298 }}(\mathrm{HCCH})$.

As mentioned earlier in $\$ 1$ (a), the gas phase acidity of HF has been established by using the precise values of $\mathrm{DH}_{0,298 \mathrm{~K}}(\mathrm{HF}), \mathrm{IP}(\mathrm{H}), \mathrm{EA}(\mathrm{F})$ in eq(11). $\mathrm{D}_{0}(\mathrm{HF})$ is known[52] to be $135.2 \pm 0.2 \mathrm{kcal} / \mathrm{mol}$ and the electron affinity[53] of fluorine atom is $\operatorname{EA}(F)=3.401$ $190 \pm 0.000004 \mathrm{eV}$; consequently $\Delta \mathrm{H}_{\mathrm{acid}, 0 \mathrm{~K}}(\mathrm{HF})=370.5 \pm 0.2 \mathrm{kcal} / \mathrm{mol}$. If the appropriate heat capacity corrections are applied, one finds $\Delta \mathrm{H}_{\text {acid, } 298 \mathrm{~K}}(\mathrm{HF})=371.4 \pm 0.2$ $\mathrm{kcal} / \mathrm{mol}$ [see Table $\mathrm{I}$; ; entropies of $\mathrm{H}^{+}, \mathrm{F}^{-}$, and $\mathrm{HF}$ lead to $\Delta S_{\text {acid,298 }}(\mathrm{HF})=19.30 \pm$ $0.01 \mathrm{cal} / \mathrm{mol} \cdot \mathrm{K}$ so eq. (11) leads to $\Delta \mathrm{G}_{\mathrm{acid}, 298 \mathrm{~K}}(\mathrm{HF})=365.6 \pm 0.2 \mathrm{kcal} / \mathrm{mol}$. Consequently we see that $\Delta \mathrm{G}_{\mathrm{rxn} 298 \mathrm{~K}}(15)=4.2 \pm 0.2 \mathrm{kcal} / \mathrm{mol}$ implies that $\Delta \mathrm{G}_{\mathrm{acid} 298 \mathrm{~K}}(\mathrm{HCC}-\mathrm{H})=369.8$ $\pm 0.3 \mathrm{kcal} / \mathrm{mol}$. We desire $\Delta \mathrm{H}_{\text {acid298 }}$ (HCC-H) so we have a final entropic correction to make; we need $\Delta S_{\text {acid298 }}$ (HCC-H). This is found[54] to be $\Delta S_{\text {acid298K }}(\mathrm{HCC}-\mathrm{H})=26.8$ $\mathrm{cal} / \mathrm{mol} \cdot \mathrm{K}$, and finally[55] we are led to $\Delta \mathrm{H}_{\mathrm{acid} 298 \mathrm{~K}}(\mathrm{HCC}-\mathrm{H})=369.9 \pm 0.3+$ $(298)(0.0268)=377.8 \pm 0.6 \mathrm{kcal} / \mathrm{mol}$. 
The case of acetylene is an unusually favorable one since the acidity can be tied directly to HFF, one of the firmly established points of the acidity scale (top of Table $\mathrm{M}$ ). What happens if the target acid cannot be tied to such a point? Consider the ketene molecule, $\mathrm{CH}_{2} \mathrm{CO}$. When treated (eq. 16) with a variety of bases in a flowing afterglow, the acidity of ketene was found[56] to be greater than $\mathrm{CH}_{3} \mathrm{CN}(373 \mathrm{kcal} / \mathrm{mol})$ and less than $\mathrm{CH}_{3} \mathrm{NO}_{2}(356 \mathrm{kcal} / \mathrm{mol})$.

$\begin{array}{llrr}\mathrm{CH}_{2} \mathrm{CO}+\mathrm{NH}_{2}^{-} & -\mathrm{HCCO}^{-}+\mathrm{NH}_{3} & \text { (fast) (16a) } \\ \mathrm{CH}_{2} \mathrm{CO}+\mathrm{CH}_{3} \mathrm{O}^{-} & -\mathrm{HCCO}^{-}+\mathrm{CH}_{3} \mathrm{OH} & \text { (fast) (16b) } \\ \mathrm{CH}_{2} \mathrm{CO}+\mathrm{CH}_{2} \mathrm{CN}^{-} & -\mathrm{HCCO}^{-}+\mathrm{CH}_{3} \mathrm{CN} & \text { (fast) (16c) } \\ \mathrm{CH}_{2} \mathrm{CO}+\mathrm{CH}_{3} \mathrm{COCH}_{2}^{-} & -\mathrm{HCCO}^{-}+\mathrm{CH}_{3} \mathrm{COCH}_{3} & \text { (equ'l'n) (16d) } \\ \mathrm{CH}_{2} \mathrm{CO}+\mathrm{CH}_{2} \mathrm{CHO}^{-} & -\mathrm{HCCO}^{-}+\mathrm{CH}_{3} \mathrm{CHO}_{3} & \text { (equ'l'n) (16e) } \\ \mathrm{CH}_{2} \mathrm{CO}+\mathrm{CF}_{3} \mathrm{CH}_{2} \mathrm{O}^{-} & -\mathrm{HCCO}^{-}+\mathrm{CF}_{3} \mathrm{CH}_{2} \mathrm{OH} & \text { (slow) (16i) } \\ \mathrm{CH}_{2} \mathrm{CO}+\mathrm{CH}_{2} \mathrm{NO}_{2}^{-} & -\mathrm{HCCO}^{-}+\mathrm{CH}_{3} \mathrm{NO}_{2} & \text { (no rxn) (16g) }\end{array}$

The equilibrium (16e) was studied in detail. Measurement of the proton transfer rates $\left(k_{16 e}\right.$ and $\mathrm{k}_{\cdot 16 \mathrm{e}}$ ) lead to $\mathrm{K}_{\text {equi }}(16 e)=6.8$ which corresponds to $\Delta \mathrm{G}_{\mathrm{rxn} 298 \mathrm{~K}}(16 e)=-1.1 \pm 0.2$ $\mathrm{kcal} / \mathrm{mol}$. Now $\Delta \mathrm{G}_{\mathrm{r \times n2} 298 \mathrm{~K}}(16 \mathrm{e})=\left[\Delta \mathrm{G}_{\mathrm{acid}}\left(\mathrm{CH}_{2} \mathrm{CO}\right)-\Delta \mathrm{G}_{\mathrm{acid}}\left(\mathrm{H}-\mathrm{CH}_{2} \mathrm{CHO}\right)\right]$ so[57] $\Delta G_{\text {acid }}\left(\mathrm{CH}_{2} \mathrm{CO}\right)=357.9 \pm 2.2 \mathrm{kcal} / \mathrm{mol}$. To extract the enthalpy, one has to compute $\Delta \mathrm{S}_{\text {acid }}\left(\mathrm{CH}_{2} \mathrm{CO}\right)$ and finds [58] a value of $23.6 \pm 2.2 \mathrm{cal} / \mathrm{mol} \cdot \mathrm{K}$. Consequently the acidity we seek, $\Delta \mathrm{H}_{\text {acid }}\left(\mathrm{CH}_{2} \mathrm{CO}\right)$, is $364.8 \pm 2.1 \mathrm{kcal} / \mathrm{mol}$.

A word about uncertainties. The weak link in this procedure is the necessary appeal to a ladder of "known" acidities. You will almost always find that the acidity of the target acid, HU, is known with respect to other acids on the acidity scale[59] to an uncertainty of about $\pm 0.2 \mathrm{kcal} / \mathrm{mol}$. In order to account for errors in anchoring the entire acidity scale, one has to include an additional $\pm 2 \mathrm{kcal} / \mathrm{mol}$ to the error bar. Converting $\Delta G_{\text {acid }}$ to $\Delta H_{\text {acid }}$ implies an additional uncertainty $(T \delta(\Delta S))$ of $\pm 0.6 \mathrm{kcal} / \mathrm{mol}$. Consequently the final uncertainty in a typical acidity measurement[60] swells to $\pm\left(0.2^{2}+2^{2}+0.6^{2}\right)^{1 / 2}$ or \pm 2.1 
$\mathrm{kcal} / \mathrm{mol}[61]$. Unless great care is taken to tie the unknown acid, HU, to one of the primary anchors, the resulting acidity $\Delta \mathrm{H}_{\text {acid }}(\mathrm{HU})$ is generally uncertain to roughly \pm 2 or 3 $\mathrm{kcal} / \mathrm{mol}$.

Another difficulty in acidity measurements is the availability of handy reference compounds. In order to make equilibrium measurements as in eq. (13), you must relate the unknown ion, $U^{-}$, with a reference acid, HA. The acidity of HA and HU have to be witivin about $5 \mathrm{kcal} / \mathrm{mol}$ of each other and this is not always easy to arrange. There is a useful chart of acidities published by Bartmess[62] which shows that the acidity scale is rather sparse from $\mathrm{H}_{2} \mathrm{O}(391 \mathrm{kcal} / \mathrm{mol})$ to $\mathrm{NH}_{3}(404 \mathrm{kcal} / \mathrm{mol})$ and $\mathrm{CH}_{4}(416 \mathrm{kcal} / \mathrm{mol})$.

An alternative to the single point ( $3^{\text {rd }}$ law) method described above in (13) is to study the temperature dependence of the equilibrium (2nd law) in a pulsed electron beam mass spectrometer[63]. This technique has not been applied as frequently as the constant temperature kinetic measurements in a flowing afterglow or an ICR. Consider the study of the acidity of methanol[64].

$$
\mathrm{HO}^{-}+\mathrm{CH}_{3} \mathrm{OH}-\mathrm{H}_{2} \mathrm{O}+\mathrm{CH}_{3} \mathrm{O}^{-}
$$

While varying the temperature over the range $298 \mathrm{~K}$ to $700 \mathrm{~K}$, the equilibrium constant (18) was measured.

$$
\mathrm{K}_{\text {equi }}(\mathrm{T})=\frac{\left[\mathrm{CH}_{3} \mathrm{O}^{-}\right]\left[\mathrm{H}_{2} \mathrm{O}\right]}{\left[\mathrm{HO}^{-}\right]\left[\mathrm{CH}_{3} \mathrm{OH}\right]}
$$

Since $K_{\text {equi }}(T)$ and $\Delta G_{r \times n}(17)$ are related, one can use:

$$
\ln K_{\text {equi }}(T)=\frac{-\Delta H_{r \times n}}{R T}+\frac{\Delta S_{r \times n}}{R}
$$


So a plot of $\ln K_{\text {equil }}(T)$ vs. $T^{-1}$ provides a straight line with $\left[\Delta S_{r \times n} / R\right]$ as the intercef: and $\left[-\Delta H_{r \times n} / R\right]$ as the slope. Since $\Delta H_{r \times n}$ is directly related to $\delta \Delta H_{2 c i d} \Delta H_{a c i d}\left(H_{2} O\right)$ fixes the acidity of methanol, $\Delta \mathrm{H}_{\mathrm{acid}}\left(\mathrm{CH}_{3} \mathrm{O}-\mathrm{H}\right)$.

(c) There are a number of cases when two-way equilibrium measurements are just not possible. Then all one can do is to bracket the acidity. Consider the acidity of methyleneimine, $\mathrm{CH}_{2} \mathrm{NH}$. One[65] can measure $\mathrm{K}_{20}$ but since $\mathrm{CH}_{2} \mathrm{NH}$ is not an available reagent, $k_{.20}$ cannot be found.

$$
\mathrm{CH}_{2} \mathrm{~N}^{-}+\mathrm{HA}-\mathrm{CH}_{2} \mathrm{NH}+\mathrm{A}^{-}
$$

In such cases, all that can be done is to bracket the unknown ion, $U^{-}$.

As a specific example[37], consider the vinylidene anion, $\mathrm{H}_{2} \mathrm{CC}^{-}$. If one prepares the $\mathrm{H}_{2} \mathrm{CC}^{-}$ion in a SIFT, one rapidly sees that the acidity is somewhere between water and

$$
\begin{aligned}
& \mathrm{H}_{2} \mathrm{CC}^{-}+\mathrm{H}_{2} \mathrm{O}-\mathrm{H}_{2} \mathrm{CCH}+\mathrm{HO}^{-} \\
& \mathrm{H}_{2} \mathrm{CC}^{-}+\mathrm{CH}_{3} \mathrm{OH}-\mathrm{H}_{2} \mathrm{CCH}+\mathrm{CH}_{3} \mathrm{O}^{-}
\end{aligned}
$$

methanol. The facts are that the vinylidene anion does not react with water. With the detection limits of the flowing afterglow, this implies $\mathrm{k}_{21 \mathrm{a}} \leq 4 \times 10^{-12} \mathrm{~cm}^{3} / \mathrm{sec}$. The fastest that the reverse reaction could go is at the collision rate (if one had samples of the $\mathrm{H}_{2} \mathrm{CCH}$ radical to measure it); $k_{-21 \mathrm{a}} \cong 1.4 \times 10^{-9} \mathrm{~cm}^{3} / \mathrm{sec}$. So $\mathrm{K}_{21 \mathrm{a}} \leq 0.003$ and $\Delta \mathrm{G}_{21 \mathrm{a}} \geq 3.5$ $\mathrm{kcal} / \mathrm{mol}$. From the acidity of water, this implies $\Delta \mathrm{G}_{\text {acid }}\left(\mathrm{H}_{2} \mathrm{CC}-\mathrm{H}\right) \leq 380.4 \pm 0.3 \mathrm{kcal} / \mathrm{mol}$. In the case of methanol, $\mathrm{H}_{2} \mathrm{CC}^{-}$reacts very rapidly to produce $\mathrm{CH}_{3} \mathrm{O}^{-} ; \mathrm{k}_{21 \mathrm{~b}}=1.20 \times 10^{-9}$ $\mathrm{cm}^{3} / \mathrm{sec}$ and $\mathrm{k}_{-21 \mathrm{~b}}$ could not be measured. Consequently $\Delta \mathrm{G}_{\text {acid }}\left(\mathrm{H}_{2} \mathrm{CC}-\mathrm{H}\right)$ is greater than that of methanol[66], so $\Delta \mathrm{G}_{\mathrm{acid}}\left(\mathrm{H}_{2} \mathrm{CC}-\mathrm{H}\right) \geq 375.1 \pm 0.6 \mathrm{kcal} / \mathrm{mol}$.

What is the bottom line? $\Delta \mathrm{G}_{\text {acid }}\left(\mathrm{H}_{2} \mathrm{CC}-\mathrm{H}\right)$ is estimated by splitting the difference between water and methanol; $\Delta G_{\text {acid }}\left(\mathrm{H}_{2} \mathrm{CC}-\mathrm{H}\right)=377.6 \pm 3.1 \mathrm{kcal} / \mathrm{mol}$. If we estimate that 
$\Delta \mathrm{S}_{\text {acid }}\left(\mathrm{H}_{2} \mathrm{CC} \cdot \mathrm{H}\right) \equiv \mathrm{S}_{298}\left(\mathrm{H}^{+}\right)=26 \pm 4 \mathrm{cal} /$ mole $\cdot \mathrm{K}$, one finally computes the acidity of the vinyl radical[67], $\Delta \mathrm{H}_{\mathrm{acid}}\left(\mathrm{H}_{2} \mathrm{CC}-\mathrm{H}\right)=385 \pm 3 \mathrm{kcal} / \mathrm{mol}$.

(d) One usually regards photoionization as the creation of a positive ion-electron pair upon interaction of sufficiently energetic photons with gaseous molecules. However, ionization can also occur without the formation of an electron, by production of a positive ion-negative ion pair. Photoion pair formation can occur below the normal ionization threshold of the molecule.

$$
\mathrm{RH}+\mathrm{hv}_{\text {Thresh }} \rightarrow \mathrm{R}^{-}+\mathrm{H}^{+}
$$

Consider a diatomic molecule, $\mathrm{MX}$. One can readily show that the ion-pair process may occur below IP(MX) if EA(X) exceeds $D_{0}\left(M^{+}\right)$. Photoion-pair formation can occur by dissociation or predissociation. In the former, an electronic transition takes place between the ground state and the ion-pair state. The latter has (by definition) a long range attractive force. In the absence of additional attractive covalent forces, the equilibrium separation of the ion-pair state will usually occur at much longer internuclear distances than in the ground state. Consequently, the Franck-Condon factors will not be favorable. Predissociation involves curve crossing. The initial photoabsorption can occur to a quasi-bound state whose geometry is close to that of the ground state, allowing for favorable Franck-Condon factors. This quasi-bound state is crossed by an ion-pair state, and predissociation to ionpairs occurs, just as predissociation into neutrals can proceed. When the process of ion-pair formation is predissociative, one can anticipate a structured photoion yield curve, whereas direct dissociation, usually accessing the repulsive limb of the potential curve, will be structureless. Most experimentally observed cases of photoion-pair formation are predissociative.

About 40 examples of photoion-pair formation are known. This field has been the topic of a recent review article[68]. Here, we note that several examples relate to gas phase 
acidity determinations, e.g. $\mathrm{H}_{2}, \mathrm{HF}, \mathrm{H}_{2} \mathrm{O}, \mathrm{H}_{2} \mathrm{~S}, \mathrm{HCN}$ and $\mathrm{C}_{2} \mathrm{H}_{2}$. In all of these cases, the threshold for photoion-pair formation is the gas phase acidity. A few of these pair potentials are listed in Table III. These thresholds are just the gas phase acidities at $0 \mathrm{~K}$; consequently $\Delta \mathrm{H}_{\text {acid } \mathrm{OK}}(\mathrm{RH})$ and $\Delta \mathrm{H}_{\text {acid } 298 \mathrm{~K}}(\mathrm{RH})$ are tabulated for comparison to Table II and the agreement is good.

(e) Recent progress in mass spectroscopy[69] has demonstrated the fact that collision-induced dissociation of proton bound dimer ions, [U.HA] , reflects the relative acidities of the product acids. The ratio of product $\mathrm{CDD}$ ions, $\mathrm{U}^{-} / \mathrm{A}^{-}$,

$$
[U \cdot H A]^{-}+\mathrm{CID} \sum_{\mathrm{KUU}_{\mathrm{HA}}}^{\mathrm{k}_{\mathrm{HA}}} \mathrm{U}^{-}+\mathrm{HA}
$$

reflects only the difference in acidity, $\Delta G_{\text {acid }}(H U)$ and $\Delta G_{\text {acid }}(H A)$. If $H A$ and $H U$ are similar species with comparable acidities, then the thresholds for dissociation to $\mathrm{U}^{-}$or $\mathrm{A}^{-}$ will be quite similar. Under such conditions[70], it is claimed that:

$$
\ln \left[\frac{k_{H A}}{k_{H U}}\right]=\ln \left(\frac{\left[U^{-}\right]}{\left[A^{-}\right]}\right)=\frac{\delta \Delta G_{\text {acid }}}{R T}
$$

Such a CID approach may become an important avenue to secure thermochemical parameters for ultra-trace samples, or molecules with high molecular weights, or substances which are unavailable in a pure state.

As an example, the relative acidities of $\mathrm{CH}_{3} \mathrm{CH}_{2} \mathrm{OH}$ and its isotopomers $\left(\mathrm{CH}_{3} \mathrm{CD}_{2} \mathrm{OH}, \mathrm{CD}_{3} \mathrm{CH}_{2} \mathrm{OH}\right.$, and $\left.\mathrm{CD}_{3} \mathrm{CD}_{2} \mathrm{OH}\right)$ were scrutinized[71] by $\mathrm{CID}$ studies of the cluster ions such as, $\left[\mathrm{CH}_{3} \mathrm{CH}_{2} \mathrm{O}^{-} \mathrm{HOCD} \mathrm{CD}_{3}\right]$. When the dimer ion is subjected to $\mathrm{CID}$, 
more $\mathrm{CH}_{3} \mathrm{CH}_{2} \mathrm{O}^{-}$is formed than $\mathrm{CD}_{3} \mathrm{CD}_{2} \mathrm{O}^{-}$reflecting the greater exothermicity toward the $\mathrm{d}_{\mathrm{o}}$ product ion, $\mathrm{C}_{2} \mathrm{H}_{5} \mathrm{O}$.

$$
(<50 \%) \mathrm{C}_{2} \mathrm{H}_{5} \mathrm{OH}+\mathrm{C}_{2} \mathrm{D}_{5} \mathrm{O}^{-}-\left[\mathrm{C}_{2} \mathrm{H}_{5} \mathrm{O}^{-} \mathrm{HOC}_{2} \mathrm{D}_{5}\right] \rightarrow(>50 \%) \mathrm{C}_{2} \mathrm{H}_{5} \mathrm{O}^{-}+\mathrm{C}_{2} \mathrm{D}_{5} \mathrm{OH}
$$

Adoption of the ICR acidity of ethanol permitted the results of the $\mathrm{CD}$ process (25) to be analyzed and to convert the relative ethanol acidities to absolute values: $\Delta \mathrm{H}_{\text {acid }}\left(\mathrm{CH}_{3} \mathrm{CD}_{2} \mathrm{O}\right.$ $\mathrm{H})=377.85 \pm 0.15 \mathrm{kcal} / \mathrm{mol}, \Delta \mathrm{H}_{\mathrm{acid}}\left(\mathrm{CD}_{3} \mathrm{CH}_{2} \mathrm{O}-\mathrm{H}\right)=377.70 \pm 0.15 \mathrm{kcal} / \mathrm{mol}$, and $\Delta \mathrm{H}_{\mathrm{acid}}\left(\mathrm{CD}_{3} \mathrm{CD}_{2} \mathrm{O}-\mathrm{H}\right)=378.00 \pm 0.15 \mathrm{kcal} / \mathrm{mol}$. Notice that these $\mathrm{CID}$ relative acidities are found to within less than $\pm 0.5 \mathrm{kcal} / \mathrm{mol}$. Error bars this small are only possible when the components of the proton bound dimer, $[\mathrm{U} \cdot \mathrm{HA}]^{-}$, have similar acidities, $\Delta \mathrm{G}_{\mathrm{acid}}(\mathrm{HA}) \equiv$ $\Delta \mathrm{G}_{\text {acid}}(\mathrm{HU})$.

\section{Electron Affinities}

In a separate experiment, the electron affinity of radical $R$ can be measured. Just as in the case of the acidity measurements, this is a gas phase measurement, the EA(R) is just the energy required to detach an electron.

$$
R^{-}+h v \rightarrow R+e^{-}
$$

There are several ways to utilize (26) to measure EA(R). A very precise method[72] is to scan the photon energy, $h v$, to find the threshold for photodetachment $\left(h v_{\text {Thresh }}\right)$ which is the threshold for photodestruction of the ions. Thus the electron affinity of the $\mathrm{H}$ atom has been measured by observation of the photodestruction threshold[73] for $\mathrm{H}^{-}$at $6082.99 \pm$ $0.15 \mathrm{~cm}^{-1}$, corresponding to $\mathrm{EA}(\mathrm{H})=0.754195 \pm 0.000019 \mathrm{eV}$; the threshold for $\mathrm{D}^{-}$was found to be $6086.2 \pm 0.6 \mathrm{~cm}^{-1}$, implying that $E A(D)=0.754593 \pm 0.000074 \mathrm{eV}$. When this can be carried out on a polyatomic molecule, very precise electron affinities can be determined. As an example[74], the threshold for the detachment $\mathrm{CH}_{2} \mathrm{CHO}^{-} \rightarrow \mathrm{CH}_{2} \mathrm{CHO}$ is measured to be $v_{\text {Thresh }}=14718_{-5}^{+2} \mathrm{~cm}^{-1}$ or $\mathrm{EA}\left(\mathrm{CH}_{2} \mathrm{CHO}\right)=42.08 \pm 0.01 \mathrm{kcal} / \mathrm{mol}$. 
Alternatively[75] one can find $E A(R)$ by irradiating with a fixed frequency laser, $\mathrm{hv}_{\mathrm{o}}$, and measuring the kinetic energies of the scattered photoelectrons. Fig. 4 is a schematic view of this experiment. Ions are extracted from a source at about $1 / 3 \mathrm{Torr}$, formed into a beam, velocity-selected with a Wien filter, and delivered to a vacuum chamber maintained below $10^{-8}$ Torr. In this chamber ions are irradiated with a $\mathrm{CW}$ argon ion laser operating at a single frequency. Typically $v_{0}$ is $488.0 \mathrm{~nm}(2.540 \mathrm{eV})$ or $351.1 \mathrm{~nm}$ (3.531 $\mathrm{eV}$ ); consequently it is a limitation of this $\mathrm{CW}$ laser experiment that high EA species $(E A \geq 3.5 \mathrm{eV})$ cannot be studied. In Fig. 4, the scattered photoelectrons are energy analyzed with a hemispherical electrostatic analyzer. As an example of negative ion photoelectron spectroscopy[76], irradiation of a mass-selected ion beam of $\mathrm{CH}_{2} \mathrm{~N}^{-}$ions with a $488 \mathrm{~nm}$ Ar II laser permits the determination of $\mathrm{EA}\left(\mathrm{CH}_{2} \mathrm{~N}\right)$. The kinetic energy of photoelectrons belonging to the $(0,0)$ transition is $2.030 \pm 0.006 \mathrm{eV}$; since the laser photon energy is $2.540 \mathrm{eV}$ the binding energy of the electron is $0.510 \pm 0.006 \mathrm{eV}$. This is the "raw" electron affinity which often must be corrected for the fact that the spectrometer cannot resolve individual rotational transitions or spin-orbit states. After small rotational corrections, $\mathrm{EA}\left(\mathrm{CH}_{2} \mathrm{~N}\right)=0.511 \pm 0.008 \mathrm{eV}$ or $11.8 \pm 0.2 \mathrm{kcal} / \mathrm{mol}$. With the proper assignment of the $(0,0)$ band in the spectrum, it is a common finding that nearly all modern photodetachment studies measure the electron affinity to an uncertainty of $\pm 0.03 \mathrm{eV}$ ( \pm 0.7 $\mathrm{kcal} / \mathrm{mol}$ ) or better.

In addition to simple ions, larger clustered ions have also been successfully[77] photodetached. Recent developments[78] with pulsed lasers have led to photodetachment machines that use excimer lasers as the light source. Instead of conventional electrostatic analyzers, the photodetached electrons are detected by time-of-flight spectrometers. These pulsed lasers have energies up to $6.4 \mathrm{eV}$ and permit the study of high electron affinity species. Excellent reviews of molecular electron affinities have been published[79]. 


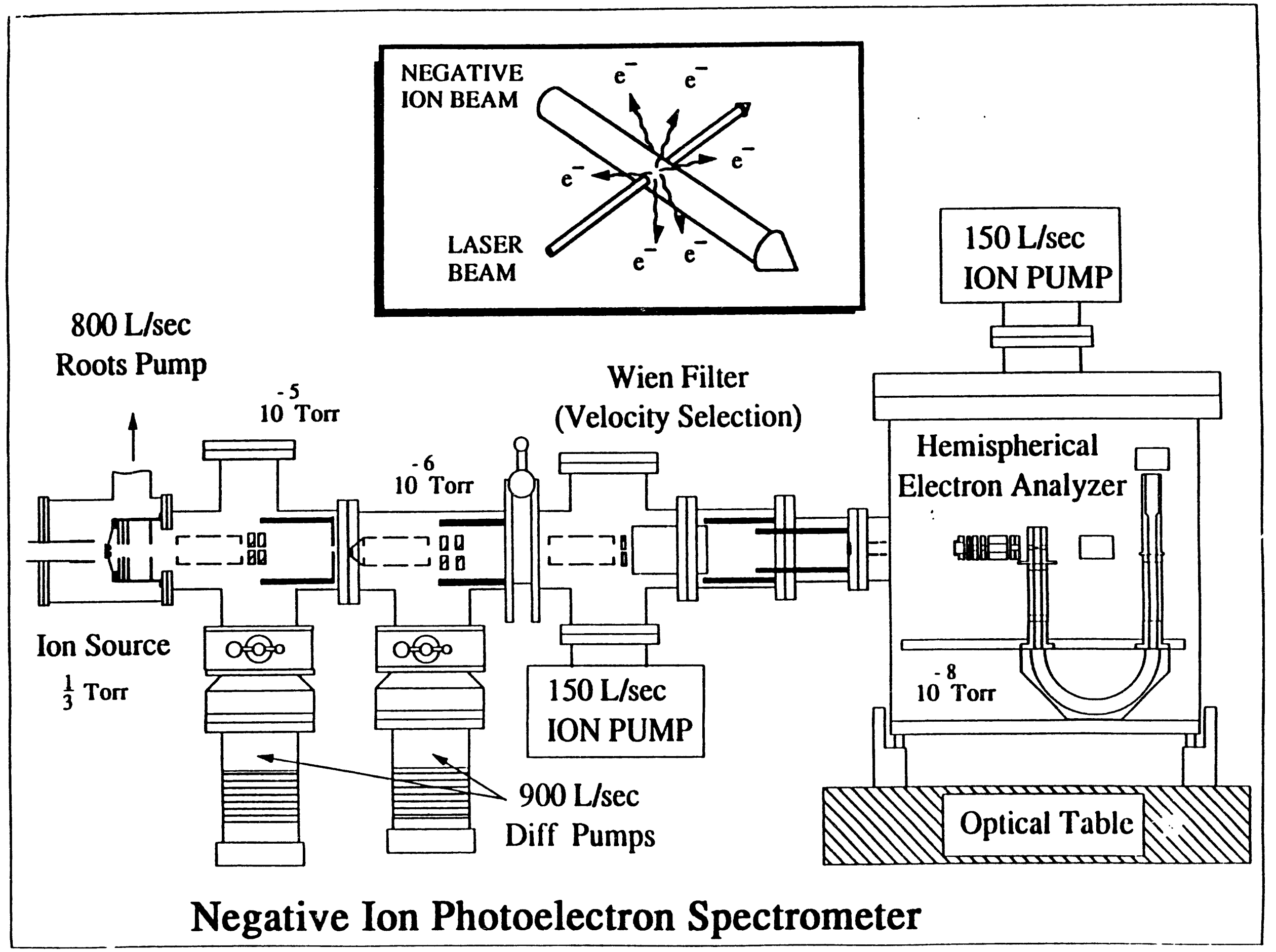


We now present a partial survey of the acidity/EA technique. Table II collects about 30 representative molecules for which the acidities, electron affinities, and bond enthalpies are available. The species above the solid line have their acidities computed from known $E A(R)$ and $D_{0,0 K}(R-H)$ values; those below the line use the measured $E A(R)$ and $\Delta \mathrm{H}_{\text {acid }}(\mathrm{R}-\mathrm{H})$ to determine the $\mathrm{BDE}(\mathrm{R}-\mathrm{H})$. In addition to hydrogen sulfide, arsine, phosphine, and silane which we need for comparison with PIMS and radical kinetics studies, we list a number of important organic species. Acetylene and ethylene are the two simplest $s p$-hybridized $(\mathrm{HCCH})$ and $s p^{2}$-hybridized $\left(\mathrm{CH}_{2} \mathrm{CH}_{2}\right)$ hydrocarbons. Benzene is the standard of aromaticity while the allylic species (derived from $\mathrm{CH}_{2}=\mathrm{CH}-\mathrm{CH}_{3}$ ) and benzylic species (derived from $\mathrm{C}_{6} \mathrm{H}_{5} \mathrm{CH}_{3}$ ) are two of the most fundamental conjugated systems. Formaldehyde $\left(\mathrm{CH}_{2} \mathrm{O}\right)$, acetaldehyde $\left(\mathrm{CH}_{3} \mathrm{CHO}\right)$, and ketene $\left(\mathrm{CH}_{2} \mathrm{CO}\right)$ are three of the most important carbonyl systems. The only measured[80] acidity for $\mathrm{CH}_{2} \mathrm{O}$ is $\Delta \mathrm{H}_{\text {acid }}(\mathrm{H}-\mathrm{CHO})=402 \pm 5 \mathrm{kcal} / \mathrm{mol}$ but this value is now known to be incorrect. From the extensive, thorough studies of the photochemistry of formaldehyde[81], the bond energy is now established as $\mathrm{D}_{\mathrm{o}}(\mathrm{H}-\mathrm{CHO})=86.57 \pm 0.16 \mathrm{kcal} / \mathrm{mol}$ while the $\mathrm{EA}(\mathrm{HCO})$ is measured[82] to be $0.313 \pm 0.005 \mathrm{eV}$. The acidity computed via eq (11) is $\Delta \mathrm{H}_{\mathrm{acid}}(\mathrm{H}$ $\mathrm{CHO})=394.4 \pm 0.3 \mathrm{kcal} / \mathrm{mol}$. Methanol and ethanol are two of the simplest alcohols while hydrogen sulfide and thiomethanol are elementary mercaptans. Both isomeric nitriles, $\left(\mathrm{CH}_{3} \mathrm{CN}, \mathrm{CH}_{3} \mathrm{NC}\right)$, have been scrutinized. The isomeric sulfur ions, $\left(\mathrm{HSCH}_{2}, \mathrm{CH}_{3} \mathrm{~S}^{-}\right)$, have both been prepared but not completely studied yet; no one has ever observed the $\mathrm{HOCH}_{2}^{-}$ion. Likewise all efforts to generate the simple alkyl anions, $\left(\mathrm{C}_{2} \mathrm{H}_{5}, \mathrm{C}_{3} \mathrm{H}_{7}{ }^{-}\right.$and $\mathrm{C}_{4} \mathrm{H}_{9}$ ) have failed; so it is not possible to compare acidity/EA measured alkyl $\mathrm{C}-\mathrm{H}$ bonds with Tables I and IV. In general, it is straightforward to use these negative ion measurements to find the bond enthalpies of several hundred compounds.

For the special case of $\mathrm{CH}_{2} \mathrm{CH}_{2}$, the bond energy resulting from the acidity/EA cycle, $\mathrm{D}_{0}\left(\mathrm{CH}_{2} \mathrm{CH}-\mathrm{H}\right)=109.7 \pm 0.8 \mathrm{kcal} / \mathrm{mol}$, is higher than the kinetically determined 
energy of $104-105 \mathrm{kcal} / \mathrm{mol}$ although it is compatible with the AP/IP measurements. These AP/IP studies have their own difficulties as described below in $\$ C$. This high bond energy in Table II results from measurements of $\mathrm{EA}\left(\mathrm{CH}_{2} \mathrm{CH}\right)$ and $\Delta \mathrm{H}_{\text {acid }}\left(\mathrm{CH}_{2} \mathrm{CH}-\mathrm{H}\right)$. The experimental EA has been investigated on two different photoelectron spectrometers and three isotopically substituted vinyl anions were studied. All lead to a consistent $(0,0)$ assignment, $\mathrm{EA}\left(\mathrm{CH}_{2} \mathrm{CH}\right)=0.67 \pm 0.02 \mathrm{eV}$. But if our EA of $0.67 \mathrm{eV}$ was "lowered" by 5 $\mathrm{kcal} / \mathrm{mol}$, the acidity would lead to a $\mathrm{BDE}\left(\mathrm{CH}_{2} \mathrm{CH}_{2}\right)$ of $105 \mathrm{kcal} / \mathrm{mol}$. Consequently a $\mathrm{BDE}\left(\mathrm{CH}_{2} \mathrm{CH}_{2}\right)$ of $105 \mathrm{kcal} / \mathrm{mol}$ might imply an $\mathrm{EA}\left(\mathrm{CH}_{2} \mathrm{CH}\right)$ of roughly $0.46 \mathrm{eV}$. This was checked by searching for charge transfer to $\mathrm{O}_{2}$ since $\mathrm{EA}\left(\mathrm{O}_{2}\right)$ is [83] $0.451 \pm 0.007 \mathrm{eV}$; the $\mathrm{CH}_{2} \mathrm{CH}^{-}$should charge transfer to $\mathrm{O}_{2}$ in a flow tube if the EA of vinyl radical is approximately $0.46 \mathrm{eV}$. When $\mathrm{CH}_{2} \mathrm{CH}^{-}$was added to excess $\mathrm{O}_{2}$ in an afterglow, no charge transfer to oxygen was observed.

How about the acidity of ethylene? In separate experiments, the acidity of ethylene was determined by proton transfer studies with amide ion, $\mathrm{NH}_{2}^{-}$.

$$
\mathrm{NH}_{2}^{-}+\mathrm{CH}_{2} \mathrm{CH}_{2}=\mathrm{NH}_{3}+\mathrm{CH}_{2} \mathrm{CH}^{-}
$$

Both rate constants were measured $\left[k_{27}=(2.7 \pm 1.0) \times 10^{-13} \mathrm{~cm}^{3} \mathrm{~s}^{-1}\right.$ and $\mathrm{k}_{-27}=(5.5 \pm$ $0.9) \times 10^{-10} \mathrm{~cm}^{3} \mathrm{~s}^{-1}$ ]. The exceedingly slow rate, $k_{27}$, was independently checked by calibration with an internal $\mathrm{HCCH}$ standard; this cross check lead to $k_{27}=2.6 \times 10^{-13}$ $\mathrm{cm}^{3} \mathrm{~s}^{-1}$ in good agreement with the directly determined $\mathrm{k}_{27}$. The rate constants lead to $\Delta \mathrm{G}_{\mathrm{rxn}}(27)=4.5 \pm 0.2 \mathrm{kcal} / \mathrm{mol}$. Now the gas phase acidity of ammonia anchors ethylene since $\Delta G_{\mathrm{rxn}}(27)=\Delta \mathrm{G}_{\mathrm{acid}}\left(\mathrm{CH}_{2} \mathrm{CH}_{2}\right)-\Delta \mathrm{G}_{\mathrm{acid}}\left(\mathrm{NH}_{3}\right)$; but Table $\Pi$ shows that $\Delta \mathrm{G}_{\text {acid }}\left(\mathrm{NH}_{3}\right)$ is known from PIMS studies and the EA(NH$\left.)_{2}\right)$. All of these negative ion studies suggests that a $\mathrm{CH}$ bond energy of $104-105 \mathrm{kcal} / \mathrm{mol}$ is incompatible with the measured $\mathrm{EA}\left(\mathrm{CH}_{2} \mathrm{CH}\right)$ and $\Delta \mathrm{G}_{\text {acid }}\left(\mathrm{CH}_{2} \mathrm{CH}_{2}\right)$. 
Two remarks are in order as to the accuracy and range of acidity/EA measurement of BDEs. Generally bond energies found by this approach are reliable to roughly \pm 2 or $3 \mathrm{kcal} / \mathrm{mol}$ and the major reason for this is the use of a ladder of reference acids. In a few cases such as $\mathrm{HCCH}$ and $\mathrm{CH}_{2} \mathrm{CH}_{2}$ (see Table II), one can control the uncertainties to less than $1 \mathrm{kcal} / \mathrm{mol}$ but this is not commonly done. However the range of the acidity/EA cycle is impressive. There are over 2,500 negative ions that have been prepared and studied. In a great number of cases[84], the acidity is reported by ICR studies as well as by flowing afterglow and variable temperature mass spectrometry. It is almost always the case that these different mass spectrometric measurements (ICR, flow tube studies, and high temperature mass spectrometry) find the same value, within their respective uncertainties.

The "chemical" control of the target ions is an important feature of the acidity/EA cycle. By manipulating the structure[85] of the target ion, one can fix the $\mathrm{R}-\mathrm{H}$ bond that is to be studied. Negative ions are straightforward to work with since they can be prepared by sensible ion chemistry[86] and are not prone to rearrangements.

An example of this control is shown by acetaldehyde; there are now two types of protons to account for. How can one measure the bond energy of each of the these two different $\mathrm{C}-\mathrm{H}$ bonds?

$$
\begin{aligned}
& \mathrm{H}-\mathrm{CH}_{2} \mathrm{CHO} \rightarrow \mathrm{CH}_{2} \mathrm{CHO}^{-}+\mathrm{H}^{+} \\
& \mathrm{CH}_{3} \mathrm{CO}-\mathrm{H} \rightarrow \mathrm{CH}_{3} \mathrm{CO}^{-}+\mathrm{H}^{+}
\end{aligned}
$$

The acetaldehyde enolate ion, $\left(\mathrm{CH}_{2} \mathrm{CHO}\right)^{-}$is the easiest to prepare by removal of the most

$$
\mathrm{HO}^{-}+\mathrm{CH}_{3} \mathrm{CHO} \rightarrow \mathrm{H}_{2} \mathrm{O}+\left(\mathrm{CH}_{2} \mathrm{CHO}\right)^{-}
$$


acidic methyl proton. ICR studies[87] report $\Delta \mathrm{H}_{\mathrm{acid}}\left(\mathrm{H}-\mathrm{CH}_{2} \mathrm{CHO}\right)=365.8 \pm 2.2 \mathrm{kcal} / \mathrm{mol}$ while threshold photodetachment studies[74] find $\mathrm{EA}\left(\mathrm{CH}_{2} \mathrm{CHO}\right)=1.8248 \pm 0.0006 \mathrm{eV}$. These findings lead to the bond energies, $\mathrm{DH}_{0,298 \mathrm{~K}}\left(\mathrm{H}_{-}-\mathrm{CH}_{2} \mathrm{CHO}\right)=94.3 \pm 2.2 \mathrm{kcal} / \mathrm{mol}$, and $\mathrm{D}_{0}\left(\mathrm{H}-\mathrm{CH}_{2} \mathrm{CHO}\right)=92.8 \pm 2.2 \mathrm{kcal} / \mathrm{mol}$. In contrast, the more reactive acyl anion, $\left(\mathrm{CH}_{3} \mathrm{CO}^{-}\right)$, is not so easy to prepare and has to be forced by a fluorodesilylation reaction.

$$
\mathrm{F}^{-}+\left(\mathrm{CH}_{3}\right)_{3} \mathrm{Si}-\mathrm{COCH}_{3} \rightarrow \mathrm{FSi}\left(\mathrm{CH}_{3}\right)_{3}+\left(\mathrm{CH}_{3} \mathrm{CO}^{-}\right)
$$

In this way the acidity of the acyl proton in acetaldehyde, (28b), has been studied. At 298 $\mathrm{K}$, the acidity has been measured in a flowing afterglow[88], $\Delta \mathrm{H}_{\text {acid }}\left(\mathrm{CH}_{3} \mathrm{CO}-\mathrm{H}\right)=391.1$ $\pm 2.1 \mathrm{kcal} / \mathrm{mol}$. Likewise the electron affinity is reported[89] as $\mathrm{EA}\left(\mathrm{CH}_{3} \mathrm{CO}\right)=0.423 \pm$ $0.037 \mathrm{eV}$; consequently use of eq (11) determines the bond energy, $\mathrm{DH}_{0.298 \mathrm{~K}}\left(\mathrm{CH}_{3} \mathrm{CO}-\mathrm{H}\right)$ $=87.2 \pm 2.3 \mathrm{kcal} / \mathrm{mol}$. With a heat capacity correction, the bond energy becomes, $\mathrm{D}_{0}\left(\mathrm{CH}_{3} \mathrm{CO}-\mathrm{H}\right)=85.7 \pm 2.3 \mathrm{kcal} / \mathrm{mol}$.

Some other pairs of isomeric ions that have been synthesized are: Acetic acid[90] $\left(\mathrm{HOOCCH}_{2},{ }^{-} \mathrm{CH}_{3} \mathrm{COO}\right)$, Thiomethanol[91] $\left(\mathrm{HSCH}_{2}, \mathrm{CH}_{3} \mathrm{~S}\right)$, Formic acid[92] (HOOC, $\mathrm{HCOO}^{-}$), and the isomeric nitriles[93] $\left(\mathrm{CH}_{2} \mathrm{NC}^{-}, \mathrm{CH}_{2} \mathrm{CN}^{-}\right)$. As Table II shows, only the nitriles have been completely studied.

As a demonstration of the exquisite chemical control that negative ion techniques offer, we turn to propene. There are four different $\mathrm{C}$ - $\mathrm{H}$ bonds in $\mathrm{CH}_{2}=\mathrm{CH}-\mathrm{CH}_{3}$ to consider; the methyl $\mathrm{C}-\mathrm{H}$ and three distinct vinyl $\mathrm{C}-\mathrm{H}$ bonds. As Table II shows, study of the allylic ion has furnished $\mathrm{D}_{0}\left(\mathrm{CH}_{2} \mathrm{CHCH}_{2}-\mathrm{H}\right)=86.7 \pm 2.1 \mathrm{kcal} / \mathrm{mol}$. Since the methyl $\mathrm{C}-\mathrm{H}$ is the most acidic site, the $\left(\mathrm{CH}_{2} \mathrm{CHCH}_{2}\right)^{-}$ion is readily formed by an appropriate base.

$$
\mathrm{HO}^{-}+\mathrm{H}^{-\mathrm{CH}_{2} \mathrm{CHCH}_{2}}=\mathrm{H}_{2} \mathrm{O}+\left[\mathrm{CH}_{2} \mathrm{CHCH}_{2}\right]^{-}
$$


Using technology based on the fluorodesilylation of substituted trimethylsilanes[94], ir nas been possible to synthesize two stereoisomeric 1-propenyl anions[95].<smiles>CC=C(C)[SiH2]CCC[I+]C</smiles><smiles>C[CH-]C(C)C</smiles>

(Z)-1-propenyl carbanion<smiles>CC=C1CC[Si]1C</smiles><smiles>CC=[C-]CC</smiles>

(E)-1-propenyl carbanion

Flowing afterglow studies have clearly demonstrated that these stereoisomeric carbanions (31a and 31b) are configurationally stable; they exhibit different chemistry. Finally the 2propenyl anion can be prepared by use of an ingenious synthetic route based on diazirines

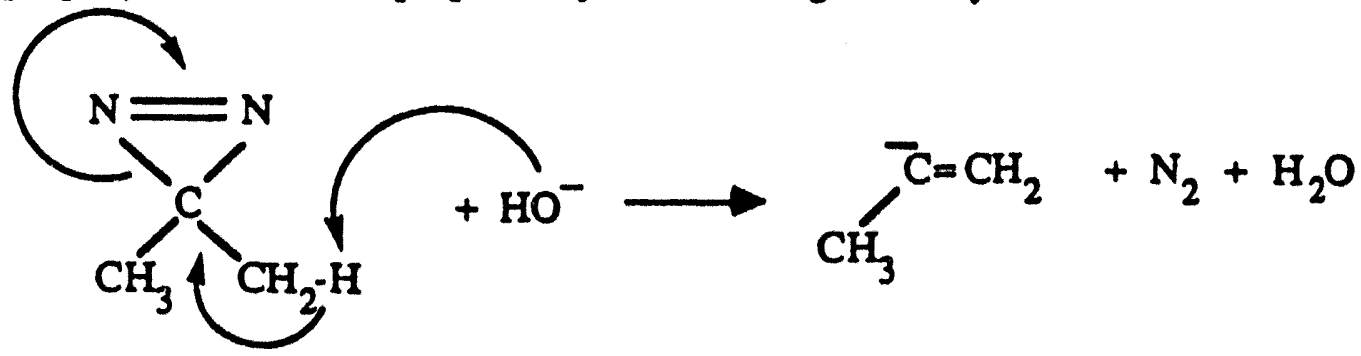

pioneered by Kass[96]. Treatment of an appropriate diazirine with $\mathrm{OH}^{-}$generates the 2 propenyl carbanion. Since the three isomeric propenyl ions have been prepared, (31), it will be possible to complete the acidity/EA cycle and measure the bond dissociation energies of three different vinyl C-H bonds, (32). 
(2) $\mathrm{C}-\mathrm{H}$ bond $\rightarrow \mathrm{H}$

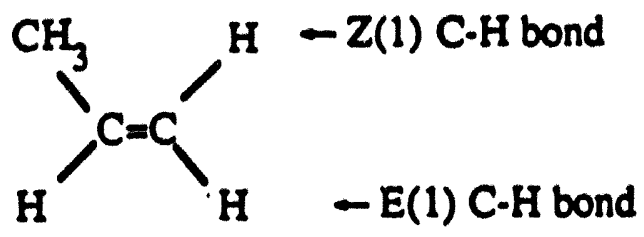

Such measurements will provide heats of formation of the (Z)-1-propenyl radical, the (E)1-propenyl radical, and the 2-propenyl radicals. All are isomers of the allyl radical, $\mathrm{CH}_{2} \mathrm{CHCH}_{2}$. The stereospecific radicals, (Z)-1-propenyl and (E)-1-propenyl radicals, are likely to be configurationally stable but this remains to be proven.

Finally a very general route to carbene radical ions needs to be explicitly noted. Ion molecule reactions[97] with $\mathrm{O}^{-}$generate the anions of diradicals. Species such as $\mathrm{CX}_{2}$, $\mathrm{CH}_{2} \mathrm{C}^{-}, \mathrm{C}_{6} \mathrm{H}_{4}^{-}, \mathrm{CHCN}^{-}$, and $\left(\mathrm{CH}_{2} \mathrm{COCH}_{2}\right)^{-}$have been reported. As a result, an avenue is open to the thermochemical properties of the corresponding diradicals $[98,99,100,101,102]: \mathrm{CX}_{2}, \mathrm{CH}_{2} \mathrm{C}, \mathrm{C}_{6} \mathrm{H}_{4}, \mathrm{CHCN}$, and $\left(\mathrm{CH}_{2} \mathrm{COCH}_{2}\right)$.

$$
\begin{array}{ll}
\mathrm{O}^{-}+\mathrm{H}_{2} \mathrm{CX}_{2} & -\mathrm{H}_{2} \mathrm{O}+\left[\mathrm{CX}_{2}\right]^{-} \\
\mathrm{O}^{-}+\mathrm{H}_{2} \mathrm{CCH}_{2} & -\mathrm{H}_{2} \mathrm{O}+\left[\mathrm{CH}_{2} \mathrm{C}\right]^{-} \\
\mathrm{O}^{-}+\mathrm{C}_{6} \mathrm{H}_{6} & -\mathrm{H}_{2} \mathrm{O}+\left[\mathrm{C}_{6} \mathrm{H}_{4}\right]^{-} \\
\mathrm{O}^{-}+\mathrm{H}_{3} \mathrm{CC}=\mathrm{N} & -\mathrm{H}_{2} \mathrm{O}+\left[\mathrm{HCCN}^{-}\right. \\
\mathrm{O}^{-}+\mathrm{CH}_{3} \mathrm{COCH}_{3} & \rightarrow \mathrm{H}_{2} \mathrm{O}+\left[\mathrm{CH}_{2} \mathrm{COCH}_{2}\right]^{-} \text {and }\left[\mathrm{CH}_{3} \mathrm{COCH}^{-}\right.
\end{array}
$$

\section{Photoionization Mass Spectrometry}

1. Introduction

As mentioned earlier (eq. 4), this approach depends upon the determination of (a) an accurate onset energy for the appearance of $\mathrm{R}^{+}$, together with (b) an independent (and usually much more difficult) measurement of the adiabatic ionization potential of the radical, $\mathrm{IP}(\mathrm{R})$. This appearance potential/ionization potential method (AP/IP) has several advantages: 
i) Detection of a charged species, $R^{+}$, is usually much more sensitive than that of neutral species.

ii) In most cases, selection rules or correlation rules do not prevent the observation of the lowest energy fragment.

iii) Experience has shown that the onset of tragmentation can be observed even at energies where the He I photoelectron spectrum does not indicate states of the parent ion. This so-called Franck-Condon gap region is evidently fllled in, to some extent, by autoionization processes.

iv) If the adiabatic ionization potential of $R$ is accurately known, then the AP of $R^{+}$ provides a rigorous upper limit to $\Delta \mathrm{H}_{f}{ }^{\circ}\left(\mathrm{R}^{+}\right), \Delta \mathrm{H}_{f}{ }^{\circ}(R)$ and $\mathrm{D}_{0}(R-H)$.

v) Both the AP and IP experiments can, in principle, be performed with the same apparatus. Photoion-pair formation is also investigated with this type of instrument.

The disadvantages of this method are:

i) The AP of $\mathrm{R}^{+}$provides a rigorous upper limit, but is it the true thermochemical onset? When one considers the reverse of fragmentation, i.e. an ion-molecule reaction, it is obvious that there exists a long-range $\left(\frac{1}{r^{4}}\right)$ attractive potential, and in most cases, a short-range valence attraction. If these attractive potentials are separated by a substantial repulsive barrier, then the first sign of fragmentation may be accompanied by excess internal energy, or excess kinetic energy. Usually, this is not the case.

ii) If the ionization process $R \rightarrow R^{+}$involves a large change in molecular geometry, the Franck-Condon factors (i.e. vibrational progression in the cation) may be extensive. In such a case, the $0 \rightarrow 0$ transition may be difficult to observe, or to distinguish from a hot band.

iii) If the desired fragmentation process is not the lowest energy fragmentation, then it may be retarded in energy (kinetic shift), due to competition from the lower energy process in their respective unimolecular decay modes. 
iv) For large molecules, unimolecular decay may be very slow, even if the desired fragmentation process is the lowest energy one. On the usual experimental dime scale of several microseconds, a significant, or even serious kinetic shift may be manifest. Thus, for $\mathrm{C}_{7} \mathrm{H}_{7}^{+}$from toluene $\left(\mathrm{C}_{6} \mathrm{H}_{5} \mathrm{CH}_{3}\right)$ it may be a few tenths of an eV, which could be corrected by experiments employing longer characteristic times, but for $\mathrm{C}_{58}{ }^{+}$from $\mathrm{C}_{60}$, it may be[103] tens of volts!

The above comments apply to the determination of bond energies in general, not just to $D_{0}(R \cdot H)$.

\section{Experimental Procedures}

Photoionization mass spectrometry has been practiced for about 3 decades, and is by now quite standard. Basically, one requires a broad-banded source of vacuum ultraviolet (VUV) radiation, a dispersive device (typically a VUV monochromator), a vacuum vessel where the selected wavelengths traverse the target gas sample, and the usual ion optics for introduction of ions to a mass analyzer, with subsequent detection. It nis also necessary to monitor simultaneously the intensity of the VUV radiation, in order to construct a normalized photoion yield curve, i.e. normalized ion intensity as a function of photon energy, hv. Nowadays, the light source may be a) capillary discharge in $\mathrm{H}_{2}$, He, $A r, b)$ synchrotron radiation; or c) a VUV laser. The mass analyzer may be of magnetic or quadrupole type, or (especially useful with a pulsed light source) a time-of-flight instrument. There are advantages and disadvantages to each of these instruments, but such a discussion is beyond the scope of this review.

In the measurement of appearance potentials, the onset of fragmentation is not abrupt. Typically, there is a linear increase in the fragment photoion yield just above threshold, with an exponential tail to still lower energies, attributable to a Boltzmann distribution of internal thermal energy in the initial gas sample. 
It has been shown[104] that, if the inherent fragment photoion yield curve is linear (i.e if a hypothedcal experimen: at $0 \mathrm{~K}$ gives rise to a sudden linear ascent), then the effect of a Boltzmann distribution of target internal energy is to shift the linear function to lower energy by precisely the internal (vibrational plus rotational) energy, and to add an exponential tail to still lower energy. (see Fig. 5) Consequently, to recover the $0 \mathrm{~K}$ threshold from the experimental photoion yield curve, one extrapolates the linear portion to the background level, and then adds to the photoin energy at this extrapolated value the average internal energy. For small molecules investigated at room temperature, this correction is usually $<0.1 \mathrm{eV}$, and typically about $0.04 \mathrm{eV}$. Sometimes, the approach to threshold is more gradual. This may be due to a "tight" transition state preceding the unimolecular decay, competition from a lower energy fragmentation, or traversal of a potential barrier. However, if the process involves a simple bond rupture $\left(\mathrm{RH} \rightarrow \mathrm{R}^{+}+\right.$ $\mathrm{H})$, and if this is the lowest energy fragmentation process, such pathology is less likely (but note the case of $\mathrm{C}_{2} \mathrm{H}_{4}-\mathrm{C}_{2} \mathrm{H}_{3}^{+}+\mathrm{H}$, below). Another problem that must be recognized is the site of bond cleavage, e.g. $\mathrm{HCOOH}-\left({ }^{+} \mathrm{COOH}\right.$ or $\left.\mathrm{HCOO}^{+}\right)+\mathrm{H}$, $\mathrm{CH}_{3} \mathrm{OH}-\left({ }^{+} \mathrm{CH}_{2} \mathrm{OH}\right.$ or $\left.\mathrm{CH}_{3} \mathrm{O}^{+}\right)+\mathrm{H}$, and $\mathrm{CH}_{3} \mathrm{SH} \rightarrow\left({ }^{+} \mathrm{CH}_{2} \mathrm{SH}\right.$ or $\left.\mathrm{CH}_{3} \mathrm{~S}^{+}\right)+\mathrm{H}$. In these cases, the appropriate process (which corresponds to the least endothermic fragmentation) has been proven by selective deuterium substitution.

The more difficult experiment involves the determination of the adiabatic ionization potential of the radical, IP(R). In the generation of a transient species, one usually loses at least one order of magnitude in partial pressure of sample, compared to a stable species. There may also be some additional background, attributable to the method of generation. Various methods have been used, depending upon the most facile technique appropriate to a particular species. These include pyrolysis, photolysis, electrical discharge and chemical abstraction reactions. The latter processes, involving the reaction of $\mathrm{H}$ or $\mathrm{F}$ atoms with an appropriate reagent, have proven to be particularly effective: $R H+F \rightarrow R+H F$. 
A schematic diagram of this method for generating transient species in situ is shown in Fig. 6. A more extensive discussion, and a list of species prepared by various means, appears elsewhere[105].

\section{Examples of experimental results}

a. Early success stories with redundancy

About 20 years ago, a discrepancy arose regarding $D_{0}(\mathrm{HF})$. A solution was provided by a measurement[106] determining the AP of $\mathrm{H}^{+}$from HF. In this case, there was no need to determine the IP of the fragment. From the observed threshold (19.42 \pm $0.01 \mathrm{eV})$, and the internal energy correction $(0.025 \mathrm{eV})$ and $\mathrm{IP}(\mathrm{H})=13.5985 \mathrm{eV}$, one uses eq. (5) to obtain $D_{0}(H F)=5.85 \pm 0.01 \mathrm{eV}$. An independent experiment yielded $D_{0}(D F)=$ $5.91_{2} \pm 0.005 \mathrm{eV}$, consistent with zero point energy differences. Subsequently, Di Lonardo and Douglas[107] obtained $D_{0}(\mathrm{HF})=5.869 \pm 0.007 \mathrm{eV}$ from the onset of predissociation. Photoion-pair formation is also prominent in this system. It manifests itself as sharp, predissociative structure. The threshold for $\mathrm{H}^{+}+\mathrm{F}^{-}$from $\mathrm{HF}$ is $\geq 773 \mathrm{~A}$ (or $\mathrm{S}$ $16.039 \mathrm{eV}$ ). If we take $3.401190 \pm 0.000004 \mathrm{eV}$ as the electron affinity[53] of $F$, and the aforementioned $\mathbb{I P}(\mathrm{H})$, one obtains $\mathrm{D}_{0}(\mathrm{HF}) \leq 5.84 \mathrm{eV}$. The lower value $h-r e$ is due to the fact that internal thermal energy has not been taken into account.

Another potential case incorporating redundancy was that of $\mathrm{HCN}$. The threshold for formation of $\mathrm{H}^{+}+\mathrm{CN}$ (corrected for internal energy) was found[108] to be $19.00 \pm$ $0.01 \mathrm{eV}$, and hence $D_{0}(\mathrm{H}-\mathrm{CN})=5.40 \pm 0.01 \mathrm{eV}[109]$. The threshold for photoion-pair formation $\left(\mathrm{H}^{+}+\mathrm{CN}^{-}\right)$was observed to be $15.18 \pm 0.02 \mathrm{eV}$. At that time, the electron affinity of $\mathrm{CN}$ was not well known, and hence this measurement was used to deduce $\mathrm{EA}(\mathrm{CN})=3.82 \pm 0.02 \mathrm{eV}$. Since that time, $\mathrm{EA}(\mathrm{CN})$ has been studied[110] by optogalvanic spectroscopy and reported to be $3.821 \pm 0.004 \mathrm{eV}$. More recently[111] 
photodetachment studies have clearly shown that the correct $E A(C N)$ is $3.862 \pm 0.004 \mathrm{eV}$, slightly above these earlier values. Unpublished work from our laboratory indicates that $\mathrm{H}_{2} \mathrm{O}$ and $\mathrm{H}_{2} \mathrm{~S}$ undergo photoion-pair formation $\left(\mathrm{H}^{+}+\mathrm{OH}^{-} \mathrm{H}^{+}+\mathrm{SH}^{-}\right)$, with thresholds consistent with currently available knowledge on $D_{0}(H-O H), D_{0}(H-S H)$ and EA(OH), EA(SH).

b. Other successful applications of the AP/IP method to $D_{0}(R-H)$

$\mathrm{D}_{0}\left(\mathrm{H}-\mathrm{C}_{2} \mathrm{H}_{5}\right)$

The AP of $\mathrm{C}_{2} \mathrm{H}_{5}{ }^{+}$from $\mathrm{C}_{2} \mathrm{H}_{6}$ has some ambiguity, possibly due to the contribution of a weak photoion-pair process $\left(\mathrm{C}_{2} \mathrm{H}_{6} \rightarrow \mathrm{C}_{2} \mathrm{H}_{5}^{+}+\mathrm{H}^{-}\right)$. However, thermodynamics offers other altematives. It is only important that one establishes $\Delta \mathrm{H}_{f}{ }^{\circ}\left(\mathrm{C}_{2} \mathrm{H}_{5}{ }^{\dagger}\right)$ and the photolysis of ethyl lodide was used to accomplish just this.

$$
\mathrm{C}_{2} \mathrm{H}_{5} \mathrm{I}+\mathrm{hv} \text { AP } \rightarrow \mathrm{C}_{2} \mathrm{H}_{5}^{+}+\mathrm{I}+e^{-}
$$

Rosenstock et al.[112] summarized earlier studies of ethyl halides, and incorporated their own photoion-photoelectron coincidence study of $\mathrm{C}_{2} \mathrm{H}_{5} \mathrm{I}$ to arrive at the threshold for $\mathrm{C}_{2} \mathrm{H}_{5}{ }^{+}$appearance of $10.52 \pm 0.01 \mathrm{eV}$; use of standard heats of formation of ethyl iodide and I atom leads to $\Delta \mathrm{H}_{10}{ }^{\circ}\left(\mathrm{C}_{2} \mathrm{H}_{5}{ }^{+}\right)=218.8 \pm 0.5 \mathrm{kcal} / \mathrm{mol}$. Ruscic et al.[113]prepared $\mathrm{C}_{2} \mathrm{H}_{5}$ by the reaction of $\mathrm{F}+\mathrm{C}_{2} \mathrm{H}_{6}$. The photoion yield curve yields $\mathrm{IP}\left(\mathrm{C}_{2} \mathrm{H}_{5}\right)=8.117 \pm$ $0.008 \mathrm{eV}$. Thus, $\Delta \mathrm{H}_{10}{ }^{\circ}\left(\mathrm{C}_{2} \mathrm{H}_{5}\right)=\Delta \mathrm{H}_{10}{ }^{\circ}\left(\mathrm{C}_{2} \mathrm{H}_{5}{ }^{+}\right)-\mathrm{IP}\left(\mathrm{C}_{2} \mathrm{H}_{5}\right)=31.6 \pm 0.5 \mathrm{kcal} / \mathrm{mol}$. The heats of formation of $\mathrm{C}_{2} \mathrm{H}_{6}\left(\Delta \mathrm{H}_{\mathrm{fO}}{ }^{\circ}=-16.3 \pm 0.1 \mathrm{kcal} / \mathrm{mol}\right)$, and $\mathrm{H}\left(\Delta \mathrm{H}_{\mathrm{fO}}{ }^{\circ}=51.634\right.$ $\mathrm{kcal} / \mathrm{mol})$ are well established. Thus, $\mathrm{D}_{0}\left(\mathrm{H}-\mathrm{C}_{2} \mathrm{H}_{5}\right)=99.5 \pm 0.5 \mathrm{kcal} / \mathrm{mol}$.

$$
\mathrm{D}_{0}\left(\mathrm{H}-\mathrm{CH}_{2} \mathrm{OH}\right)
$$

The AP of $\mathrm{CH}_{2} \mathrm{OH}^{+}$from $\mathrm{CH}_{3} \mathrm{OH}$ has been reported[114] to be $11.67 \pm 0.03 \mathrm{eV}$ at $0 \mathrm{~K}$. This is the lowest energy fragment, and hence should experience a negligible kinetic shift. It has also been established that the structure is $\mathrm{CH}_{2} \mathrm{OH}^{+}$, and not $\mathrm{CH}_{3} \mathrm{O}^{+}$. 
which is much less stable. In the reaction of $\mathrm{F}$ atoms with $\mathrm{CH}_{3} \mathrm{OH}$, both $\mathrm{CH}_{2} \mathrm{OH}$ and $\mathrm{CH}_{3} \mathrm{O}$ are generated. Photoionization of these species produces ions with the same $\mathrm{m} / \mathrm{e} 31$. However, by using selectively deuterated samples $\left(\mathrm{CD}_{3} \mathrm{OH}, \mathrm{CH}_{3} \mathrm{OD}\right)$, it is possible to distinguish the ionization potentials of these species. Thus, it was found[115] that $\mathbb{P}$ $\left(\mathrm{CH}_{2} \mathrm{OH}\right)=7.549 \pm 0.006 \mathrm{eV}$, whereas $\operatorname{IP}\left(\mathrm{CD}_{3} \mathrm{O}\right)=10.762 \pm 0.008 \mathrm{eV}$. The high value of $\mathbb{P}\left(\mathrm{CD}_{3} \mathrm{O}\right)$ compared to $\mathbb{P}\left(\mathrm{CH}_{2} \mathrm{OH}\right)$ provides further evidence that $\mathrm{CH}_{3} \mathrm{O}^{+}$is much less stable than $\mathrm{CH}_{2} \mathrm{OH}^{+}$. In fact, $\mathrm{CH}_{3} \mathrm{O}^{+}$was not observed. Apparently, there is a barrier to decomposition of this species, which is a triplet, into the singlet manifold of either $\mathrm{CH}_{2} \mathrm{OH}^{+}$or the decomposition products $\mathrm{HCO}^{+}+\mathrm{H}_{2}$. This leads to an isotope effect, enabling $\mathrm{CD}_{3} \mathrm{O}^{+}$to survive during the characteristic lifetime of the experiment, but not $\mathrm{CH}_{3} \mathrm{O}^{+}$. By combining AP $\left(\mathrm{CH}_{2} \mathrm{OH}^{+}\right)$with IP $\left(\mathrm{CH}_{2} \mathrm{OH}\right)$, one obtains $\mathrm{D}_{0}\left(\mathrm{H}-\mathrm{CH}_{2} \mathrm{OH}\right)=$ $4.12 \pm 0.03 \mathrm{eV} \equiv 95.0 \pm 0.7 \mathrm{kcal} / \mathrm{mol}$.

$\mathrm{D}_{\mathrm{o}}\left(\mathrm{H}-\mathrm{CH}_{2} \mathrm{SH}\right)$

Thiomethanol displays some interesting differences from methanol, in both its thermochemistry and dynamics. In methanol, the $\mathrm{O}-\mathrm{H}$ bond is stronger than the $\mathrm{C}-\mathrm{H}$ bond, and hence $\mathrm{CH}_{2} \mathrm{OH}$ is more stable than $\mathrm{CH}_{3} \mathrm{O}$. In thiomethanol, the reverse is true; the $\mathrm{S}-\mathrm{H}$ bond is weaker than the $\mathrm{C}-\mathrm{H}$ bond. This conclusion has been definitively established in recent studies. The lowest energy fragment in the photoionization[116] of $\mathrm{CH}_{3} \mathrm{SH}$ is not $\mathrm{CH}_{2} \mathrm{SH}^{+}$, but $\mathrm{CH}_{2} \mathrm{~S}^{+}$. This decomposition proceeds through a "tight" transition state. The ion of $\mathrm{m} / \mathrm{e} 47\left(\mathrm{CH}_{3} \mathrm{~S}^{+} / \mathrm{CH}_{2} \mathrm{SH}^{+}\right)$begins to appear at a photon energy about $1 \mathrm{eV}$ higher than $\mathrm{CH}_{2} \mathrm{~S}^{+}$, but rapidly overtakes it in intensity. (see Fig. 7). In fact, when the $\mathrm{m} / \mathrm{e} 47$ ion initially appears, the relative cross section for $\mathrm{CH}_{2} \mathrm{~S}^{+}$abruptly declines, presumably due to strong competition from the more facile bond rupture process ("loose complex") associated with m/e 47. This behavior serves to establish $\mathrm{AP}=11.611 \pm 0.005 \mathrm{eV}$ for $\mathrm{m} / \mathrm{e} 47$. 
At the time of the original photoionization study, it was not clear whether $\mathrm{m} / \mathrm{e} 47$ was to be associated with $\mathrm{CH}_{2} \mathrm{SH}^{+}$or $\mathrm{CH}_{3} \mathrm{~S}^{+}$. Recent ab initio calculations[117] have clearly established that it is $\mathrm{CH}_{2} \mathrm{SH}^{+}$.

Reaction of $\mathrm{F}$ atoms with $\mathrm{CH}_{3} \mathrm{SH}$ forms both $\mathrm{CH}_{3} \mathrm{~S}$ and $\mathrm{CH}_{2} \mathrm{SH}$. Once again, these species can be distinguished by selective deuteration $\left(\mathrm{CH}_{3} \mathrm{SD} / \mathrm{CD}_{3} \mathrm{SH}\right)$. Photoionization of these species[118] (see Fig. 8) yields $\mathrm{IP}\left(\mathrm{CH}_{2} \mathrm{SH}\right)$ at $1645.3 \pm 0.7 \AA$ (三 $7.536 \pm 0.003 \mathrm{eV})$ and $\operatorname{IP}\left(\mathrm{CH}_{3} \mathrm{~S}\right)$ at $1338.6 \pm 0.7 \AA(\equiv 9.262 \pm 0.005 \mathrm{eV})$. The lower IP of $\mathrm{CH}_{2} \mathrm{SH}$ is further evidence that the lowest energy process forming $\mathrm{m} / \mathrm{e} 47$ ions from $\mathrm{CH}_{3} \mathrm{SH}$ must have the $\mathrm{CH}_{2} \mathrm{SH}^{+}$structure. By combining $\mathrm{AP}\left(\mathrm{CH}_{2} \mathrm{SH}^{+}\right)$from $\mathrm{CH}_{3} \mathrm{SH}$ with IP $\left(\mathrm{CH}_{2} \mathrm{SH}\right)$, we obtain $\mathrm{D}_{0}\left(\mathrm{H}-\mathrm{CH}_{2} \mathrm{SH}\right)=4.075 \pm 0.006 \mathrm{eV} \equiv 93.97 \pm 0.14$ $\mathrm{kcal} / \mathrm{mol}$. Nicovich et al.[26] have recently determined $\Delta \mathrm{H}_{\mathrm{fO}}{ }^{\circ}\left(\mathrm{CH}_{3} \mathrm{~S}\right)=31.44 \pm 0.54$ $\mathrm{kcal} / \mathrm{mol}$ by kinetic studies analogous to those presented in this review. When combined with $\Delta \mathrm{H}_{\mathrm{fO}}{ }^{\circ}\left(\mathrm{CH}_{3} \mathrm{SH}\right)=-3.0 \pm 0.1 \mathrm{kcal} / \mathrm{mol}$, this leads to $\mathrm{D}_{0}\left(\mathrm{CH}_{3} \mathrm{~S}-\mathrm{H}\right)=86.1 \pm 0.6$ $\mathrm{kcal} / \mathrm{mol}$. Thus, the $\mathrm{C}-\mathrm{H}$ bond is stronger than the $\mathrm{S}-\mathrm{H}$ bond, by about $8 \mathrm{kcal} / \mathrm{mol}$.

A number of $\mathrm{R}-\mathrm{H}$ bonds in inorganic molecules have been successfully established by this approach. In fact, it has been possible to determine not just the first RH bond energy, but the successive ones in these molecules. For example, by determining the AP's (or heats of formation) of $\mathrm{NH}_{2}{ }^{+}$and $\mathrm{NH}^{+}$, and the corresponding IP(NH${ }_{2}$ ) and IP(NH), one can deduce $\mathrm{D}_{0}\left(\mathrm{H}_{2} \mathrm{~N}-\mathrm{H}\right), \mathrm{D}_{0}(\mathrm{HN}-\mathrm{H})$ and $\mathrm{D}_{0}(\mathrm{~N}-\mathrm{H})$. Similar complete results have been obtained for $\mathrm{PH}_{3}, \mathrm{AsH}_{3}, \mathrm{H}_{2} \mathrm{Se}$ and $\mathrm{SiH}_{4}$. Other systems, where not all of the sequential bond energies have been obtained, include $\mathrm{D}_{0}\left(\mathrm{~B}_{2} \mathrm{H}_{5}-\mathrm{H}\right), \mathrm{D}_{0}\left(\mathrm{~B}_{2} \mathrm{H}_{4}-\mathrm{H}\right), \mathrm{D}_{0}\left(\mathrm{H}_{3} \mathrm{Ge}-\mathrm{H}\right)$, $\mathrm{D}_{0}\left(\mathrm{H}_{3} \mathrm{SiSiH}_{2}-\mathrm{H}\right), \mathrm{D}_{0}\left(\mathrm{H}_{2} \mathrm{SiSiH}_{2}-\mathrm{H}\right), \mathrm{D}_{0}\left(\mathrm{H}_{2} \mathrm{NNH}-\mathrm{H}\right)$ and $\mathrm{D}_{0}(\mathrm{HNNH}-\mathrm{H})$. The pertinent references are included in Table IV. 
c. Difficult cases

$\mathrm{D}_{0}\left(\mathrm{C}_{2} \mathrm{H}_{3}-\mathrm{H}\right)$

While ethylene has the well-known planar, double-bonded structure, current evidence indicates that $\mathrm{C}_{2} \mathrm{H}_{3}{ }^{+}$has a bridged, non-classical structure, the odd proton forming a 3-membered ring with the two carbons[119]. Thus, the fragmentation reaction $\mathrm{C}_{2} \mathrm{H}_{4}+\mathrm{hv}-\mathrm{C}_{2} \mathrm{H}_{3}^{+}+\mathrm{H}+\mathrm{e}^{-}$requires considerable rearrangement. Two high quality photoionization studies[120,121] had arrived at $\mathrm{AP}\left(\mathrm{C}_{2} \mathrm{H}_{3}{ }^{+}\right)$from $\mathrm{C}_{2} \mathrm{H}_{4}$ of $13.25 \pm 0.05$ $\mathrm{eV}$ and $13.22 \pm 0.02 \mathrm{eV}$, equivalent to $\Delta \mathrm{H}_{\mathrm{fO}}{ }^{\circ}\left(\mathrm{C}_{2} \mathrm{H}_{3}{ }^{+}\right)=268.4 \pm 1.2 \mathrm{kcal} / \mathrm{mol}$ and $267.8 \pm$ $0.5 \mathrm{kcal} / \mathrm{mol}$. However, a recent study[122] of the reaction $\mathrm{HCCH}^{+}$with hydrogen at collision energies of less than $0.5 \mathrm{meV}$ concluded that $\Delta \mathrm{H}_{\mathrm{fo}}{ }^{\circ}\left(\mathrm{C}_{2} \mathrm{H}_{3}{ }^{+}\right)=265_{-2.1}^{+1.1} \mathrm{kcal} / \mathrm{mol}$.

$$
\mathrm{C}_{2} \mathrm{H}_{2}^{+}+\mathrm{H}_{2} \rightarrow \mathrm{C}_{2} \mathrm{H}_{3}^{+}+\mathrm{H}
$$

Consequently, a barrier of $2-3 \mathrm{kcal} / \mathrm{mol}$ magnitude may exist in the fragmentation of $\mathrm{C}_{2} \mathrm{H}_{4}$ into $\mathrm{C}_{2} \mathrm{H}_{3}^{+}+\mathrm{H}$, preventing the attainment of a true threshold.

The vinyl radical $\mathrm{C}_{2} \mathrm{H}_{3}$ is known to have an ethylene-like structure (missing an $\mathrm{H}$ atom). Given the aforementioned structure for $\mathrm{C}_{2} \mathrm{H}_{3}{ }^{+}$, the Franck-Condon factors connecting $\mathrm{C}_{2} \mathrm{H}_{3}$ and $\mathrm{C}_{2} \mathrm{H}_{3}{ }^{+}$should be weak (perhaps very weak) near threshold. Two recent photoionization studies, one by PIMS[123] and the other by photoelectron spectroscopy[124] (PES) have attempted to determine the adiabatic IP of $\mathrm{C}_{2} \mathrm{H}_{3}$. In the PIMS experiments, two different sources of $\mathrm{C}_{2} \mathrm{H}_{3}$ were utilized: the $\mathrm{F}+\mathrm{C}_{2} \mathrm{H}_{4}$ reaction, and the pyrolysis of $\mathrm{Hg}\left(\mathrm{C}_{2} \mathrm{H}_{3}\right)_{2}$, divinyl mercury. Similar photoion yield curves were obtained, displaying autoionization structure in the vicinity of $1180-1340 \AA$, and a gradually declining intensity to longer wavelengths. With the $\mathrm{H}$ abstraction source, the lowest detectable signal occurred at roughly $1448 \AA \equiv 8.56 \mathrm{eV}$. The vinyl radical is believed to equilibrate to near room temperature in this type of experiment. With the 
pyrolysis source operating at about $1200 \mathrm{~K}$, the lowest detectable signal was at roughly $1476 \AA \equiv 8.40 \mathrm{eV}$. It was concluded that the lower energy threshold in the pyrolysis experiment was attributable to hot bands. With additional analysis, an upper limit of $8.59 \pm$ $0.03 \mathrm{eV}$ was selected for $\mathrm{IP}\left(\mathrm{C}_{2} \mathrm{H}_{3}\right)$.

The PES experiment employed a pulsed nozzle pyrolysis source, a pulsed laser line source and time-of-flight analysis of the photoelectrons. Two different precursors, $\mathrm{C}_{2} \mathrm{H}_{3} \mathrm{CO}_{2} \mathrm{C}\left(\mathrm{CH}_{3}\right)_{3}$ and $\mathrm{C}_{2} \mathrm{H}_{3} \mathrm{NO}_{2}$ were pyrolyzed. The published photoelectron spectrum was obtained with $h v_{0}=10.49 \mathrm{eV}$ and displays a declining photoelectron intensity from about $1 \mathrm{eV}$ kinetic energy out to more than $3 \mathrm{eV}$. A point on this curve has been chosen, near the asymptotic base line, which corresponds to an adiabatic IP of $8.25_{-0.05}^{+0.20} \mathrm{eV}$. The authors argue that their method of preparation provides vibrationally cold vinyl radicals, and therefore that $8.25 \mathrm{eV}$ is an unambiguous lower bound to $\operatorname{IP}\left(\mathrm{C}_{2} \mathrm{H}_{3}\right)$. It should be noted that a time-of-flight spectrum which is linear in velocity, becomes compressed with increasing kinetic energy on an energy scale. With IP of $8.25 \mathrm{eV}$ and $10.49 \mathrm{eV}$ photons, the photoionized electrons have a kinetic energy of $2.24 \mathrm{eV}$ and appear in such a compressed region.

In summary, there is an ambiguity of $2-3 \mathrm{kcal} / \mathrm{mol}$ in $\Delta \mathrm{H}_{\mathrm{fO}}{ }^{\circ}\left(\mathrm{C}_{2} \mathrm{H}_{3}{ }^{+}\right)$and upper and lower bounds to $\operatorname{IP}\left(\mathrm{C}_{2} \mathrm{H}_{3}\right)$ which differ by $0.34 \mathrm{eV} \equiv 7.8 \mathrm{kcal} / \mathrm{mol}$. The various combinations allow for a broad range of $\mathrm{D}_{0}\left(\mathrm{C}_{2} \mathrm{H}_{3}-\mathrm{H}\right)$. Thus, with $\Delta \mathrm{H}_{\mathrm{fO}}{ }^{\circ}\left(\mathrm{C}_{2} \mathrm{H}_{3}{ }^{+}\right)=267.8$ $\mathrm{kcal} / \mathrm{mol}, \mathrm{D}_{0}\left(\mathrm{C}_{2} \mathrm{H}_{3}-\mathrm{H}\right) \geq 106.8 \pm 0.9 \mathrm{kcal} / \mathrm{mol}$, or $114.6_{-4.6}^{+1.1} \mathrm{kcal} / \mathrm{mol}$. Alternatively, using $\Delta \mathrm{H}_{\mathrm{fO}}{ }^{\circ}\left(\mathrm{C}_{2} \mathrm{H}_{3}{ }^{+}\right)=265 \mathrm{kcal} / \mathrm{mol}, \mathrm{D}_{0}\left(\mathrm{C}_{2} \mathrm{H}_{3}-\mathrm{H}\right) \geq 104.0 \pm 0.9 \mathrm{kcal} / \mathrm{mol}$ or $111.8_{-4.6}^{+1.1}$

$\mathrm{kcal} / \mathrm{mol}$. The other methods described in this review unfortunately do not help to resolve the discrepancy. The kinetic approach yields $\mathrm{D}_{0}\left(\mathrm{C}_{2} \mathrm{H}_{3}-\mathrm{H}\right)=105.1 \pm 0.3 \mathrm{kcal} / \mathrm{mol}$, whereas the method based on gas phase acidity arrives at $109.7 \pm 0.8 \mathrm{kcal} / \mathrm{mol}$.

$$
\mathrm{D}_{0}\left(\mathrm{C}_{6} \mathrm{H}_{5}-\mathrm{H}\right)
$$


Even though $\mathrm{C}_{6} \mathrm{H}_{5}{ }^{+}$is the lowest energy fragment upon photodissociative ionization of $\mathrm{C}_{6} \mathrm{H}_{6}$, the rate of decay is too small at the thermochemical threshold to be observed by conventional PIMS. This is an example of the kinetic shift expected for large molecules. Hence, one strategy is to determine the decay rate as a function of excess energy. By modelling this decay, using one or another form of unimolecular decay theory, one can infer a threshold energy. Photoelectron-photoion coincidence measurements are often used to measure decay rates as a function of time. However, in early forms of such experiments, the mass analyzers could not clearly separate $m / e ~ 78\left(\mathrm{C}_{6} \mathrm{H}_{6}{ }^{+}\right)$from $\mathrm{m} / \mathrm{e} 77$ $\left(\mathrm{C}_{6} \mathrm{H}_{5}{ }^{+}\right)$. Two alternative approaches have been employed that bear upon this problem.

i) Instead of $\mathrm{C}_{6} \mathrm{H}_{6}$, halobenzene targets have been used. This overcomes the mass separability problem, and still enables one to determine $\Delta \mathrm{H}_{\mathrm{fO}}{ }^{\circ}\left(\mathrm{C}_{6} \mathrm{H}_{5}{ }^{\dagger}\right)$, if $\Delta \mathrm{H}_{\mathrm{fO}}{ }^{\circ}\left(\mathrm{C}_{6} \mathrm{H}_{5} \mathrm{X}\right)$ is well known. Some loss in accuracy does occur here, since $\Delta \mathrm{H}_{80}{ }^{\circ}\left(\mathrm{C}_{6} \mathrm{H}_{6}\right)$ is known to \pm $0.2 \mathrm{kcal} / \mathrm{mol}$, whereas for example, $\Delta \mathrm{H}_{\mathrm{fO}}{ }^{\circ}\left(\mathrm{C}_{6} \mathrm{H}_{5} \mathrm{l}\right)$ has an uncertainty of $\pm 1.4 \mathrm{kcal} / \mathrm{mol}$. Dannacher et al.[125] performed such a coincidence measurement on $\mathrm{C}_{6} \mathrm{H}_{5} \mathrm{I}$, and inferred $\Delta \mathrm{H}_{10}{ }^{\circ}\left(\mathrm{C}_{6} \mathrm{H}_{5}{ }^{+}\right)=270.8 \pm 1.4 \mathrm{kcal} / \mathrm{mol}$. Malinovich and Lifshitz[126] determined the decay rate at longer times ( $\mathrm{msec}$ as well as $\mu \mathrm{sec}$ ), utilizing a cylindrical ion trap to contain the ions. Modelling of their data by quasi-equilibrium theory led to $\Delta \mathrm{H}_{\mathrm{fo}}{ }^{\circ}\left(\mathrm{C}_{6} \mathrm{H}_{5}{ }^{+}\right)=272.7 \pm$ $2.4 \mathrm{kcal} / \mathrm{mol}$.

ii) Kuhlewind et al.[127]solved the mass separability problem in $\mathrm{C}_{6} \mathrm{H}_{6}$ by using a reflectron time-of-flight mass spectrometer, which has superior resolution. Their method of establishing the internal energy of $\mathrm{C}_{6} \mathrm{H}_{6}{ }^{+}$also differed. They used two-photon ionization via a selected intermediate state to create $\mathrm{C}_{6} \mathrm{H}_{6}{ }^{+}$with very little excess energy, and then (using another tunable laser) excited $\mathrm{C}_{6} \mathrm{H}_{6}{ }^{+}$to selected energies while examining the timeof-flight distribution of various ions. Their modelling of the rate constant for $\mathrm{C}_{6} \mathrm{H}_{6}^{+} \rightarrow$ $\mathrm{C}_{6} \mathrm{H}_{5}{ }^{+}+\mathrm{H}$ by RRKM yielded $\mathrm{E}_{0}=3.66 \mathrm{eV}$ for this reaction. With $\mathrm{IP}\left(\mathrm{C}_{6} \mathrm{H}_{6}\right)=9.2459 \pm$ 
$0.0002 \mathrm{eV}$, the AP of $\mathrm{C}_{6} \mathrm{H}_{5}{ }^{+}$from $\mathrm{C}_{6} \mathrm{H}_{6}$ becomes $12.90_{6} \mathrm{eV}$, or $\Delta \mathrm{H}_{60}{ }^{\circ}\left(\mathrm{C}_{6} \mathrm{H}_{5}{ }^{+}\right)=270.0$ $\mathrm{kcal} / \mathrm{mol}$. Thus, an uncertainty of $<3 \mathrm{kcal} / \mathrm{mol}$ persists.

The IP $\left(\mathrm{C}_{6} \mathrm{H}_{5}\right)$ was measured by Sergeev et al.[128] by PIMS, using pyrolysis of azobenzene as a source. These authors obtained a value of $8.1 \pm 0.1 \mathrm{eV}$. More recently, Butcher et al.[129] prepared $\mathrm{C}_{6} \mathrm{H}_{5}$ by the $\mathrm{F}+\mathrm{C}_{6} \mathrm{H}_{6}$ reaction, and obtained a $\mathrm{He}$ I photoelectron spectrum. Their lowest observed ionization band occurred at $\operatorname{IP}\left(\mathrm{C}_{6} \mathrm{H}_{5}\right)=$ $8.32 \pm 0.04 \mathrm{eV}$. However, their ab initio calculations led them to conclude that the lowest electronic state of the cation $\left({ }^{1} A_{1}\right)$ was not being observed, but rather the excited ${ }^{3} B_{1}$, which is favored by Franck-Condon overlap. They consequently estimated the adiabatic IP $\left(\mathrm{C}_{6} \mathrm{H}_{5}\right)$ to be $8.0 \pm 0.1 \mathrm{eV}$. If we accept their interpretation, the range of IP's $(8.1 \pm 0.1$; $8.0 \pm 0.1 \mathrm{eV})$ and the range of AP's $(12.906,13.01 \pm 0.10 \mathrm{eV})$ leads to a range of bond energies $D_{0}\left(C_{6} \mathrm{H}_{5}-\mathrm{H}\right)$ from 110.8 to $115.6 \mathrm{kcal} / \mathrm{mol}$.

$$
\mathrm{D}_{0}\left(\mathrm{C}_{6} \mathrm{H}_{5} \mathrm{CH}_{2}-\mathrm{H}\right)
$$

i) $\Delta \mathrm{H}_{80}{ }^{\circ}\left(\mathrm{C}_{6} \mathrm{H}_{5} \mathrm{CH}_{2}{ }^{+}\right)$

Photoion-photoelectron coincidence measurements determine the fractional abundance of parent and fragment ion as a function of photon energy. The data are often presented in a so-called breakdown diagram. Unimolecular decay theory, which involves an activation energy and the assumed entropic properties (vibrations, structure) of a transition state, can then be used to simulate the experimental breakdown diagram. Consider the dissociative ionization of toluene:

$$
\mathrm{C}_{6} \mathrm{H}_{5} \mathrm{CH}_{3}+\mathrm{hv} \rightarrow \mathrm{C}_{7} \mathrm{H}_{7}^{+}+\mathrm{H}+\mathrm{e}^{-}
$$

Bombach et al.[130] obtained such a diagram corresponding to the process $\mathrm{C}_{7} \mathrm{H}_{8}{ }^{+} \rightarrow$ $\mathrm{C}_{7} \mathrm{H}_{7}{ }^{+}+\mathrm{H}$, but could not simulate the curve as long as a single transition state was 
employed. They were not surprised, since earlier work had demonstrated that two isomers of $\mathrm{C}_{7} \mathrm{H}_{7}+$ could be formed - the more stable tropylium ion and the benzyl ion.

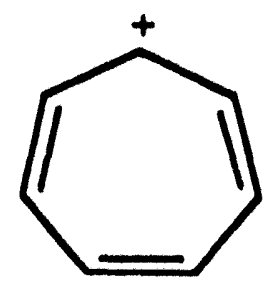

tropylium cation

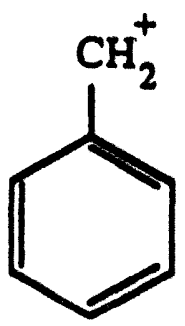

benzyl cation

However, by using a model employing two transition states and two products, each with its own activation energy, they were able to obtain a good fit. From this simulation, they derived the individual threshold energies for tropylium cation and benzyl cation. The latter quantity enabled them to compute $\Delta \mathrm{H}_{10}{ }^{\circ}\left(\mathrm{C}_{6} \mathrm{H}_{5} \mathrm{CH}_{2}{ }^{+}\right)=223.5 \pm 2.2 \mathrm{kcal} / \mathrm{mol}$. It is apparent that this type of study involves a more complex experiment and analysis than conventional PIMS. The latter would, at best, yield the appearance potential of tropylium cation, but even that value would experience a kinetic shift.

Baer et al.[131] opted for an alternative approach. Other evidence had demonstrated that benzyl bromide produces only benzyl cation (not tropylium) upon dissociative ionization. They thereupon chose to study $\mathrm{C}_{6} \mathrm{H}_{5} \mathrm{CH}_{2} \mathrm{Br}$ by photoion-photoelectron coincidence spectroscopy, and to obtain a breakdown diagram. Their analysis of this curve by RRKM/QET calculations led them to $\Delta \mathrm{H}_{\mathrm{fo}}{ }^{\circ}\left(\mathrm{C}_{6} \mathrm{H}_{5} \mathrm{CH}_{2}{ }^{+}\right)=219 \pm 1.2 \mathrm{kcal} / \mathrm{mol}$. A discrepancy of about $4 \mathrm{kcal} / \mathrm{mol}$ persists. The heat of formation of benzyl bromide is not as well known as that of toluene, but according to Pedley et al.[132] its uncertainty is \pm 0.5 $\mathrm{kcal} / \mathrm{mol}$, which cannot account for the difference.

ii) $\mathrm{IP}\left(\mathrm{C}_{6} \mathrm{H}_{5} \mathrm{CH}_{2}\right)$ 
A recent experiment performed by Eiden and Weisshaar[133] on $\mathrm{C}_{6} \mathrm{H}_{5} \mathrm{CH}_{2}$ is perhaps a harbinger of the precision in the determination of ionization potentials which will become available in the near future, even for larger radicals. These authors prepared a beam of cold benzyl radicals by laser photolysis of diluted toluene, expanded through a supersonic nozzle. Thereupon, photoionization is achieved by using two tunable dye lasers, one tuned to a vibronic state of benzyl radical, the other scanning through the ionization region. The benzyl ions formed are detected by time-of-flight mass spectrometry. The adiabatic ionization potential is determined from the onset of ionization, and found to be $7.2487 \pm 0.0006 \mathrm{eV}$.

The combination of $\Delta \mathrm{H}_{\mathrm{fO}}{ }^{\circ}\left(\mathrm{C}_{6} \mathrm{H}_{5} \mathrm{CH}_{2}{ }^{+}\right)$from Bombach et al. together with IP $\left(\mathrm{C}_{6} \mathrm{H}_{5} \mathrm{CH}_{2}\right)$ and $\Delta \mathrm{H}_{50}{ }^{\circ}$ (toluene), leads to $\mathrm{D}_{0}\left(\mathrm{C}_{6} \mathrm{H}_{5} \mathrm{CH}_{2}-\mathrm{H}\right)=90.4 \pm 2.1 \mathrm{kcal} / \mathrm{mol}$. With $\Delta \mathrm{H}_{80}{ }^{\circ}\left(\mathrm{C}_{6} \mathrm{H}_{5} \mathrm{CH}_{2}{ }^{+}\right)$from Baer et al., one obtains $86.6 \pm 1.1 \mathrm{kcal} / \mathrm{mol}$. For comparison, recent kinetics studies by Hippler and Troe[134] and Walker and Tsang[135] enable one to arrive at $\mathrm{D}_{0}\left(\mathrm{C}_{6} \mathrm{H}_{5} \mathrm{CH}_{2}-\mathrm{H}\right)=89.0 \pm 1.0 \mathrm{kcal} / \mathrm{mol}$, and $87.2 \mathrm{kcal} / \mathrm{mol}$, respectively. The essential difference in the two kinetics studies is their choice of $\mathrm{S}^{\circ}\left(\mathrm{C}_{6} \mathrm{H}_{5} \mathrm{CH}_{2}\right)$. We have re-examined this quantity[136], availing ourselves of recently calculated ab initio frequencies for benzyl radical, as well as experimental ones, where possible. Our resulting $\mathrm{S}^{\circ}\left(\mathrm{C}_{6} \mathrm{H}_{5} \mathrm{CH}_{2}\right)$ is much closer to that of Walker and Tsang. Consequently we favor their value for $\mathrm{D}_{0}\left(\mathrm{C}_{6} \mathrm{H}_{5} \mathrm{CH}_{2}-\mathrm{H}\right)$, which is also in good agreement with the valued based on gas phase acidity measurements, $86.8 \pm 2.1 \mathrm{kcal} / \mathrm{mol}$ (see Table II).

$\mathrm{D}_{0}(\mathrm{H}-\mathrm{COOH})$

The appearance potential of $\mathrm{COOH}^{+}$from $\mathrm{HCOOH}$ has been re-investigated recently by photoion-photoelectron coincidence spectroscopy[137]. A value of $12.30 \pm$ $0.02 \mathrm{eV}$ was obtained. The structure of the $\mathrm{m} / \mathrm{e} 45$ ion was established to be: 
$\mathrm{O}=\mathrm{C}=\mathrm{OH}^{+} \quad$ rather than<smiles>O=C[OH2+]</smiles>

From this measurement, one can derive the proton affinity $(\mathrm{PA})$ of $\mathrm{CO}_{2}$ to be $129.2 \pm 0.5$ $\mathrm{kcal} / \mathrm{mol}$, in good agreement with a contemporary direct measurement[138], $\mathrm{PA}\left(\mathrm{CO}_{2}\right)=$ $128.5 \pm 1 \mathrm{kcal} / \mathrm{mol}$.

The products of the $\mathrm{F}+\mathrm{HCOOH}$ reaction were studied by PIMS[139]. It was established by selective deuteration that $\mathrm{HCOO}+\mathrm{hv} \rightarrow \mathrm{HCOO}^{+}+e^{-}$could not be observed, whereas $\mathrm{COOH}+\mathrm{hv}-\mathrm{COOH}^{+}+e^{-}$was detected. A step-like structure was noted in the photoion yield curve near threshold, indicative of a Franck-Condon progression, and hence a geometry change upon photoionization. The primary progression appears to be the $\mathrm{C}-\mathrm{O}$ stretch, with a frequency of roughly $2300 \mathrm{~cm}^{-1}$. The lowest step observed corresponds to an adiabatic $\mathbb{I P}(\mathrm{COOH})=8.486 \pm 0.012 \mathrm{eV}$, but a still weaker, lower step is not ruled out. The presence of such a step would lower the IP to $8.20 \mathrm{eV}$. Thus, $D_{0}(\mathrm{H} \cdot \mathrm{COOH})=12.30 \mathrm{eV} \cdot(58.468 \mathrm{eV}) \geq 3.81 \mathrm{eV} \equiv 88 \mathrm{kcal} / \mathrm{mol}$, and possibly $D_{0}$ $=12.30-8.20=4.10 \mathrm{eV}=94.5 \mathrm{kcal} / \mathrm{mol}$. A recent ab initio calculation[140] arrives at $93.9 \mathrm{kcal} / \mathrm{mol}$ for this bond energy, suggesting that there may exist a heretofore unobserved lower step in the photoion yield curve.

4. Cases solved by photoion-pair formation

Attempts to determine the R-H bond energies of two small molecules, $\mathrm{HCN}$ and $\mathrm{C}_{2} \mathrm{H}_{2}$, by the AP/IP approach using IP(R) have thus far been thwarted. In both cases, the direct determination of the adiabatic IP of the free radical $\left(\mathrm{CN}\right.$ and $\left.\mathrm{C}_{2} \mathrm{H}\right)$ has not been accomplished. For the example of $\mathrm{HCN}$, discussed previously, this does not present a problem for establishing $\mathrm{D}_{0}(\mathrm{H}-\mathrm{CN})$, since the lowest AP corresponds to formation of $\mathrm{H}^{+}$. 
rather than $\mathrm{CN}^{+}$. However, in the dissociative photoionization of acetylene, the lowest energy fragmentation involves $\mathrm{C}_{2} \mathrm{H}^{+}+\mathrm{H}+\mathrm{e}^{-}$, and hence one needs $\mathrm{PP}\left(\mathrm{C}_{2} \mathrm{H}\right)$. In addition, there remains some controversy regarding $\mathrm{AP}\left(\mathrm{C}_{2} \mathrm{H}^{+}\right)$from $\mathrm{C}_{2} \mathrm{H}_{2}$.

Fortunately, both $\mathrm{HCN}$ and $\mathrm{C}_{2} \mathrm{H}_{2}$ (which are isoelectronic) manifest the photoionpair formation process. In a search for $\mathrm{C}_{2} \mathrm{H}^{-}$upon photoexcitation of $\mathrm{C}_{2} \mathrm{H}_{2}$, Ruscic and Berkowitz[136] were surprised to observe two bands. The dependence of one band on the partial pressure of $\mathrm{C}_{2} \mathrm{H}_{2}$ was linear, the other quadratic. The linearly-dependent process, associated with photoion-pair production $\left(\mathrm{H}^{+}+\mathrm{C}_{2} \mathrm{H}^{-}\right)$, had a threshold at $16.33_{5} \pm 0.02$ eV. This threshold, together with $\mathrm{IP}(\mathrm{H})$ and the electron affinity[141], EA $\left(\mathrm{C}_{2} \mathrm{H}\right)=2.969 \pm$ $0.010 \mathrm{eV}$, gives $D_{0}(\mathrm{HCC}-\mathrm{H}) \leq 5.70_{6} \pm 0.02 \mathrm{eV}=131.6 \pm 0.5 \mathrm{kcal} / \mathrm{mol}$. The quadratically-dependent process was interpreted as the two-step reaction:

$$
\begin{aligned}
& \mathrm{C}_{2} \mathrm{H}_{2}+h v-\mathrm{C}_{2} \mathrm{H}_{2}++e^{-}(\mathrm{KE}) \\
& e^{-}(\mathrm{KE})+\mathrm{C}_{2} \mathrm{H}_{2}-\mathrm{C}_{2} \mathrm{H}^{-}+\mathrm{H}
\end{aligned}
$$

The kinetic energy of the scattered electron, $e^{-}(\mathrm{KE})$, is fixed by the IP(HCCH) and the photon's energy, hv. The threshold for (38a) is the IP of $\mathrm{C}_{2} \mathrm{H}_{2}, 11.400 \mathrm{eV}$. Photon energies higher then this value continue to form $\mathrm{C}_{2} \mathrm{H}_{2}{ }^{+}$in its ground vibronic state, the excess energy being carried away by the photoelectron. Process (38b), referred to as dissociative atrachment, has a threshold at $14.072 \mathrm{eV}$. This corresponds to a photoelectron kinetic energy of $2.672 \mathrm{eV}$. (In fact, this process had been investigated previously using thermally generated, accelerated electrons[142]. The observed threshold was $2.8 \pm 0.2$ $e V)$. A detailed analysis of the dissociative attachment threshold in (38b) arrives at a value of $E_{0}=2.71_{5} \pm 0.03_{2} e V$ and $E_{0}(38 b)=D_{0}(H C C-H)-E A(C C H)$. When combined with the aforementioned EA $\left(\mathrm{C}_{2} \mathrm{H}\right)$, this process leads to $\mathrm{D}_{0}(\mathrm{HCC}-\mathrm{H})=5.68_{4} \pm 0.03_{4} \mathrm{eV}=$ $131.1 \pm 0.8 \mathrm{kcal} / \mathrm{mol}$, in very good agreement with the value obtained from the photoionpair threshold. 


\section{Bond Energies}

In this essay, we have concentrated on three methods to determine $\mathrm{R} \cdot \mathrm{H}$ bond energies, although two techniques (kinetics and PDMS studies) can generally be applied to other bond energies. The EA/acidity measurements are, by definition, restricted to R-H bond energies only; but well established thermochemical data bases[129] make it possible to complete a huge number of separate cycles. To conclude we give some examples in Charts I, I, and III.
a) $\mathrm{CH}_{4}$

The removal of successive hydrogen atoms from methane requires 103, 108, 101, and $80 \mathrm{kcal} / \mathrm{mol}$ respectively.[143] Thus the strongest bond is that corresponding to $\mathrm{D}_{0}\left(\mathrm{H}_{2} \mathrm{C}-\mathrm{H}\right)$. In contrast, the corresponding bond in silane and germane, $\mathrm{D}_{0}\left(\mathrm{H}_{2} \mathrm{Si} \cdot \mathrm{H}\right)$ and $\mathrm{D}_{0}\left(\mathrm{H}_{2} \mathrm{Ge}-\mathrm{H}\right)$, is the weakest one in those sequences. This is graphically illustrated in Fig.

9. The explanation for this disparate behavior is intimately related to the ground states of the dihydrides. In $\mathrm{CH}_{2}$ it is ${ }^{3} \mathrm{~B}_{1}$ while $\mathrm{SiH}_{2}$ and $\mathrm{GeH}_{2}$ are singlets, ' $\mathrm{A}_{1}$. The two nonbonding electrons of the radical are unpaired in methylene but are coupled to form singlets in silylene and germylene. Consequently, in order to add a $\mathrm{H}$ atom to the latter, it is necessary to supply energy to uncouple the singlet pair, effectively forming the excited ${ }^{3} \mathrm{~B}_{1}$ state. This expenditure of energy manifests itself in a weaker $D_{0}\left(H_{2} \mathrm{Si} \cdot \mathrm{H}\right)$ and $\mathrm{D}_{0}\left(\mathrm{H}_{2} \mathrm{Ge}\right.$ H). 


\section{b) $\mathrm{CH}_{3} \mathrm{CH}_{3}$}

The C.H bond energy in ethane $(99.6 \pm 0.4 \mathrm{kcal} / \mathrm{mol})$ is slightly weaker than that in methane. Although the precise value is still controversial, the C.H bond in ethylene is $107.5 \pm 2.5 \mathrm{kcal} / \mathrm{mol}$, distinctly larger than in ethane. In acetylene, there is a substantial increase to $131.3 \pm 0.6 \mathrm{kcal} / \mathrm{mol}$. By contrash, removal of a $\mathrm{H}$ atom from the echyl radical requires only $34.2 \pm 0.4 \mathrm{kcal} / \mathrm{mol}$, and from vinyl radical, $35.7 \pm 2.5 \mathrm{kcal} / \mathrm{mol}$. (Chart I) These anomalously low bond energies are readily understood when one recognizes that the products of bond rupture form additional bonds, and hence gain stability. Thus ethyl radical decomposes to generate ethylene with a $\mathrm{C}=\mathrm{C}$ bond. Likewise vinyl radical loses a $\mathrm{H}$ atom to produce acetylene with its $\mathrm{CmC}$ bond. The oscillation in these bond energies in $\mathrm{C}_{2} \mathrm{H}_{6}$ and also $\mathrm{Si}_{2} \mathrm{H}_{6}$ (but with smaller amplitude) can be seen in Fig. 10.

In a similar manner, one can anticipate weak bonds in many of the radicals derived from acetaldehyde, methanol, and thiomethanol. 


\section{Conclusions}

These three different techniques have only a few disagreements among them; the case of ethylene is the most serious. For the overwhelming number of studies, all measurements lead to bond energies within each other's error bars. Likewise the agreement between the photoion-pair thresholds (Table III) and the gas phase acidities (Table II) is satisfactory.

When they can be successfully applied, both radical kinetic studies and PIMS measurements generally produce bond energies with an accuracy of better than \pm 1 $\mathrm{kcal} / \mathrm{mol}$. With few exceptions, the acidity/EA cycle is not as precise as kinetic determinations or AP/IP experiments. Since the acidity is almost always tied to a ladder of reference compounds, uncertainties of \pm 2 or $3 \mathrm{kcal} / \mathrm{mol}$ are unavoidable for many molecules at the present time.

None of these methods is completely satisfactory. The kinetics of halogen abstraction with unsaturated molecules is sometimes complicated by addition reactions; thus this method does not work with $\mathrm{CH}_{3} \mathrm{C} \equiv \mathrm{CH}$ or $\mathrm{CH}_{2}=\mathrm{CHCH}=\mathrm{CH}_{2}$. Likewise PIMS depends on finding an accurate and thermochemically significant appearance energy $\mathrm{E}_{\mathrm{AP}}(\mathrm{R} \cdot \mathrm{H})$. For example, since $\mathrm{CH}_{3} \mathrm{O}^{+}$is roughly $80 \mathrm{kcal} / \mathrm{mol}$ less stable than ${ }^{+} \mathrm{CH}_{2} \mathrm{OH}$, the appearance potential of this $\mathrm{m} / \mathrm{e} 31$ fragment must be expected to have the ${ }^{+} \mathrm{CH}_{2} \mathrm{OH}$ structure; the higher energy form will rearrange and not manifest a new onset. Hence $\mathrm{D}_{0}\left(\mathrm{H} \cdot \mathrm{CH}_{2} \mathrm{OH}\right)$ is accessible to determination by the AP/IP method, but not $\mathrm{D}_{0}\left(\mathrm{CH}_{3} \mathrm{O}-\mathrm{H}\right)$. In addition PIMS requires a clean determination of the radical IP(R). Sometimes the proper $(0,0)$ band of the IP cannot be easily found due to unfavorable Franck-Condon factors. Thus there is still continued concern about the $\operatorname{IP}\left(\mathrm{CH}_{2} \mathrm{CH}\right)$ and $\mathrm{IP}\left(\mathrm{C}_{6} \mathrm{H}_{5}\right)$. Negative ion chemistry/spectroscopy also has its headaches. In many cases one cannot prepare the target ion (e.g. $\left(\mathrm{CH}_{3}\right)_{3} \mathrm{C}^{-}$or $\mathrm{HOCH}_{2}{ }^{-}$for example) or the ion is simply too fragile to study its 
ion chemistry (e.g. $\mathrm{CH}_{3} \mathrm{~N}^{-}$or $\mathrm{BH}_{3}^{-}$). Sometimes the ion has a huge $\mathrm{EA}(\mathrm{R})$ and has not yet been detached $\left(\mathrm{CH}_{3} \mathrm{CO}_{2}{ }^{-}\right.$for example) or the detachment process is complicated by photodissociation $\left(\mathrm{CO}_{3}\right)$. In spite of these limitations these negative ion cycles are very useful since the breadth of the EA/acidity approach is huge. Thousands of molecular acidities are securely known and the latest EA tabulation lists hundreds of radical electron affinities. Table II could be expanded to include several hundred species.

The combination of these three approaches leads to a large number of accurate. consistent bond dissociation energies. Clearly these techniques will be extended to determine the energetics of larger and more complex molecules.

\section{Acknowledgement}

We particularly thank Dr. W.H. Kirchhoff of the United States DOE for his series of combustion meetings which suggested this Review. GBE wishes to thank his colleagues Chuck DePuy, Veronica Bierbaum, C.J. Howard, Marin Robinson, Richard O'Hair, Michèle Krempp, Mark L. Polak, Lawrence B. Harding, and Carl Lineberger for their usual spirited comments. Special recognition to Prof. Kent M. Ervin for his consistent advice and skillful editorial help. Prof. John Bartmess has given us helpful advice about Gas Phase Acidities. The work in Boulder was supported by a grant from the Chemical Physics Program, United States Department of Energy (DE-FG02-87ER13695).

DG acknowledges support for this work from the National Science Foundation (CHE-9102038). Thanks is given to those who developed and conducted the photoionization mass spectrometry experiments discussed here: John J. Russell, Jorma A. Seetula, Paul W. Seakins, Yan Feng, Jukka T. Niiranen, and Lev N. Krasnoperov. A special thanks is given to Irene $\mathrm{R}$. Slagle for her support, advice, and valuable assistance.

JB wishes to especially recognize the work of Branko Ruscic, whose labors are reflected in many of the photoionization studies reported here. We also acknowledge suppor by the U.S. Department of Energy, Office of Basic Energy Sciences, under Contract No. W-31-109-ENG-38. 


\section{Table I}

Second- and Third-Law Determinations of Radical Heats of Formation Based on Studies of the Kinetics of $\mathrm{Br}+\mathrm{RH} \rightleftharpoons \mathrm{R}+\mathrm{HBr}$ Equilibria

\begin{tabular}{|c|c|c|c|c|}
\hline \multirow[b]{2}{*}{ Radical } & \multicolumn{2}{|c|}{$\Delta \mathrm{H}_{\mathrm{f298}}{ }^{\circ}(\mathrm{kcal} / \mathrm{mol})$} & \multirow[b]{2}{*}{$\mathrm{DH}_{0,298 \mathrm{~K}(\mathrm{R}-\mathrm{H})}$} & \multirow[b]{2}{*}{ Reference } \\
\hline & Second Law & Third Law & & \\
\hline $\mathrm{CH}_{3}$ & $34.8 \pm 0.3$ & $34.7 \pm 0.6$ & $104.7 \pm 0.3$ & $144,32,33$ \\
\hline $\mathrm{CH}_{3} \mathrm{CH}_{2}$ & $29.1 \pm 0.4$ & $29.2 \pm 0.4$ & $101.0 \pm 0.4$ & 25 \\
\hline $\mathrm{CH}\left(\mathrm{CH}_{3}\right)_{2}$ & $21.3 \pm 0.3$ & $21.6 \pm 0.5$ & $98.6 \pm 0.4$ & 25 \\
\hline $\mathrm{CH}_{3} \mathrm{CHCH}_{2} \mathrm{CH}_{3}$ & $16.2 \pm 0.7$ & $16.1 \pm 0.5$ & $98.2 \pm 0.5$ & 25 \\
\hline $\mathrm{C}\left(\mathrm{CH}_{3}\right)_{3}$ & $12.3 \pm 0.4$ & $12.3 \pm 0.4$ & $96.5 \pm 0.4$ & 25 \\
\hline $\mathrm{CH}_{2} \mathrm{OH}$ & - & $-2.9 \pm 0.4$ & $97.2 \pm 0.4$ & 1,145 \\
\hline $\mathrm{CH}_{3} \mathrm{CO}$ & $-2.5 \pm 0.4$ & $-2.4 \pm 0.3$ & $89.4 \pm 0.3$ & 146 \\
\hline $\mathrm{SiH}_{3}$ & $48.0 \pm 0.7$ & $47.8 \pm 0.6$ & $91.8 \pm 0.8$ & 21 \\
\hline $\mathrm{SH}$ & $34.0 \pm 0.7$ & $34.4 \pm 0.7$ & $91.2 \pm 0.7$ & 26 \\
\hline $\mathrm{CH}_{3} \mathrm{~S}$ & $29.9 \pm 0.4$ & $29.7 \pm 0.4$ & $87.4 \pm 0.4$ & 26 \\
\hline
\end{tabular}




\section{TABLE II}

Molecular Acidities \& Electron Affinities

Above the solid line, $\Delta \mathrm{H}_{\mathrm{acid}}(\mathrm{RH})$ is computed from $\mathrm{EA}(\mathrm{R})$ and $\mathrm{D}_{0}(\mathrm{RH})$. Below the line, $\mathrm{D}(\mathrm{RH})$ is determined by $E A(R)$ and $\Delta H_{a c i d}(R H)$. All values are in $\mathrm{kcal} /$ mol; see text for further details.

\begin{tabular}{|c|c|c|c|c|c|c|}
\hline Molecul & & $\Delta H_{a c i d, 298 K}(R-H)$ & Electron Affinity(R) & $\underline{\mathrm{DH}}_{0,298 \mathrm{~K}}(\mathrm{R}-\mathrm{H})$ & $\underline{D}_{0}(\mathrm{R}-\mathrm{H})$ & Reference \\
\hline $\mathrm{H}_{2}$ & $\equiv$ & $400.353 \pm 0.002$ & $17.392 \pm 0.002$ & $104.174 \pm 0.002$ & $103.267 \pm 0.002$ & 147 \\
\hline HF & $\equiv$ & $371.4 \pm 0.2$ & $78.433 \pm 0.0001$ & $136.3 \pm 0.2$ & $135.2 \pm 0.2$ & 148 \\
\hline $\mathrm{HCl}$ & $\equiv$ & $333.5 \pm 0.1$ & $83.311 \pm 0.001$ & $103.2 \pm 0.1$ & $102.2 \pm 0.1$ & 149 \\
\hline $\mathrm{HBr}$ & $\equiv$ & $323.5 \pm 0.1$ & $77.599 \pm 0.069$ & $87.5 \pm 0.1$ & $86.7 \pm 0.1$ & 149 \\
\hline HI & $\equiv$ & $314.3 \pm 0.1$ & $70.545 \pm 0.002$ & $71.3 \pm 0.1$ & $70.4 \pm 0.1$ & 149 \\
\hline $\mathrm{H}_{2} \mathrm{O}$ & $\equiv$ & $390.5 \pm 0.3$ & $42.1471 \pm 0.0005$ & $119.1 \pm 0.2$ & $117.9 \pm 0.3$ & 150 \\
\hline $\mathrm{CH}_{2} \mathrm{O}$ & $\equiv$ & $394.4 \pm 0.3$ & $7.2 \pm 0.1$ & $88.0 \pm 0.2$ & $86.6 \pm 0.2$ & 151 \\
\hline $\mathrm{NH}_{3}$ & $\equiv$ & $404.0 \pm 0.3$ & $17.8 \pm 0.1$ & $108.0 \pm 0.3$ & $106.7 \pm 0.3$ & 152 \\
\hline $\mathrm{CH}_{4}$ & $\equiv$ & $416.4 \pm 0.7$ & $1.8 \pm 0.7$ & $104.7 \pm 0.2$ & $103.2 \pm 0.1$ & 153 \\
\hline $\mathrm{HCN}$ & & $351.1 \pm 0.5$ & $89.1 \pm 0.1$ & $127.0 \pm 0.6$ & $125.5 \pm 0.5$ & 154 \\
\hline $\mathrm{H}_{2} \mathrm{~S}$ & & $351.1 \pm 2.0$ & $53.43 \pm 0.05$ & $90.7 \pm 2.0$ & $89.8 \pm 2.0$ & 155 \\
\hline $\mathrm{H}_{2} \mathrm{Se}$ & & $350.5 \pm 4.6$ & $51.0 \pm 0.7$ & $87.9 \pm 4.7$ & $86.4 \pm 4.7$ & 156 \\
\hline
\end{tabular}




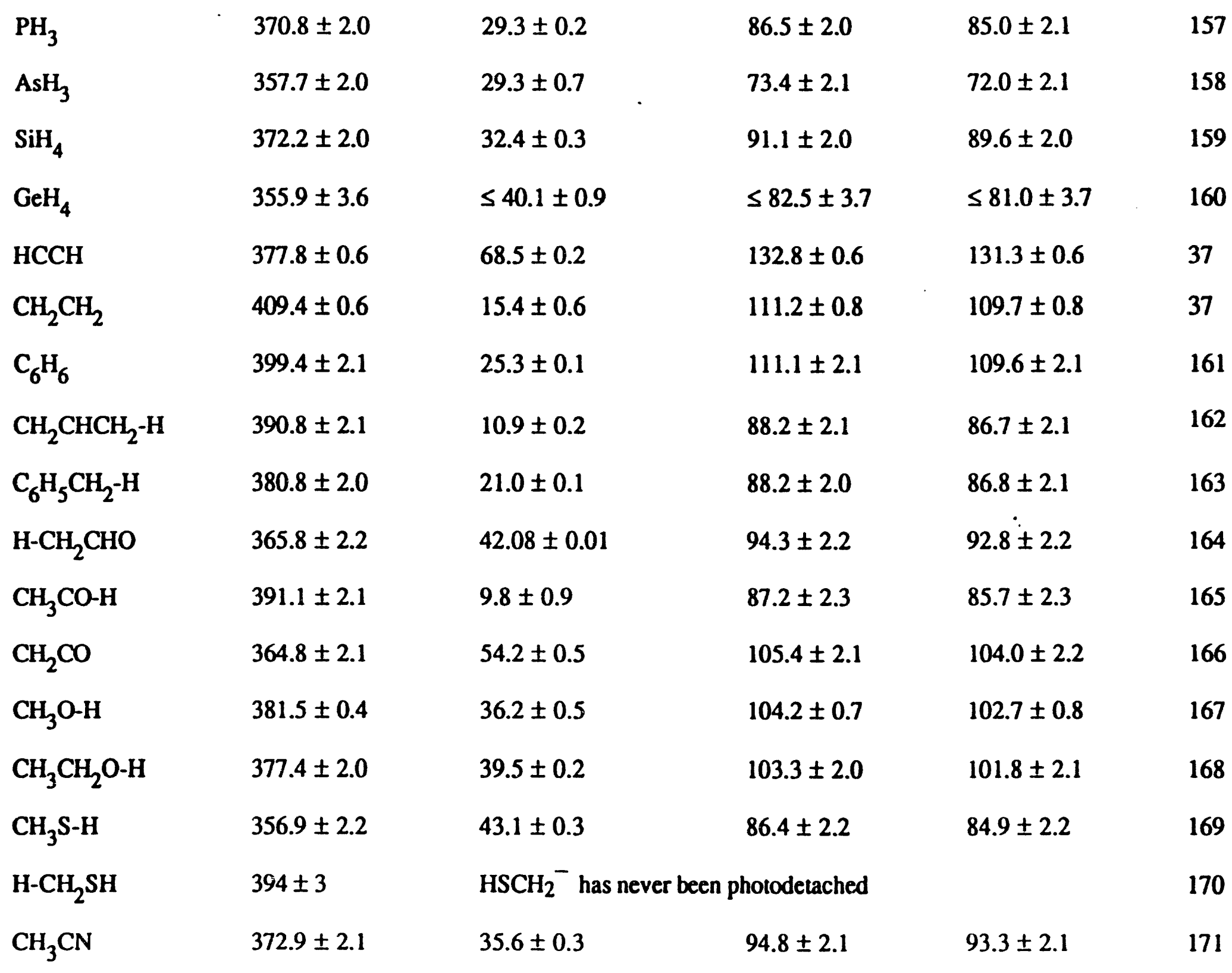




\begin{tabular}{|c|c|c|c|}
\hline $\mathrm{CH}_{3} \mathrm{NC}$ & $380.0 \pm 2.0$ & $24.4 \pm 0.6$ & $89.5 \pm 2.1$ \\
\hline HCOO-H & $345.3 \pm 2.2$ & $\mathrm{HCOO}^{-}$has never been photodetached & \\
\hline $\mathrm{H}-\mathrm{COOH}$ & \multicolumn{2}{|c|}{ - $\mathrm{COOH}$ acidity could not be determined } & \\
\hline $\mathrm{CH}_{3} \mathrm{COO}-\mathrm{H}$ & $341.5 \pm 3.0$ & $\mathrm{CH}_{3} \mathrm{COO}^{-}$has never been photodetached & \\
\hline $\mathrm{H}-\mathrm{CH}_{2} \mathrm{COOH}$ & $368.1 \pm 3.1$ & $\mathrm{HOOCCH}_{2}^{-}$has never been photodetached & \\
\hline $\mathrm{H}-\mathrm{CH}_{2} \mathrm{OH}$ & \multicolumn{3}{|c|}{$\mathrm{HOCH}_{2}^{-}$has never been prepared } \\
\hline $\mathrm{CH}_{3} \mathrm{CH}_{3}$ & \multirow{2}{*}{\multicolumn{3}{|c|}{$\begin{array}{l}\mathrm{CH}_{3} \mathrm{CH}_{2}^{-} \text {has never been prepared } \\
\left(\mathrm{CH}_{3}\right)_{2} \mathrm{CH}^{-} \text {has never been prepared }\end{array}$}} \\
\hline$\left(\mathrm{CH}_{3}\right)_{2} \mathrm{CH}_{2}$ & & & \\
\hline$\left(\mathrm{CH}_{3}\right)_{3} \mathrm{CH}$ & \multicolumn{3}{|c|}{$\left(\mathrm{CH}_{3}\right)_{3} \mathrm{C}^{-}$has never been prepared } \\
\hline
\end{tabular}


Table III

Photoion-Pair Thresholds: $\mathrm{RH}+\mathrm{hv} \rightarrow \mathrm{R}^{-}+\mathrm{H}^{+}$

Molecule Ion-pair Threshold/eV $\Delta \mathrm{H}_{\text {acid } 0 \mathrm{~K}}(\mathrm{RH}) / \mathrm{kcal} \mathrm{mol}^{-1} \quad \Delta \mathrm{H}_{\text {acid } 298 \mathrm{~K}^{(\mathrm{RH}) / \mathrm{kcal} \text { mol }}}{ }^{-1}$

$\begin{array}{llll}\mathrm{HF} & 16.039 \pm 0.021 & 369.9 \pm 0.5 & 370.8 \pm 0.5 \\ \mathrm{H}_{2} \mathrm{O} & 16.87 \pm 0.03 & 389.0 \pm 0.7 & 390.2 \pm 0.7 \\ \mathrm{HCN} & 15.18 \pm 0.02 & 350.1 \pm 0.5 & 351.4 \pm 0.5 \\ \mathrm{HCCH} & 16.335 \pm 0.02 & 376.7 \pm 0.5 & 378.1 \pm 0.5\end{array}$


Table IV

Photoionization Appearance Potentials and Radical Ionization Potentials

\begin{tabular}{|c|c|c|c|c|}
\hline Molecule & $\underline{\mathrm{AP}}\left[\mathrm{R}^{+}=(\mathrm{RH})\right] \perp \mathrm{eV}$ & $\underline{\mathrm{IP}}(\mathrm{R}) / \mathrm{eV}$ & $\underline{D}_{0}(R-H) / \mathrm{kcal} \mathrm{mol}^{-1}$ & $\underline{\text { Ref. }}$ \\
\hline $\mathbf{H F}$ & $\mathrm{H}^{+}=19.42 \pm 0.01$ & 13.5985 & $134.8 \pm 0.2$ & 177 \\
\hline HO-H & $\mathrm{OH}^{+}=18.11 \pm 0.01$ & $13.01 \pm 0.01$ & $117.6 \pm 0.3$ & 178,179 \\
\hline $\mathrm{H}_{2} \mathrm{~N}-\mathrm{H}$ & $\mathrm{NH}_{2}^{+}=15.768 \pm 0.004$ & $11.14 \pm 0.01$ & $106.7 \pm 0.3$ & 180,181 \\
\hline HN-H & $\mathrm{NH}^{+}=17.440 \pm 0.005$ & $13.49 \pm 0.01$ & $91.0 \pm 0.5$ & 178,182 \\
\hline $\mathrm{H}_{3} \mathrm{C}-\mathrm{H}$ & $\mathrm{CH}_{3}^{+}=14.320 \pm 0.004$ & $9.843 \pm 0.002$ & $103.2 \pm 0.1$ & 183,184 \\
\hline $\mathrm{H}_{2} \mathrm{C}-\mathrm{H}$ & $\mathrm{CH}_{2}^{+}=15.09 \pm 0.03$ & $10.396 \pm 0.003$ & $108.2 \pm 0.7$ & 185,181 \\
\hline $\mathrm{C}_{2} \mathrm{H}_{5}-\mathrm{H}$ & $\Delta \mathrm{H}_{10}{ }^{\circ}\left(\mathrm{C}_{2} \mathrm{H}_{5}{ }^{+}\right)=218.8 \pm 0.5 \mathrm{kcal} / \mathrm{mol}$ & $8.117 \pm 0.008$ & $99.5 \pm 0.5$ & 186,187 \\
\hline $\mathrm{C}_{2} \mathrm{H}_{3}-\mathrm{H}$ & $\begin{array}{l}\mathrm{C}_{2} \mathrm{H}_{3}^{+}=13.22 \pm 0.02 \\
\Delta \mathrm{H}_{\mathrm{fO}}{ }^{\circ}\left(\mathrm{C}_{2} \mathrm{H}_{3}^{+}\right)=256_{-2}^{+1} \mathrm{kcal} / \mathrm{mol}\end{array}$ & $\begin{array}{l}\leq 8.59 \pm 0.3 \\
8.25_{-0.05}^{+0.20}\end{array}$ & $\begin{array}{l}\geq 106.8 \\
111.8_{-4.6}^{+1.1}\end{array}$ & $\begin{array}{l}188,189 \\
190,191\end{array}$ \\
\hline $\mathrm{HOCH}_{2}-\mathrm{H}$ & $\mathrm{CH}_{2} \mathrm{OH}^{+}=11.67 \pm 0.03$ & $7.549 \pm 0.006$ & $95.0 \pm 0.7$ & 192,193 \\
\hline $\mathrm{H}-\mathrm{CO}_{2} \mathrm{H}$ & ${ }^{+} \mathrm{COOH}=12.30 \pm 0.02$ & $\begin{array}{l}\leq 8.48 \pm 0.012 \\
(8.20)\end{array}$ & $\begin{array}{l}288 \\
(94.5)\end{array}$ & 194,195 \\
\hline
\end{tabular}




\begin{tabular}{|c|c|c|c|c|}
\hline $\mathrm{HSCH}_{2}-\mathrm{H}$ & $\mathrm{CH}_{2} \mathrm{SH}^{+}=11.611 \pm 0.005$ & $7.536 \pm 0.003$ & $93.97 \pm 0.14$ & 196,197 \\
\hline H-CHO & $\mathrm{HCO}^{+}=11.92 \pm 0.01$ & $8.14 \pm 0.04$ & $87.2 \pm 0.9$ & 198,199 \\
\hline H-CHS & $\mathrm{HCS}^{+}=11.46 \pm 0.016$ & $\begin{array}{r}\leq 7.499 \pm 0.005 \\
(7.412 \pm 0.007)\end{array}$ & $\begin{array}{l}291.3 \pm 0.4 \\
(93.3 \pm 0.4)\end{array}$ & 200 \\
\hline $\mathrm{H}-\mathrm{C}_{6} \mathrm{H}_{5}$ & $\begin{array}{l}\mathrm{C}_{6} \mathrm{H}_{5}^{+}=12.90_{6} \\
=13.01 \pm 0.10\end{array}$ & $\begin{array}{l}8.1 \pm 0.1 \\
8.0 \pm 0.1\end{array}$ & $110.8-115.6$ & $\begin{array}{l}201,202 \\
203,204\end{array}$ \\
\hline $\mathrm{C}_{6} \mathrm{H}_{5} \mathrm{CH}_{2}-\mathrm{H}$ & $\begin{array}{l}\mathrm{C}_{6} \mathrm{H}_{5} \mathrm{CH}_{2}^{+}=11.17 \pm 0.10 \\
\Delta \mathrm{H}_{\mathrm{f0}}{ }^{\circ}\left(\mathrm{C}_{6} \mathrm{H}_{5} \mathrm{CH}_{2}^{+}\right)=219.6 \pm 1.2\end{array}$ & $7.2487 \pm 0.006$ & $\begin{array}{l}90.4 \pm 2.3 \\
86.6 \pm 1.2\end{array}$ & $\begin{array}{r}205,206 \\
.207\end{array}$ \\
\hline $\mathrm{H}_{2} \mathrm{P}-\mathrm{H}$ & $\mathrm{PH}_{2}^{+}=13.40 \pm 0.02$ & $9.824 \pm 0.002$ & $82.46 \pm 0.46$ & 208 \\
\hline HP-H & $\mathrm{PH}^{+}\left(\mathrm{PH}_{3}\right)=12.492 \pm 0.005$ & $10.149 \pm 0.008$ & $74.8 \pm 0.5$ & 202,209 \\
\hline $\mathbf{H}_{2} \mathbf{A s - H}$ & $\mathrm{AsH}_{2}^{+}=12.69 \pm 0.01$ & $9.443 \pm 0.007$ & $74.9 \pm 0.2$ & 210 \\
\hline HAs-H & $\mathrm{AsH}^{+}\left(\mathrm{AsH}_{3}\right)=11.295 \pm 0.005$ & $9.641 \pm 0.008$ & $66.5 \pm 0.3$ & 210 \\
\hline HSe-H & $\mathrm{SeH}^{+}=13.266 \pm 0.007$ & $9.845 \pm 0.003$ & $78.89 \pm 0.18$ & 211 \\
\hline Se-H & $\mathrm{Se}^{+}\left(\mathrm{H}_{2} \mathrm{Se}\right)=11.916 \pm 0.006$ & 9.7525 & $74.27 \pm 0.23$ & 211,212 \\
\hline $\mathrm{H}_{3} \mathrm{Si}-\mathrm{H}$ & $\mathrm{SiH}_{3}{ }^{+} \leq 12.086 \pm 0.020$ & $8.135_{-0.002}^{+0.005}$ & $\leq 91.1 \pm 0.05$ & 213,214 \\
\hline $\mathrm{H}_{2} \mathrm{Si}-\mathrm{H}$ & $\mathrm{SiH}_{2}^{+}\left(\mathrm{SiH}_{4}\right)=11.54 \pm 0.01$ & $9.15 \pm 0.02$ & $267.3 \pm 0.5$ & 214,215 \\
\hline
\end{tabular}




\begin{tabular}{|c|c|c|c|c|}
\hline HSi-H & & & $75.6 \pm 1.4$ & 214 \\
\hline Si-H & & & $68.7 \pm 0.7$ & 214 \\
\hline $\mathrm{H}_{3} \mathrm{Ge}-\mathrm{H}$ & $\mathrm{GeH}_{3}^{+} \leq 11.657 \pm 0.01$ & $\leq 7.94_{8} \pm 0.005$ & $\begin{array}{l}<85.5 \\
(82 \pm 2)\end{array}$ & 216 \\
\hline $\mathrm{B}_{2} \mathrm{H}_{5}-\mathbf{H}$ & $\mathrm{B}_{2} \mathrm{H}_{5}^{+} \leq 11.40 \pm 0.05$ & $(26.945)$ & $\leq 102.7$ & 217 \\
\hline $\mathrm{B}_{2} \mathrm{H}_{4}-\mathrm{H}$ & $\mathrm{B}_{2} \mathrm{H}_{4}^{+}(\mathrm{H} 2) \leq 11.415 \pm 0.04$ & $9.70 \pm 0.12$ & $\cong \mathbf{4 0 . 1}$ & 218 \\
\hline $\mathrm{Si}_{2} \mathrm{H}_{5}-\mathrm{H}$ & $\begin{array}{l}\mathrm{Si}_{2} \mathrm{H}_{5}{ }^{+} \leq 11.59 \pm 0.02 \\
(11.41 \pm 0.03)\end{array}$ & $7.60 \pm 0.05$ & $\begin{array}{l}<92.0 \\
(87.9 \pm 1.3)\end{array}$ & 219,220 \\
\hline $\mathrm{Si}_{2} \mathrm{H}_{4}-\mathrm{H}$ & $\mathrm{Si}_{2} \mathrm{H}_{4}^{+}\left(\mathrm{Si}_{2} \mathrm{H}_{6}\right) \leq 10.04 \pm 0.02$ & $8.09 \pm 0.03$ & $(60.4 \pm 1.5)$ & 212,213 \\
\hline $\mathrm{N}_{2} \mathrm{H}_{3}-\mathrm{H}$ & $\mathrm{N}_{2} \mathrm{H}_{3}^{+}=11.112 \pm 0.01_{0}$ & $7.61 \pm 0.01$ & $80.8 \pm 0.3$ & 181,221 \\
\hline $\mathrm{N}_{2} \mathrm{H}_{2}-\mathrm{H}$ & & & $43.8 \pm 1.1$ & 221 \\
\hline
\end{tabular}




\section{TABLE V}

Recommended Bond Energies \& Heats of Formation/kcal mol-1

\begin{tabular}{|c|c|c|c|c|c|}
\hline Molecule (RH) & $\left.\Delta \mathrm{H}_{1298^{\circ}}{ }^{\circ} \mathrm{R}\right)$ & $\mathrm{DH}_{298}(\mathrm{R}-\mathrm{H})$ & $\Delta H_{10}{ }^{\circ}(R)$ & $\mathbf{D}_{0}(\mathbf{R}-\mathbf{H})$ & Ref \\
\hline $\mathrm{H}_{2}$ & $52.103 \pm 0.001$ & $104.174 \pm 0.002$ & $51.634 \pm 0.001$ & $103.267 \pm 0.002$ & 147 \\
\hline HF & $18.97 \pm 0.07$ & $136.3 \pm 0.2$ & $18.47 \pm 0.07$ & $135.2 \pm 0.2$ & 148 \\
\hline $\mathrm{HCl}$ & $28.992 \pm 0.001$ & $103.2 \pm 0.1$ & $28.590 \pm 0.001$ & $102.2 \pm 0.1$ & 149 \\
\hline $\mathrm{HBr}$ & $26.74 \pm 0.01$ & $87.5 \pm 0.1$ & $28.19 \pm 0.01$ & $86.7 \pm 0.1$ & 149 \\
\hline HI & $25.52 \pm 0.01$ & $71.3 \pm 0.1$ & $25.61 \pm 0.01$ & $70.4 \pm 0.1$ & 149 \\
\hline $\mathrm{H}_{2} \mathrm{O}$ & $9.3 \pm 0.3$ & $119.1 \pm 0.3$ & $9.2 \pm 0.3$ & $117.9 \pm 0.3$ & 150 \\
\hline $\mathrm{H}_{2} \mathrm{CO}$ & $10.0 \pm 0.2$ & $88.04 \pm 0.22$ & $9.99 \pm 0.19$ & $86.57 \pm 0.16$ & 151 \\
\hline $\mathrm{NH}_{3}$ & $45.5 \pm 1.5$ & $108.0 \pm 0.3$ & $46.2 \pm 1.5$ & $106.7 \pm 0.3$ & 152 \\
\hline $\mathrm{CH}_{4}$ & $34.7 \pm 0.3$ & $104.7 \pm 0.3$ & $35.7 \pm 0.1$ & $103.24 \pm 0.12$ & 153 \\
\hline $\mathrm{HCN}$ & $107.2 \pm 2.1$ & $127.0 \pm 0.6$ & $106.3 \pm 2.1$ & $125.5 \pm 0.5$ & 154 \\
\hline $\mathrm{H}_{2} \mathrm{~S}$ & $34.18 \pm 0.68$ & $91.2 \pm 0.7$ & $34.07 \pm 0.72$ & $89.9 \pm 0.7$ & 26 \\
\hline $\mathrm{H}_{2} \mathrm{Se}$ & $35.4 \pm 0.4$ & $80.4 \pm 0.4$ & $34.8 \pm 0.3$ & $78.89 \pm 0.18$ & 178 \\
\hline
\end{tabular}




$\begin{array}{lrrrrr}\mathrm{PH}_{3} & 37.3 \pm 0.6 & 83.9 \pm 0.5 & 37.7 \pm 0.6 & 82.46 \pm 0.46 & 205 \\ \mathrm{AsH}_{3} & 40.2 \pm 0.4 & 76.4 \pm 0.4 & 40.5 \pm 0.2 & 74.9 \pm 0.2 & 207 \\ \mathrm{SiH}_{4} & 47.9 \pm 0.6 & 91.8 \pm 0.8 & 549.5 \pm 0.5 & 591.1 \pm 0.05 & 21,132,209,110 \\ \mathrm{GeH}_{4} & <56.6 \pm 5 & <87.0 \pm 0.5 & <52.5 \pm 0.3 & <85.5 \pm 0.3 & 212 \\ \mathrm{H}_{2} \mathrm{CS} & & 292.8 \pm 0.6 & 573.3 \pm 1.0 & 291.3 \pm 0.4 & 197 \\ \mathrm{HCCH} & 135.2 \pm 0.6 & 132.8 \pm 0.6 & 134.3 \pm 0.6 & 131.3 \pm 0.6 & 37.132 \\ \mathrm{H}_{2} \mathrm{CCH}_{2} & 71.6 \pm 0.8 & 111.2 \pm 0.8 & 72.6 \pm 0.8 & 109.7 \pm 0.8 & 37,132 \\ \mathrm{C}_{6} \mathrm{H}_{6} & 78.7 \pm 2.1 & 111.1 \pm 2.1 & 81.9 \pm 2.1 & 109.6 \pm 2.1 & 132,161 \\ \mathrm{CH}_{2} \mathrm{CHCH}-\mathrm{H} & 40.9 \pm 2.1 & 88.2 \pm 2.1 & 43.5 \pm 2.1 & 86.7 \pm 2.1 & 132,162 \\ \mathrm{C}_{6} \mathrm{H}_{5} \mathrm{CH}-\mathrm{H} & 48.1 \pm 2.0 & 88.2 \pm 2.0 & 52.5 \pm 2.1 & 86.8 \pm 2.1 & 132,163 \\ \mathrm{H}_{-}-\mathrm{CH}_{2} \mathrm{CHO} & 2.5 \pm 2.2 & 94.3 \pm 2.2 & 3.6 \pm 2.2 & 92.8 \pm 2.2 & 132,164 \\ \mathrm{CH}_{3} \mathrm{CO}-\mathrm{H} & -2.4 \pm 0.3 & 89.4 \pm 0.3 & -1.4 \pm 0.5 & 87.9 \pm 0.5 & 132,146 \\ \mathrm{CH}_{2} \mathrm{CO} & 41.9 \pm 2.1 & 105.4 \pm 2.1 & 41.8 \pm 2.2 & 104.0 \pm 2.2 & 132,166 \\ \mathrm{H}_{-}-\mathrm{CH}_{2} \mathrm{OH} & -2.9 \pm 0.4 & 97.2 \pm 0.4 & -2.1 \pm 0.7 & 95.0 \pm 0.7 & 1.145 \\ \mathrm{CH}_{3} \mathrm{O}-\mathrm{H} & 4.1 \pm 0.7 & 104.2 \pm 0.7 & 5.6 \pm 0.7 & 102.7 \pm 0.8 & 132,167 \\ \mathrm{CH}_{3} \mathrm{CH}_{2} \mathrm{O}-\mathrm{H} & -5.0 \pm 2.0 & 103.3 \pm 2.0 & -2.3 \pm 2.1 & 101.8 \pm 2.1 & 132,168 \\ \mathrm{CH}_{3} \mathrm{~S}-\mathrm{H} & 29.78 \pm 0.44 & 87.35 \pm 0.58 & 31.44 \pm 0.54 & 86.1 \pm 0.6 & 26\end{array}$




$\begin{array}{llrrrr}\mathrm{H}-\mathrm{CH}_{2} \mathrm{SH} & & 595.4 \pm 0.4 & 529.9 \pm 0.9 & 594.0 \pm 0.1 & 134,194 \\ \mathrm{CH}_{3} \mathrm{CN} & 58.1 \pm 2.7 & 94.8 \pm 2.1 & 58.7 \pm 2.7 & 93.3 \pm 2.1 & 132,171 \\ \mathrm{CH}_{3} \mathrm{NC} & 78.0 \pm 2.7 & 91.0 \pm 2.1 & 78.5 \pm 2.7 & 89.5 \pm 2.1 & 132,172 \\ \mathrm{H}-\mathrm{COOH} & 2 & - & 2-54.1 \pm 0.5 & 288 & 134,136 \\ \mathrm{CH}_{3} \mathrm{CH}_{2}-\mathrm{H} & 28.9 \pm 0.4 & 101.0 \pm 0.4 & 30.9 \pm 0.5 & 99.5 \pm 0.5 & 25,186,187 \\ \mathrm{CH}_{3} \mathrm{CH}_{2} \mathrm{CH}\left(\mathrm{CH}_{3}\right)-\mathrm{H} & 16.1 \pm 0.5 & 98.2 \pm 0.5 & 21.9 \pm 0.6 & 96.7 \pm 0.6 & 25,132 \\ \left(\mathrm{CH}_{3}\right)_{2} \mathrm{CH}-\mathrm{H} & 21.5 \pm 0.4 & 98.6 \pm 0.4 & 25.6 \pm 0.6 & 97.1 \pm 0.6 & 25,132 \\ \left(\mathrm{CH}_{3}\right)_{3} \mathrm{C}-\mathrm{H} & 12.3 \pm 0.4 & 96.5 \pm 0.4 & & 95.0 \pm 0.6 & 25,132\end{array}$


1 J.A. Seetula and D. Gutman, J. Phys. Chem. 96, 5401 (1992).

2 P.G. Wenthold, J.A. Paulino, and R.R. Squires, J. Am. Chem. Soc. 113, 7414 (1991).

3 Some of the "standard reviews" are: S.W. Benson, Chem. Rev. 78. 23 (1978); D.F. McMillen and D.M. Golden, Ann. Rev. Phys. Chem. 33, 493 (1982); J.B. Pedley, R.D. Naylor, and S.P. Kirby, Thermochemical Data of Organic Compounds, $2^{\text {nd }}$ Ed. (Chapman and Hall, New York, 1986); D. Griller, J.M. Kanabus-Kaminska, and A. Maccoll, J. Mol. Structure (Theochem) 163, 125 (1988).

Bond energies of species in solution, in solids, and on surfaces are tremendously important in their own right but the measurement of these parameters is outside the scope of this article. Electrochemical data has been used to discuss bond energies in solution; see F.G. Bordwell, J.-P. Cheng, J.A. Hartelson Jr., Am. Chem. Soc. 110,1229 (1988) for example. The recent development of laser flash photolysis/photoacoustic calorimetry permits the determination of many bond energies of solvated molecules; a typical accuracy for these measurements is about $\pm 2 \mathrm{kcal} / \mathrm{mol}$. For example see: D.D.M. Wayner, J. Am. Chem. Soc. 113, 9363 (1991).

5 We have to decide on energy units. In order to be useful to most chemists, we will use $\mathrm{kcal} / \mathrm{mol}$ rather than the SI unit of $\mathrm{kJ} / \mathrm{mol}$; the two are related by a simple multiplicative factor, $1 \mathrm{kcal} / \mathrm{mol}=4.184 \mathrm{~kJ} / \mathrm{mol}$. Spectroscopists commonly repor their findings in $\mathrm{eV}\left(1 \mathrm{eV}=23.060542 \mathrm{kcal} / \mathrm{mol}=8065.5410 \mathrm{~cm}^{-1}\right)$ or $\mathrm{cm}^{-1}$ $\left(349.752 \mathrm{~cm}^{-1}=1 \mathrm{kcal} / \mathrm{mol}\right)$. See E.R. Cohen and B.N. Taylor, "The 1986 Adjustment of the Fundamental Physical Constants," Rev. Mod. Phys. 59, 1121 (1987).

6 J.A. Pople, M. Head-Gordon, D.J. Fox, K. Raghavachari, and L.A. Curtiss, J. Chem. Phys. 90, 5622 (1989); L.A. Curtiss, K. Raghavachari, G.W. Trucks, J. A. Pople, J. Chem. Phys. 94, 7221(1991); L.A. Curtiss, J. E. Carptenter, K. Ragavachari, J. A. Pople, J. Chem. Phys. 96, 9030 (1992); L.A. Curtiss, K. Raghavachari, J A. Pople, J. Chem. Phys. 98, 1293 (1993); C.W. Bauschlicher Jr. S.R. Langhoff, and P.R. Taylor, Chem. Phys. Letts. 171, 42 (1990); C.W. Bauschlicher Jr. and S.R. Langhoff, Chem. Phys. Letts. 173, 367 (1990); C.J. Wu and E.A. Carter, J. Phys. Chem. 95, 8352 (1991).

7 G.H. Herzberg, Molecular Spectra and Molecular Structure, I. Spectra of Diatomic Molecules, (D. Van Nostrand, Princeton, 1950). Ch. III, Fig. 50.

8 S.W. Benson, Thermochemical Kinetics, $2^{\text {nd }}$ Ed. (Wiley-Interscience, New York, 1976). \& 2.22

9 See G.H. Herzberg, Molecular Spectra and Molecular Structure, II. Infrared and Raman Spectra of Polyatomic Molecules, (D. Van Nostrand, Princeton, 1945) Ch. 
$V$, for a complete discussion of these issues. The connection between the energy at $O \mathrm{~K}$ and the enthalpy at some temperature, $\mathrm{T}$, is provided by equilibrium statistical mechanics. The total energy of one mole of gas (including translational as well as internal degrees of freedom) consists of the zero point energy of the gas, $\mathrm{E}_{0}$, and $n_{1}, n_{2}, n_{3}, \ldots$ molecules populating levels $\varepsilon_{1}, \varepsilon_{2}, \xi_{3}, \ldots$ above the lowest energy.

$$
E=E_{0}+n_{1} e_{1}+n_{2} \varepsilon_{2}+n_{3} \varepsilon_{3}+n_{4} \varepsilon_{4}+\ldots
$$

The population, $\left(n_{\mathfrak{j}}\right)$, is described by the Maxwell-Boltzmann law and one can use the partition function, $Q$, to write the molecular energy.

$$
E=E_{0}+R T^{2} \frac{d(\ln Q)}{d T}
$$

Consequently we can use (8) to arrive at a useful expression of the heat capacity, $C_{p}(T)=(\partial H / \partial T)_{p}$

$$
C_{p}=R+R \frac{d}{d T}\left[T^{2} \frac{d(\ln Q)}{d T}\right]
$$

Assuming symmetric tops and harmonic vibrations but ignoring internal rotations, Herzberg derives explicit formulae for the $C_{p}(T)$ expressions for molecular translation, rotation, and vibration on p. 512.

10 G.B. Kistiakowsky and E.R. Van Artsdalen, J. Chem. Phys. 12, 469 (1944).

11 B.H. Eckstein, H.A. Scheraga, and E.R. Van Artsdalen, J. Chem. Phys. 22, 28 (1954).

12 J.A. Kerr, Chem. Rev. 66, 125 (1966).

13 D.M. Golden and S.W. Benson, Chem. Rev. 69, 125 (1969).

14 H.E. O'Neal and S.W. Benson, In Free Radicals, J. K. Kochi, Ed. (Wiley: New York, 1973) Vol. 2. Chapter 17.

15 D.F. McMillen and D.M. Golden, Annu. Rev. Phys. Chem. 33, 493 (1982).

16 R. Walsh, Acc. Chem. Res. 14, 246 (1981).

17 J.J. Russell, J.A. Seetula, R.S. Timonen, D. Gutman, and D. Nava, J. Am. Chem. Soc. 110, 3084 (1988).

18 J.J. Russell, J.A. Seetula, and D. Gutman, J. Am. Chem. Soc. 110, 3092 (1988).

19 J.A. Seetula, J.J. Russell, and D. Gutman, J. Am. Chem. Soc. 112, 1347 (1990). 
20 Ref 8, Chapter 2.

21 J.A. Seetula, Y. Feng, D. Gutman, P.W. Seakins, M.J. Pilling, J. Phys. Chem. 95, 1658 (1991).

22 J. M. Nicovich, C.J. Shackelford, and P.H. Wine, J. Photobiol., AS1, 141 (1990).

23 P.W. Seakdins and M.J. Pilling, J. Phys. Chem. 95, 9874 (1991).

24 J. M. Nicovich, C.A. van Dijk, K.D. Kreutter, and P.H. Wine, J. Phys. Chem. 95, 9890 (1991).

25 P.W. Seakins, M.J. Pilling, J.T. Niiranen, D. Gutman, and L.N. Krasnoperov, J. Phys. Chem. 96, 9847 (1992).

26 J. M. Nicovich, K.D. Kreutter, C.A. van Dijk, and P.H. Wine, J. Phys. Chem. 96, 2518 (1992).

27 I. Slagle and D. Gutman, J. Am. Chem. Soc. 107, 5342 (1985).

28 W. Tsang, Int. J. Chem. Kinet. 10, 821 (1978).

29 W. Tsang, J. Am. Chem. Soc. 107, 2872 (1985).

30 R. Gordon, R.E. Ribbert, and P. Ausloos, Rare Gas Resonance Lamps: N.B.S. Technical Note 496, U. S. Government Printing Office (1969).

31 J. R. Kanofsky, D. Lucas, and D. Gutman, Symp. [Int.] Combust. 14, 285 (1974).

32 J.J. Russell, J. A. Seetula, S.M. Senkan, and D. Gutman, Int. J. Chem. Kinet. 20. 759 (1988).

33 O. Dobis and S.W. Benson, Int. J. Chem. Kinet. 19, 691 (1987).

34 J.J. Russell, S.M. Senkan, J. A. Seetula, and D. Gutman, J. Phys. Chem. 93, 5184 (1989).

35 S. S. Parmer and S. W. Benson, J. Phys. Chem. 92, 2652 (1988).

36 S. Dobe, Z. f. Phys. Chem. (Munich) 175, 123 (1992).

37 K.M. Ervin, S. Gronert, S.E. Barlow, M.K. Gilles, A.G. Harrison, V.M. Bierbaum, C.H. DePuy, W.C. Lineberger, and G.B. Ellison, J. Am. Chem. Soc. 112,5750 (1990).

38 D. Gutwan, Acc. Chem. Res. 23, 375 (1990).

39 W.J. Tsang, J. Phys. Chem. Ref. Data 16, 471 (1987). 
40 A. Burcat, in Combustion Chemistry, Ed. W.C. Gardiner Jr. (Springer Verlag, New York, 1984). pp 485-488.

41 The geometrical structure of $\mathrm{CH}_{2} \mathrm{OH}$ is taken from a recent MP2(FULL)/6-31G* calculation by Curtiss et al (L.A. Curtiss, L.D. Kock and J.A. Pople, J. Chem. Phys. 95,4040 (1991)). From this structure, we calculate principal moments of inertia $\mathrm{I}_{\mathrm{xx}}=28.3, \mathrm{I}_{\mathrm{yy}}=4.42, \mathrm{I}_{\mathrm{zz}}=32.2\left(\times 10^{-40} \mathrm{gm} \mathrm{cm}^{2}\right), \mathrm{I}_{\mathrm{xx}} \mathrm{I}_{\mathrm{yy}} \mathrm{I}_{\mathrm{zz}}=4.02 \times 10^{-117}$ $\mathrm{gm}^{3} \mathrm{~cm}^{6}$, and for the hindered rotation, $\mathrm{I}_{\mathrm{r}}=0.982 \times 10^{-40} \mathrm{gm} \mathrm{cm}^{2}$. The entropy, including $S^{\circ}$ (electronic) $=R \ln 2$, but excluding vibration and hindered rotation, is $S^{\circ}=R(4 \ln T+5.357)$. There are 9 vibrational frequencies; according to Saebo, $L$. Radom and H. F. Schaefer III, J. Chem . Phys. 78, 845 (1983), one of these is a hindered rotor about the $\mathrm{C}-\mathrm{O}$ bond. Saebo et al calculate a barrier height of 4 $\mathrm{kcal} / \mathrm{mol}$ at the MP3/6-31G** level. We have used this barrier height, the aforementioned $\mathrm{I}_{\mathrm{r}}$ and Pitzer's table (K.S. Pitzer Quantum Chemistry, PrenticeHall, Inc., Englewood Cliffs, N.J. (1953), p.498) to evaluate this contribution to $S^{\circ}$. The vibrational contribution to $S^{0}$ of the other 8 degrees of freedom was calculated by using 5 experimental frequencies (M.E. Jacox, J. Phys. Chem. Ref. Data 13, 945 (1984)) and the other 3 frequencies from Curtiss (private comm., MP2/6-31G* $\times 0.94)$, which are close to those given by Saebo et al. In particular, the major contributor of these 8 frequencies $\left(735.5 \mathrm{~cm}^{-1}\right.$ Curtiss, $765 \mathrm{~cm}^{-1}$ Saebo et a) was originally given by Jacox (1981) as $569 \mathrm{~cm}^{-1}$, but later withdrawn (Jacox, private commication). The two other experimentally unobserved frequencies are roughly $3000 \mathrm{~cm}^{-1}$, and thus have very little significance for the calculation of $S^{\circ}$ at $298 \mathrm{~K}$ and $349 \mathrm{~K}$.

$42 \quad \operatorname{IP}(\mathrm{H})=109678.758 \pm 0.001 \mathrm{~cm}^{-1}$ or $13.5984378 \pm 0.0000001 \mathrm{eV}$ or 313.587 $347 \pm 0.000001 \mathrm{kcal} / \mathrm{mol}$; C.E. Moore, "Atomic Energy Levels," vol 1, NSRDSNBS 35, 1 (1971).

43 Ref, 15; C.R. Moylan and J.I. Brauman, Annu. Rev. Phys. Chem. 34, 187 (1983).

44 C.R. Moylan and J.I. Brauman, Annu. Rev. Phys. Chem. 34, 187 (1983); S.G. Lias, J.E. Bartmess, J.F. Liebman, J.L. Holmes, R.D. Levin, and W.G. Mallard, J. Phys. and Chem. Ref. Data, 17 (supplement 1) (1988); J.E. Bartmess, NIST Negative Ion Energetics Database, SRB Database 19B, Version 2.1, (April 1990) distributed through the Office of Standard Reverence Data, NIST, Gaithersburg, MD 20899.

45 The most complete list of over 2500 acidities is compiled in: S.G. Lias, J.E. Bartmess, J.F. Liebman, J.L. Holmes, R.D. Levin, and W.G. Mallard, J. Phys. and Chem. Ref. Data, 17 (supplement 1) (1988); J.E. Bartmess, NIST Negative Ion Energetics Database, SRB Database 19B, Version 2.1, (April 1990) distributed through the Office of Standard Reverence Data, NIST, Gaithersburg, MD 20899.

46 The nice overview of molecular acidities is given by J.E. Bartmess and R.T. McIver Jr, Gas Phase Ion Chemistry (M.T. Bowers, ed) 2 (Academic Press, New York, 1979) Ch. 11 pp 88-123. 
47 J.L. Beauchamp and J.T. Armstrong, Rev. Sci. Instruments, 40, 123 (1969); :..T. McIver Jr. Rev. Sci. Instruments, 49, 111 (1978); N.M.M. Nibbering, Accts. Chem. Res. 23, 279 (1990).

48 S.T. Graul and R.R. Squires, Mass Spectrom. Rev. 7, 263 (1988).

49 P. Kebarle, Annu. Rev. 28, 495 (1977).

50 M.W. Chase Jr., C.A. Davies, J.R. Downey Jr, D.J. Frurip, R.A. McDonald, and A.N. Syverud, JANAF Thermochemical Tables, J. Phys. Chem. Ref. Data, 14, Supplement No.1 (1985)

51 The classic reviews of flowing afterglow rechnologies are: E.E. Ferguson, F.C. Fehsenfeld, and A.L. Schmeltekopf, Adv. At. Mol. Phys. 5, 1 (1969); S.T. Graul and R.R. Squires, Mass Spectrom. Rev. 7, 263 (1988); J.M. Van Doren, S.E. Barlow, C.H. DePuy, and V.M. Bierbaum, Int. J. Mass Spectrom. Ion Proc. 81, 85 (1987).

52 The JANAF Tables (ref 50) permit us to compute the bond energy: $D_{0}(\mathrm{HF})=$ $\Delta \mathrm{H}_{0,0 \mathrm{~K}}(\mathrm{H})+\Delta \mathrm{H}_{0,0 \mathrm{~K}}(\mathrm{~F}) \cdot \Delta \mathrm{H}_{0,0 \mathrm{~K}}(\mathrm{HF})$ or $=[51.6336 \pm 0.0014]+[18.47 \pm 0.07]$ - $([-65.13 \pm 0.2])$. Thus $D_{0,0 \mathrm{~K}}(\mathrm{HF})=135.2 \pm 0.2 \mathrm{kcal} / \mathrm{mol}$. The spectroscopic bond energy is listed as $47333 \pm 60 \mathrm{~cm}^{-1}$ which is $135.3 \pm 0.2 \mathrm{kcal} / \mathrm{mol}$; K.P. Huber and G. Herzberg, Constants of Diatomic Molecules, (Von Nostrand Reinhold, New York, 1979).

53 C. Blondel, P. Cacciani, C. Delsart, and R. Trainham, Phys. Rev. A40, 3698 (1989).

54 The absolute entropies can be evaluated by use of the proper statistical mechanical formulae in G.H. Herzberg, Infrared and Raman Spectra of Molecules, (Van Nostrand, Princeton, 1950) Ch V. The table below lists the thermal enthalpy, $\mathrm{H}_{298^{\circ}}$ $\mathrm{H}_{0}$, in $\mathrm{kcal} / \mathrm{mol}$ and the entropy, $\mathrm{S}_{298}$, in cal/mol $\mathrm{K}$. Molecular constants are taken from M.E. Jacox, J. Phys. Chem Ref. Data, 17, 269 (1988); K.M. Ervin and W.C. Lineberger, J. Phys. Chem. 95, 1167 (1991); P. Botschwina, in Ion and Cluster Ion Spectrscopy and Structure, J. P. Maier, Ed. (Elsevier, Amsterdam, 1989) p.59; and T. Shimanouchi, Tables of Vibrational Frequencies, Consolidated Vol. I NSRDS-NBS 39 (1972).

Species

$$
\mathrm{H}_{298}-\mathrm{H}_{0} \mathrm{~S}_{298}
$$

Harmonic Frequencies $\left(\mathrm{cm}^{-1}\right)$

$\underline{B}\left(\mathrm{~cm}^{-1}\right)$

$\begin{array}{lllll}\mathrm{HC} \equiv \mathrm{C} \tilde{\mathrm{X}}^{2} \Sigma^{+} & 2.5 & 49.6 & 3600,1840,370,370 & 1.46 \\ \mathrm{HC} \equiv \mathrm{C}^{-} \tilde{\mathrm{X}}^{1} \Sigma^{+} & 2.4 & 48.8 & 3200,1800,520,520 & 1.39 \\ \mathrm{HC} \equiv \mathrm{CH} \quad \tilde{\mathrm{X}}^{1} \Sigma_{\mathbf{g}}{ }^{+} & 2.4 & 48.0 & 3374,1974,3289,612,612,730,730 & 1.1766\end{array}$

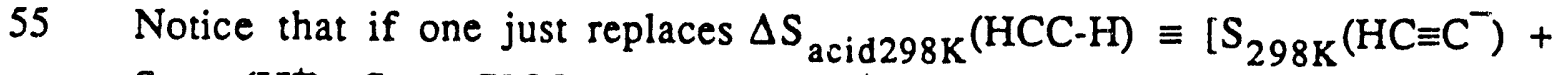
$\left.\mathrm{S}_{298 \mathrm{~K}}\left(\mathrm{H}^{+}\right)-\mathrm{S}_{298 \mathrm{~K}}(\mathrm{HCCH})\right]$ by $\mathrm{S}_{298 \mathrm{~K}}\left(\mathrm{H}^{+}\right)$, the approximation is reasonable. By 
explicit calculation, $\Delta \mathrm{S}_{\text {acid298K }}(\mathrm{HCC}-\mathrm{H})=26.8 \mathrm{cal} / \mathrm{mol} \cdot \mathrm{K}$ while $\mathrm{S}_{298 \mathrm{~K}}\left(\mathrm{H}^{+}\right)=26.0$ $\mathrm{cal} / \mathrm{mol} \cdot \mathrm{K}$.

56 J.M. Oakes, M.E. Jones, V.M. Bierbaum, and G.B. Ellison, J. Phys. Chem. 87, 4810 (1983).

$57 \Delta \mathrm{G}_{\mathrm{acid}}\left(\mathrm{H}-\mathrm{CH}_{2} \mathrm{CHO}\right)=1502 \pm 8 \mathrm{~kJ} / \mathrm{mol}$, see S.G. Lias et al. ref (45).

58 Generally if you cannot compute the entropy exactly, one can make a conjecture: $\Delta \mathrm{S}_{\text {acid }}(\mathrm{R}-\mathrm{H})=\left[\mathrm{S}\left(\mathrm{R}^{-}\right)+\mathrm{S}\left(\mathrm{H}^{+}\right)-\mathrm{S}(\mathrm{RH})\right] \equiv \mathrm{S}_{298 \mathrm{~K}}\left(\mathrm{H}^{+}\right)$or $26 \pm 4 \mathrm{cal} / \mathrm{mol} \cdot \mathrm{K}$. The error bars of $\pm 4 \mathrm{cal} / \mathrm{mol} \cdot \mathrm{K}$ are used since we assume $\left[S\left(R^{-}\right)-S(R H)\right] \equiv 0$. To see that this is not always the case, notice that $\mathrm{CH}_{3} \mathrm{CHO}$ has free rotation about the $\mathrm{CC}$ bond but in the anion, $\mathrm{CH}_{2}=\mathrm{CH}-\mathrm{O}$, this will certainly be lost and $\left[\mathrm{S}\left(\mathrm{R}^{-}\right)-\mathrm{S}(\mathrm{RH})\right]$ $\neq 0$.

59 The "official" acidity scale is tabulated in: S.G. Lias, J.E. Bartmess, J.F. Liebman, J.L. Holmes, R.D. Levin, and W.G. Mallard, J. Phys. and Chem. Ref. Data, 17 (supplement 1) (1988); J.E. Bartmess, NIST Negative Ion Energetics Database, SRB Database 19B, Version 2.1, (April 1990) distributed through the Office of Standard Reverence Data, NIST, Gaithersburg, MD 20899. This table records 4132 different properties of 2626 different ions taken from 817 references.

60 In the earlier versions of Ref. 45, the uncertainties were simply added; consequently errors of the order of $\pm[0.2+2+0.6]$ or $\pm 2.8 \mathrm{kcal} / \mathrm{mol}$ are listed. In later editions, the final uncertainty listed will be the smaller RMS error. Privately communicated by Prof. J.E. Bartmess (December, 1992).

61 We have had to make a choice about significant figures. Essentially one has to choose between being conservative or being correct. Suppose a proper analysis leads to a bond energy which is $93.3 \pm 2.1 \mathrm{kcal} / \mathrm{mol}$. Now the uncertainty is correctly computed and $2.1 \mathrm{kcal} / \mathrm{mol}$ is really the proper measure of the error associated with this bond. But it is all too common that large numbers of chemists lose track of the error bars. Thus the BDE's are picked up from a table and used elsewhere without their accompanying uncertainties. Consequently $93.3 \pm 2.1$ $\mathrm{kcal} / \mathrm{mol}$ propagates about as $93.3 \mathrm{kcal} / \mathrm{mol}$ and at some point there is an implication of an uncertainty of $\pm 0.1 \mathrm{kcal} / \mathrm{mol}$. To be conservative, in the Charts we try to round our numbers carefully; thus $93.3 \pm 2.1 \mathrm{kcal} / \mathrm{mol}$ becomes $93 \pm 2 \mathrm{kcal} / \mathrm{mol}$. In the text and our Tables, we try to be correct. Also we notice that not all uncertainties are symmetric. Thus the $\mathrm{EA}\left(\mathrm{CH}_{2} \mathrm{CHO}\right)$ is $h v_{\text {Thresh }}$ is properly $14718_{-5}^{+2} \mathrm{~cm}^{-1}$. However in all cycles, we choose a symmetric uncertainty of $\pm 5 \mathrm{~cm}^{-1}$ and report an EA of $42.08 \pm 0.01 \mathrm{kcal} / \mathrm{mol}$.

62 J.E. Bartmess, Mass Spectrom. Rev. 8, 297 (1989).

63 M. Meot-Ner (Mautner) in Gas Phase Ion Chemistry, Vol 1, (M.T. Bowers, ed) (Academic Press, New York, 1979) Ch. 6.

M. Meot-Ner and L.W. Sieck, J. Phys. Chem. 90, 6687 (1986). 
65 S.R. Kass and C.H. DePuy, J. Org. Chem. 50, 2874 (1985). This study found that $\Delta \mathrm{H}_{\text {acid }}\left(\mathrm{CH}_{2} \mathrm{~N}-\mathrm{H}\right)=388 \pm 5 \mathrm{kcal} / \mathrm{mol}$. See also: R.A.L. Peerboom, S. Ingemann, N.M.M. Nibbering, and J.F. Liebman, J. Chem. Soc. Perkin Trans II 1825 (1990).

66 Ref. 64; $\Delta \mathrm{G}_{\mathrm{acid}}\left(\mathrm{CH}_{3} \mathrm{O}-\mathrm{H}\right)=375.1 \pm 0.6 \mathrm{kcal} / \mathrm{mol}$ and $\Delta \mathrm{H}_{\text {acid }}\left(\mathrm{CH}_{3} \mathrm{O}-\mathrm{H}\right)=381.5 \pm$ $0.4 \mathrm{kcal} / \mathrm{mol}$.

67 Y. Guo and J.J. Grabowski, Int. J. Mass Spectrom. Ion Proc. 97, 253 (1990).

68 J. Berkowitz, "Photoion-Pair Formation", in VUV and Soft $X$-Ray Photoionization Studies in the series "Physics of Atoms and Molecules", U. Becker and D. A. Shirley, eds., Plenum Publ. Corp. (submitted).

R.G. Cooks and T.L. Kruger, J. Am. Chem. Soc. 99, 1279 (1977).

70 T.K. Majumdar, F. Clairet, J-C. Tabet, and R.G. Cooks, J. Am. Chem. Soc. 114, 2897 (1992); S.A. McLuckey, D. Cameron, and R.G. Cooks, J. Am. Chem. Soc. 103, 1311 (1981) discuss the scope and some limitations of this CID method.

71 T.T. Dang, E.L. Motell, M.J. Travers, E.P. Clifford, G.B. Ellison, C.H. DePuy, and V.M. Bierbaum, Int. J. Mass Spectrom. Ion Proc. 123, 171 (1993).

72 B.K. Janousek and J.I. Brauman, in Gas Phase Ion Chemistry, Vol 2, (M.T. Bowers, ed) (Academic Press, New York, 1979) Ch. 10; P.S. Drzaic, J. Marks, and J.I. Brauman, in Gas Phase Ion Chemistry, Vol 3, (M.T. Bowers, ed) (Academic Press, New York, 1984) Ch. 21; R.D. Mead, A.E. Stevens, and W.C. Lineberger, in Gas Phase Ion Chemistry, Vol 3, (M.T. Bowers, ed) (Academic Press, New York, 1984) Ch.22.

73 K.R. Lykke, K.K. Murray, and W.C. Lineberger, Phys. Rev. 43A, 6104 (1991).

74 R.L. Jackson, P.C. Hiberty, and J.I. Brauman, J. Chem. Phys. 74, 3705 (1981); K.R. Lykke, R.D. Mead, W.C. Lineberger, Phys. Rev. Letts. 52, 2221 (1984). R.D. Mead, K.R. Lykke, W.C. Lineberger, J. Marks, and J.I. Brauman, J. Chem. Phys. 81, 4883 (1984).

75 H.B. Ellis Jr and G.B. Ellison, J. Chem. Phys. 78, 6541 (1983); D.G. Leopold, K.K. Murray, A.E. Stevens Miller, and W.C. Lineberger, J. Chem. Phys. 83, 4849 (1985).

76 D.C. Cowles, M.J. Travers, J.L. Frueh, and G.B. Ellison, J. Chem. Phys. 94, 3517-3528 (1991); J. Chem. Phys. 95, 3864 (1991).

77 J.V. Coe, J.T. Snodgrass, C.B. Freidhoff, K.M. McHugh, and K.H. Bowen, J. Chem. Phys. 83, 3169 (1985); J.V. Coe, G.H. Lee, S.T. Annold, H.W. Sarkas, K.H. Bowen, C. Ludewigt, H. Haberland, and D.R. Worsnop, J. Chem. Phys. 92, 3980 (1990); O. Cheshnovosky, S.H. Yang, C.L. Pettiette, M.J. Craycraft, Y. Liu, and R.E. Smalley, Chem. Phys. Letts. 138, 119 (1987); D.W. Anold, S.E. Bradforth, E.H. Kim, and D.M. Neumark, J. Chem. Phys. 97, 9468 (1992). 
78 L.A. Posey, M.J. DeLuca, and M.A. Johnson, Chem. Phys. Lett. 131, 170 (1986); L.A. Posey and M.A. Johnson, J. Chem. Phys. 88, 5383 (1988); M.J. DeLuca, B. Niu, and M.A. Johnson, J. Chem. Phys. 89, 5857 (1988); T.N. Kitsopoulos, I.M. Waller, J.G. Loeser and D.M. Neumark, Chem Phys. Letts. 159, 300 (1989).

79 P. Kebarle and S. Chowdhury, Chem. Revs. 87, 513 (1987); E.A. Brinkman, J.L. Wilbur, and J.I. Brauman, "Electron Photodetachment Spectroscopy of Molecular Negative Ions" in Negative Ions, edited by Vladimir A. Esaulov, in press (Cambridge University Press, New York, 1993).

80 Z. Karpas and F.S. Klein, Int. J. Mass Spëctrom. Ion Proc. 18, 65 (1975).

81 M.-C. Chuang, M.F. Foltz, and C.B. Moore, J. Chem. Phys. 87, 3855 (1987) report $\mathrm{D}_{0}(\mathrm{H}-\mathrm{CHO})=86.57 \pm 0.16 \mathrm{kcal} / \mathrm{mol}$ and $\mathrm{DH}_{298}(\mathrm{H}-\mathrm{CHO})=88.0 \pm 0.2$ $\mathrm{kcal} / \mathrm{mol}$. Notice that the revised $\Delta \mathrm{H}_{\mathrm{F} 298}{ }^{\circ}\left(\mathrm{CH}_{2} \mathrm{O}\right)$ is $-25.95 \pm 0.11 \mathrm{kcal} / \mathrm{mol} ; \mathrm{D} . \mathrm{L}$. Baulch, R.A. Cox, P.J. Crutzen, R.F. Hampson Jr., J. Troe, and R.T. Watson, J. Phys. Chem. Ref Data 11, 493 (1982).

82 K.K. Murray, T.M. Miller, D.G. Leopold, and W.C. Lineberger, J. Chem. Phys. 84, 2520 (1986).

83 M.J. Travers, D.C. Cowles, and G.B. Ellison, Chem. Phys. Lett. 164, 449 (1989).

84 S.G. Lias et al. ref (45).

85 N.M.M. Nibbering, Advan. Phys. Organic Chem., vol. 24 (Academic Press, New York, 1988).

86 For a nice discussion, see C.H. DePuy and V.M. Bierbaum, in P. Ausloos and S.G. Lias (eds), Structure/Reactivity and Thermochemistry of Ions (D. Reidel, New York, 1987). pp 279-291.

87 J.E. Bartmess, J.A. Scott, and R.T. McIver Jr, J. Am. Chem. Soc. 101, 6046 (1979).

88 C.H. DePuy, V.M. Bierbaum, R. Damrauer, and J.A. Soderquist, J. Am. Chem. Soc. 107, 3385 (1985).

89 M.R. Nimlos, J.A. Soderquist, and G.B. Ellison, J. Am. Chem. Soc. 111, 7675 (1989).

90 R.A.J. O'Hair, S. Gronert, C.H. DePuy, and J.H. Bowie, J. Am. Chem. Soc. 111,3105 (1989).

91 S.R. Kass, H. Guo, and G.D. Dahlke, J. Am. Soc. Mass Spectrom. 1, 366 (1990).

92 J.C. Sheldon and J.H. Bowie, J. Am. Chem. Soc. 112, 2424 (1990). 
93 J.E. Bartmess, J.A. Scott, and R.T. McIver Jr, J. Am. Chem. Soc, 101, 6046 (1979); S. Moran, H.B. Ellis Jr., D.J. DeFrees, A.D. McLean, and G.B. Ellison, J. Am. Chem. Soc. 109, 5996 (1987). R.A.L. Peerboom, S. Ingemann, N.M.M. Nibbering, and J.F. Liebman, J. Chem. Soc. Perkin Trans. II 1825 (1990); S. Moran, H.B. Ellis Jr., D.J. DeFrees, A.D. McLean, S.E. Paulson, and G.B. Ellison, J. Am. Chem. Soc. 109, 6004 (1987).

94 C.H. DePuy, V.M. Bierbaum, L.A. Flippin, J.J. Grabowski, G.K. King, R.J. Schmitt, and S.A. Sullivan, J. Am. Chem. Soc. 102, 5012 (1980).

95 P.K. Chou and S.R. Kass, J. Am. Chem. Soc. 113, 4357 (1991).

96 R.L. Kroeker and S.R. Kass, J. Am. Chem. Soc. 112, 9024 (1990).

97 J. Lee and J.J. Grabowski, Chem. Revs. 92, 1611 (1992).

98 J.H.J. Dawson and K.R. Jennings, J. Chem Soc. Farady Trans. II 72, 700 (1976); J.J. Grabowski and S.J. Melly, Int. J. Mass Spectrom. Ion Proc. 81, 147 (1987).

99 G.C. Goode and K.R. Jennings, Adv. Mass Spectrom. 6, 797 (1974); Y. Guo and J.J. Grabowski, Int. J. Mass Spectrom. Ion Proc. 97, 253 (1990).

100 A.P. Bruins, A.J. Ferrer-Correia, A.G. Harrison, K.F. Jennings, and R.K. Mitchum, Adv. Mass Spectrom. 7, 355 (1978); Y. Guo and J.J. Grabowski, J. Am. Chem. Soc. 113, 5923 (1991).

101 H.E.K. Matimba, A.M. Crabbendam, S. Ingemann, and N.M.M. Nibbering, Int. J. Mass Spectrom. Ion Proc. 114, 85 (1992).

102 A.G. Harrison and K.R. Jennings, J. Chem. Soc. Faraday Trans 1 72, 1601 (1976); H. van der Wel and N.M.M. Nibbering, Recl. Trav. Chim. Pays-Bas 107, 479 (1988).

103 R.K. Yoo, B. Ruscic, and J. Berkowitz, J. Chem. Phys. 96, 911 (1992).

104 P. M. Guyon and J. Berkowitz, J. Chem. Phys. 54, 1814 (1971).

$105 \mathrm{~J}$. Berkowitz and B. Ruscic in Vacuum Ultraviolet Photoionization and Photodissociation fo Molecules and Clusters, C.Y. Ng. ed., World Scientific, Singapore (1991), pp. 1-41.

106 J. Berkowitz, W.A. Chupka, P.M. Guyon, J.H. Holloway and R. Spohr, J. Chem. Phys. 54, 5165 (1971).

107 G. Di Lonardo and A.E. Douglas, Can. J. Phys. 51, 434 (1973).

108 J. Berkowitz, W. A. Chupka and T. A. Walter, J. Chem. Phys. 50, 1497 (1969). 
109 Recently Morely et al. have deduced $D_{0}(H-C N)=5.42_{3} \pm 0.01_{9}$ eV; see C.P. Morely, I.R. Lambert, M.N.R. Ashfold, K.N. Rosser, and C.M. Western, J. Chem. Phys. 97, 3157 (1992).

110 R. Klein, R.P. McGinnis and S.R. Leone, Chem. Phys. Lett. 100, 475 (1983).

111 S.E. Bradforth, E.H. Kim, D.W. Arnold, and D.M. Neumark, J. Chem. Phys. 98, 800 (1993).

112 H.M. Rosenstock, R. Buff, M.A.A. Ferreira, S.G. Lias, A.C. Parr, R.L. Stockbauer, and J.L. Holmes, J. Am. Chem. Soc. 104, 2337 (1982); these authors use: $\Delta \mathrm{H}_{\mathrm{fO}}{ }^{\circ}\left(\mathrm{C}_{2} \mathrm{H}_{5} \mathrm{I}\right)=7.5 \pm 2 \mathrm{~kJ} / \mathrm{mol}$ and $\left.\Delta \mathrm{H}_{\mathrm{fO}}{ }^{\circ} \mathrm{I}\right)=107.25 \pm 0.04$ $\mathrm{kJ} / \mathrm{mol}$.

113 B. Ruscic, J. Berkowitz, L.A. Curtiss and J.A. Pople, J. Chem. Phys. 91, 114 (1989).

114 K. M. A. Refaey and W. A. Chupka, J. Chem. Phys. 48, 5205 (1968).

115 B. Ruscic and J. Berkowitz, J. Chem. Phys. 95, 4033 (1991); see also 202nd National Meeting, American Chemical Society, Div. of Fuel Chemistry Symposium, New York, preprints of papers vol. 36, 1571 (1991).

116 R.E. Kutina, A.K. Edwards, G.L. Goodman and J. Berkowitz, J. Chem. Phys. 77, 5508 (1982).

117 L.A. Curtiss, R. H. Nobes, J.A. Pople and L. Radom, J. Chem. Phys. 97, 6766 (1992).

118 B. Ruscic and J. Berkowitz, J. Chem. Phys. 97, 1818 (1992).

119 To use more qualitative language, $\mathrm{C}_{2} \mathrm{H}_{3}{ }^{+}$is just protonated acetylene.

120 W.A. Chupka, J. Berkowitz and K.M.A. Refaey, J. Chem. Phys. 50, 1938 (1969); $\Delta \mathrm{H}_{\mathrm{fO}}{ }^{\circ}\left(\mathrm{C}_{2} \mathrm{H}_{4}\right)=61.0 \pm 0.3 \mathrm{~kJ} / \mathrm{mol}$ and $\Delta \mathrm{H}_{\mathrm{fO}}{ }^{\circ}(\mathrm{H})=216.035 \pm 0.006$ $\mathrm{kJ} / \mathrm{mol}$

121 R. Stockbauer and M.G. Inghram, J. Chem. Phys. 62, 4862 (1978).

122 M. Hawley and M.A. Smith, J. Am. Chem. Soc. 111, 8293 (1989).

123 J. Berkowitz, C.A. Mayhew and B. Ruscic, J. Chem. Phys. 88, 7396 (1988).

124 J.A. Blush and P. Chen, J. Phys. Chem. 96, 4138 (1992).

125 J. Dannacher, H.M. Rosenstock, R. Buff, A.C. Parr, R.L. Stockbauer, R. Bombach and J.-P. Stadelmann, Chem. Phys. 75, 23 (1983).

126 Y. Malinovich and C. Lifshitz, J. Phys. Chem. 90, 2200 (1986). 
127 H. Kuhlewind, A. Kiermeier and H.J. Neusser, J. Chem. Phys. 85, 4427 (1986).

128 Yu.L. Sergeev, M.E. Akopyan and F.I. Vilesov, Opt. Spektrosk. 32, 230 (1972).

129 V. Butcher, M.L. Costa, J.M. Dyke, A.R. Ellis and J.A. Morris, Chem. Phys. 115, 261 (1987).

130 R. Bombach, J. Dannacher and J.-P. Stadelmann, J. Am. Chem. Soc. 105, 4205 (1983).

131 T. Baer, J.C. Morrow, J. D. Shao and S. Olesik, J. Am. Chem. Soc. 110, 5633 (1988).

132 J.B. Pedley, R.D. Naylor, and S.P. Kirby, Thermochemistry of Organic Compounds $2^{\text {nd }}$ ed., (Chapman \& Hall, London, 1986).

133 G.C. Eiden and J. C. Weisshaar, J. Phys. Chem. 95, 6194 (1991); G.C. Eiden, F. Weinhold and J.C. Weisshaar, J. Chem. Phys. 95, 8665 (1991).

134 H. Hippler and J. Troe, J. Phys. Chem. 94, 3803 (1990).

135 J.A. Walker and W. Tsang, J. Phys. Chem. 94, 3324 (1990).

136 Walker and Tsang studied the gas phase equilibrium $\mathrm{C}_{6} \mathrm{H}_{5} \mathrm{CH}_{3}-\mathrm{C}_{6} \mathrm{H}_{5} \mathrm{CH}_{2}+\mathrm{H}$ at almost the same time as Hippler and Troe, both using shock tubes. Both agree that their equilibrium constants are nearly the same, but Hippler and Troe obtain $\Delta \mathrm{H}_{1298}{ }^{\circ}\left(\mathrm{C}_{6} \mathrm{H}_{5} \mathrm{CH}_{2}\right)=210.5 \pm 4 \mathrm{~kJ} / \mathrm{mol}$, whereas Walker and Tsang repor 203 $\mathrm{kJ} / \mathrm{mol}$ for this quantity, the difference resulting from different values of $\mathrm{S}^{\circ}$ $\left(\mathrm{C}_{6} \mathrm{H}_{5} \mathrm{CH}_{2}\right)$. We have independently calculated this entropy, using still different sources - the geometrical structure from Rice, Handy and Knowles [J. Chem. Soc. Far. Trans. II 83, 1643 (1987)] and the 17 experimentally known [M. E. Jacox, J. Phys. Chem. Ref. Data 19, 1515 (1990)] vibrational frequencies. The additional 19 frequencies were estimated by comparing $a b$ inito calculated frequencies [R. F. Gunion, M. K. Gilles, M. L. Polak and W. C. Lineberger, Int. J. Mass Spectrom. Ion Proc. 117, 601 (1992), J.C. Weisshaar, private communication] with experimental values, and applying the resulting correction factor to the experimentally unknown frequencies. Seven of these 19 frequencies have $\omega \geq$ $3000 \mathrm{~cm}^{-1}$, and contribute little to the entropy. In this way, we arrive at $\mathrm{S}_{1000}{ }^{\circ}\left(\mathrm{C}_{6} \mathrm{H}_{5} \mathrm{CH}_{2}\right)=127.7 \pm 0.7 \mathrm{cal} / \mathrm{deg}-\mathrm{mol} \equiv 534.3 \pm 2.7 \mathrm{~J} / \mathrm{deg}-\mathrm{mol}$, closer to the value of Walker and Tsang (533.2 J/deg-mol) than to that of Hippler and Troe $\left(540.7 \mathrm{~J} / \mathrm{deg}\right.$-mol). If we therefore accept $\Delta \mathrm{H}_{\mathrm{fO}}{ }^{\circ}\left(\mathrm{C}_{6} \mathrm{H}_{5} \mathrm{CH}_{2}\right)=203 \mathrm{~kJ} / \mathrm{mol}$ from Walker and Tsang, we obtain $\mathrm{D}_{0}\left(\mathrm{C}_{6} \mathrm{H}_{5} \mathrm{CH}_{2}-\mathrm{H}\right)=87.2 \mathrm{kcal} / \mathrm{mol}$, in good agreement with gas phase acidity measurements $(87 \pm 2 \mathrm{kcal} / \mathrm{mol})$. These results favor $\Delta \mathrm{H}_{\mathrm{fO}}{ }^{\circ}\left(\mathrm{C}_{6} \mathrm{H}_{5} \mathrm{CH}_{2}\right)$ from Baer et al, which gives $86.6 \pm 1.1 \mathrm{kcal} / \mathrm{mol}$ for the bond dissociation energy.

137 B. Ruscic, M. Schwarz and J. Berkowitz, J. Chem. Phys. 91,6772 (1989). 
138 N.G. Adams, D. Smith, M. Tichy, G. Jawahery, N.D. Twiddy and E.E. Ferguson, J. Chem. Phys. 91, 4037 (1989).

139 B. Ruscic, M. Schwarz ard J. Berkowitz, J. Chem. Phys. 91, 6780 (1989).

140 L.A. Curtiss, private communication.

141 K.M. Ervin and W.C. Lineberger, J. Phys. Chem. 95, 1167 (1991).

142 L. von Trepka and H. Neuert, Z. Naturf. 18\&, 1295 (1963).

143 The bond energies of methane are $(\mathrm{kcal} / \mathrm{mol}): \mathrm{D}_{0}\left(\mathrm{H}_{3} \mathrm{C} \cdot \mathrm{H}\right)=103.24 \pm 0.12$, $D_{0}\left(H_{2} C-H\right)=108.6 \pm 0.6, D_{0}(H C-H)=100.7 \pm 1.0$, and $D_{0}(C-H)=79.9 \pm 0.1$. See: W.A. Chupka, J. Chem. Phys. 48, 2337 (1968), D.G. Leopold, K.K. Murray, A.E. Stevens Miller, and W.C. Lineberger, J. Chem. Phys. 83, 4849 (1985), and K.P. Huber and G. Herzberg, Molecular Spectra and Molecular Structure IV. Constants of Diatomic Molecules (Van Nostrand, New York, 1979). JANF lists $\Delta \mathrm{H}_{\mathrm{fO}}{ }^{\circ}\left(\mathrm{CH}_{4}\right)=-15.92 \pm 0.07 \mathrm{kcal} / \mathrm{mol}, \Delta \mathrm{H}_{\mathrm{fO}}{ }^{\circ}(\mathrm{C})=170.0 \pm 0.1$ $\mathrm{kcal} / \mathrm{mol}$, and $\Delta \mathrm{H}_{\mathrm{fO}}{ }^{\circ}(\mathrm{H})=51.634 \pm 0.001 \mathrm{kcal} / \mathrm{mol}$; consequently the sum of the four $\mathrm{C}-\mathrm{H}$ bonds in methane must add to $392.4 \pm 0.1 \mathrm{kcal} / \mathrm{mol}$.

144 Based on study of $\mathrm{Cl}+\mathrm{CH}_{4}-\mathrm{CH}_{4}+\mathrm{HCl}$ equilibrium.

145 S. Dobe, Z. Phys. Chem. (Munich) 175, 123 (1992); see text and ref. [41] for a discussion of the "best" entropy.

146 J.K. Niiranen, D. Gutman, and L.N.Krasnoperov, J. Phys. Chem. 96, 5881 (1992).

147 JANAF Thermochemical Tables, (ref 50); ref 73.

148 JANAF Thermochemical Tables, (ref 50); ref 53.

149 JANAF Thermochemical Tables, (ref 50); H. Hotop and W.C. Lineberger, J. Phys. Chem. Ref Data 14, 731 (1985).

150 JANAF Thermochemical Tables, (ref 50); P.A. Schulz, R.D. Mead, P.L. Jones, and W.C. Lineberger, J. Chem. Phys. 77, 1153 (1982).

151 The acidity reported by Z. Karpas and F.S. Klein, Int. J. Mass Spectrom. Ion Proc. 18, 65 (1975) is incorrect. We list the computed acidity derived from the EA(HCO) [K.K. Murray, T.M. Miller, D.G. Leopold, and W.C. Lineberger, J. Chem. Phys. 84, 2520 (1986)] and [M.-C. Chuang, M.F. Foltz, and C.B. Moore, J. Chem. Phys. 87, 3855 (1987) report $\left.\mathrm{DH}_{298}(\mathrm{H}-\mathrm{CHO})=88.0 \pm 0.2 \mathrm{kcal} / \mathrm{mol}\right]$.

152 S.T. Gibson, J.P. Greene, and J. Berkowitz, J. Chem. Phys. 83, 4319 (1985); C.T. Wickham-Jones, K.M. Ervin, G.B. Ellison, and W.C. Lineberger, J. Chem. Phys. 91, 2762 (1989). 
153 W.A. Chupka, J. Chem. Phys. 48, 2337 (1968); G.B. Ellison, P.C. Engelking, and W.C. Lineberger, J. Am. Chem. Soc. 100, 2556 (1978).

154 The threshold for photoion-pair formation is reported in Table III as $15.18 \pm 0.02$ eV or $350.1 \pm 0.5 \mathrm{kcal} / \mathrm{mol} ;$ D.W. Arnold, S.E. Bradforth, E.H. Kim, and D.M. Neumark, J. Chem. Phys. 97, 9468 (1992).

155 J.E. Bartmess, J.A. Scott, and R.T. McIver Jr. J. Am. Chem. Soc. 101, 6047 (1979); F. Breyer, P. Frey, and H. Hotop, Z. Phys. A300, 7 (1981).

156 D.A. Dixon, D. Holtz, J.L. Beauchamp, Inorg. Chem. 11, 960 (1972); R.C. Stoneman and D.J. Larsen, J. Phys. B19, L405 (1986).

157 J.E. Bartmess, J.A. Scott, and R.T. Mclver Jr, J. Am. Chem. Soc. 101, 6046 (1979); P.F. Zittle and W.C. Lineberger, I. Chem. Phys. 65, 1236 (1976).

158 J.-F. Gal, P.-C. Maria, and M. Decouzon, Int. J. Mass Spectrom. Ion Proc. 93, 87 (1989); K.C. Smyth and J.I. Brauman, J. Chem. Phys. 56, 4620 (1972).

159 J.E. Bartmess, J.A. Scott, and R.T. Mclver Jr, J. Am. Chem. Soc. 101, 6046 (1979); M.R. Nimlos and G.B. Ellison, J. Am. Chem. Soc. 108, 6522 (1986).

160 K.J. Reed and J.I. Brauman, J. Chem. Phys. 61, 4830 (1974).

161 C.H. DePuy, V.M. Bierbaum, R.Damrauer, J. Am. Chem. Soc. 106, 4051 (1984); H.K.K. Matimba, A.M. Crabbendam, S. Ingemann, and N.M.M. Nibbering, J. Chem. Soc. Chemical Communications, 644 (1991); R.Gunion, M. Gilles, M. Polak, and W.C. Lineberger, Int. J. Mass Spectrom. Ion Proc. 117, 621 (1992).

162 G.I. McKay, M.H. Lien, A.C. Hopkinson, and D.K. Bohme, Can. J. Chem. 56, 131 (1978); J.M. Oakes and G.B. Ellison, J. Am. Chem. Soc. 106, 7734 (1984); M.L. Polak and W.C. Lineberger (unpublished, 1992).

163 J.E. Bartmess, J.A. Scott, and R.T. McIver Jr., J. Am. Chem. Soc. 101, 6047 (1979); R.Gunion, M. Gilles, M. Polak, and W.C. Lineberger, Int. J. Mass Spectrom. Ion Proc.117, 601 (1992).

164 J.E. Bartmess, J.A. Scott, and R.T. McIver Jr., J. Am. Chem. Soc. 101, 6047 (1979); R.D. Mead, K.R. Lykke, W.C. Lineberger, J. Marks, and J.I. Brauman, J. Chem. Phys. 81, 4883 (1984).

165 C.H. DePuy, V.M. Bierbaum, R. Damrauer, and J.A. Soderquist, J. Am. Chem. Soc. 107, 3385 (1985); M.R. Nimlos, J.A. Soderquist, and G.B. Ellison, J. Am. Chem. Soc. 111, 7675 (1989).

166 J.M. Oakes, M.E. Jones, V.M. Bierbaum, and G.B. Ellison, J. Phys. Chem. 87 , 4810 (1983).

167 Ref. 64; P.C. Engelking, G.B. Ellison, W.C. Lineberger, J. Chem. Phys. 69, 1826 (1978). 
168 T.T. Dang, E.L. Motell, M.J. Travers, E.P. Clifford, G.B. Ellison, C.H. DePuy, and V.M. Bierbaum, Int. J. Mass Spectrom. Ion Proc. 123, 171 (1993).

169 J.E. Bartmess, J.A. Scott, and R.T. Mclver Jr. J. Am. Chem. Soc. 101, 6047 (1979); S. Moran and G.B. Ellison, J. Phys. Chem. 92, 1794 (1988)

170 S.R. Kass, H. Guo, and G.D. Dahlke, J. Am. Soc. Mass Spectrom. 1, 366 (1990).

171 J.E. Bartmess, J.A. Scott, and R.T. Mclver Jr. J. Am. Chem. Soc. 101, 6047 (1979); S. Moran, H.B. Ellis Jr., D.J. DeFrees, A.D. McLean, and G.B. Ellison, J. Am. Chem. Soc. 109, 5996 (1987).

172 R.A.L. Peerboom, S. Ingemann, N.M.M. Nibbering, and J.F. Liebman, J. Chem. Soc. Perkin Trans. II 1825 (1990); S. Moran, H.B. Ellis Jr., D.J. DeFrees, A.D. McLean, S.E. Paulson, and G.B. Ellison, J. Am. Chem. Soc. 109, 6004 (1987).

173 G. Caldwell, R. Renneboog, and P. Kebarle, Can. J. Chem. 67, 661 (1989).

174 J.C. Sheldon and J.H. Bowie, J. Am. Chem. Soc. 112, 2424 (1990).

175 J.B. Cumming and P. Kebarle, Can. J. Chem. 56, 1 (1978).

176 J.J. Grabowski and X. Cheng, J. Am. Chem. Soc. 111, 3106 (1989).

177 J. Berkowitz, W. A. Chupka, P. M. Guyon, J. Holloway and R. Spohr, J. Chem. Phys. 54, 5165 (1971).

178 J. Berkowitz, Photoabsorption, Photoionization and Photoelectron Spectroscopy, (Academic Press, N.Y., 1979), pp. 244, 247.

179 W. van Lonkhuyzen and C. A. de Lange, Mol. Phys. 51,551 (1984).

180 K. E. McCulloh, Int. J. Mass Spectrom. Ion Proc. 21, 333 (1976).

181 S. T. Gibson, J. P. Greene and J. Berkowitz, J. Chem. Phys. 83, 4319 (1985).

182 S. J. Dunlavey, J. M. Dyke, N. Jonathan, and A. Morris, Mol. Phys. 39, 1121 (1980).

183 W. A. Chupka, J. Chem. Phys. 48, 2337 (1968).

184 G. Herzberg, Proc. Roy. Soc. (Lond.) A262, 291 (1961).

185 W. A. Chupka and C. Lifshitz, J. Chem. Phys. 48, 1109 (1968).

186 H. M. Rosenstock, R. Buff, M.A.A. Ferreira, S. G. Lias, A. C. Parr, R. L.Stockbauer and J. L. Holmes, J. Am. Chem Soc. 104, 2337 (1982).

187 B. Ruscic, J. Berkowitz, L.A. Curtiss and J.A. Pople, J. Chem Phys. 91,114 (1989). 
188 R. Stockbauer and M.G. Inghram, J. Chem. Phys. 62, 4862 (1975).

189 J. Berkowitz, C. A. Mayhew and B. Ruscic, J. Chem Phys. 88, 7896 (1988).

190 M. Hawley and M.A. Smith, J. Am. Chem. Soc. 111, 8293 (1989).

191 J. A. Blush and P. Chen, J. Phys. Chem. 96, 4138 (1992).

192 K.M.A. Refaey and W.A. Chupka, J. Chem Phys. 48, 5205 (1968).

193 B. Ruscic and J. Berkowitz, J. Chem. Phys. 95, 4033 (1991).

194 B. Ruscic, M. Schwarz and J. Berkowitz, J. Chem. Phys. 91,6772 (1989).

195 B. Ruscic, M. Schwarz and J. Berkowitz, J. Chem. Phys. 91,6780 (1989).

196 R. E. Kutina, A. K. Edwards, G. L. Goodman and J. Berkowitz, J. Chem. Phys. 77, 5508 (1982).

197 B. Ruscic and J. Berkowitz, J. Chem. Phys. 97,1818 (1992).

198 P. M. Guyon, W. A. Chupka and J. Berkowitz, J. Chem. Phys. 64, 1419 (1976).

199 J. M. Dyke, J. Chem. Soc. Far. Trans. II 83, 69 (1987).

200 B. Ruscic and J. Berkowitz, J. Chem. Phys. 98, 2568 (1993).

201 H. Kuhlewind, A. Kiermeier and H.J. Neusser, J. Chem. Phys. 85, 4427 (1986).

202 Yu. L. Sergeev, M.E. Akopyan, and F. I. Vilesov, Opt. Spektrosk. 32, 230 (1972).

203 Y. Malinovich and C. Lifshitz, J. Phys. Chem. 90, 2200 (1986).

204 V. Butcher, M.L. Costa, J.M. Dyke, A. R. Ellis and A. Morris, Chem. Phys. 115, 261 (1987).

205 R. Bombach, J. Dannacher and J.-P. Stadelmann, J. Am. Chem. Soc. 105, 4205 (1983).

206 G.C. Eide.t : ñث J.C. Weisshaar, J. Phys. Chem. 95, 6194 (1991); G.C. Eiden, F. Weinhold and J.C. Weisshaar, J. Chem. Phys. 95, 8665 (1991).

207 T. Baer, J.C. Morrow, J.D. Shao and S. Olesik, J. Am. Chem. Soc. 110, 5633 (1988).

208 J. Berkowitz, L.A. Curtiss, S.T. Gibson, J.P. Greene, G.L. Hillhouse and J. A. Pople, J. Chem. Phys. 84, 375 (1986).

209 J. Berkowitz and H. Cho, J. Chem. Phys. 90, 1 (1989). 
210 J. Berkowitz, J. Chem. Phys. 89, 7065 (1988).

211 S.T. Gibson, J.P. Greene and J. Berkowikz, J. Chem. Phys. 85, 4815 (1980).

212 C.E. Moore, "Atomic Energy Levels", NBS Circ. 467, vol. 2, U.S. Govt. Printing Office, Wash., D.C. (1971).

213 J. Berkowitz, J.P. Greene, H. Cho and B. Ruscic, J. Chem. Phys. 86, 1235 (1987).

214 R.D. Johnson III, B.P. Tsai and J.W. Hudgens, J. Chem. Phys. 91, 3340 (1989).

215 J. Berkowitz and B. Ruscic, "Photoionization Mass Spectrometric Studies of Free Radicals", in Vacuum Ultraviolet Photoionization and Photodissociation of Molecules and Clusters, C. Y. Ng. ed., World Scientific, Singapore (1991), pp. 1. 41.

216 B. Ruscic, M. Schwarz and J. Berkowitz, J. Chem. Phys. 92, 1865 (1990).

217 B. Ruscic, M. Schwarz and J. Berkowitz, J. Chem. Phys. 91,4183 (1989).

218 B. Ruscic, M. Schwarz and J. Berkowitz, J. Chem. Phys. 91,4576 (1989).

219 B. Ruscic and J. Berkowitz, J. Chem. Phys. 95, 2407 (1991).

220 B. Ruscic and J. Berkowitz, J. Chem. Phys. 95, 2416 (1991)

221 B. Ruscic and J. Berkowitz, J. Chem. Phys. 95, 4378 (1991). 


\section{Chart I}

Ethane Experimental Bond Strengths $\left(D_{0}\right.$ in keal mol-1)

$$
\begin{array}{ll}
\mathrm{CH}_{3} \mathrm{CH}_{2}-\mathrm{H} \stackrel{99.5 \pm 0.5}{\longrightarrow} & \mathrm{CH}_{3} \mathrm{CH}_{2}+\mathrm{H} \\
\tilde{\mathrm{X}}^{1} \mathrm{~A}_{1 \mathrm{~g}} & \tilde{\mathrm{X}}^{2} \mathrm{~A}^{\prime}
\end{array}
$$

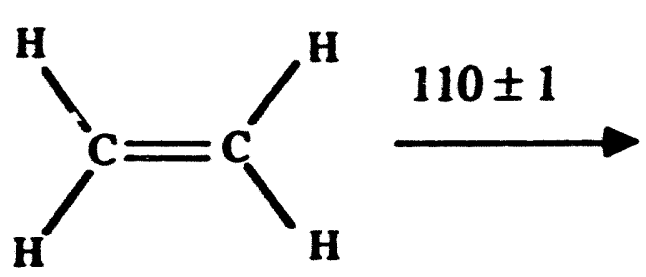

$\widetilde{\mathbf{X}}^{1} \mathbf{A}_{\mathbf{g}}$

$$
\begin{gathered}
\mathrm{H}-\mathrm{CH}_{2} \mathrm{CH}_{2} \stackrel{34.2 \pm 0.4}{\longrightarrow} \underset{\tilde{\mathrm{X}}^{2} \mathrm{~A}^{\prime}}{\longrightarrow} \\
\mathrm{CH}_{2} \mathrm{CH}_{2}+\mathrm{H} \\
\tilde{\mathrm{X}}^{\prime} \mathrm{A}_{8}
\end{gathered}
$$
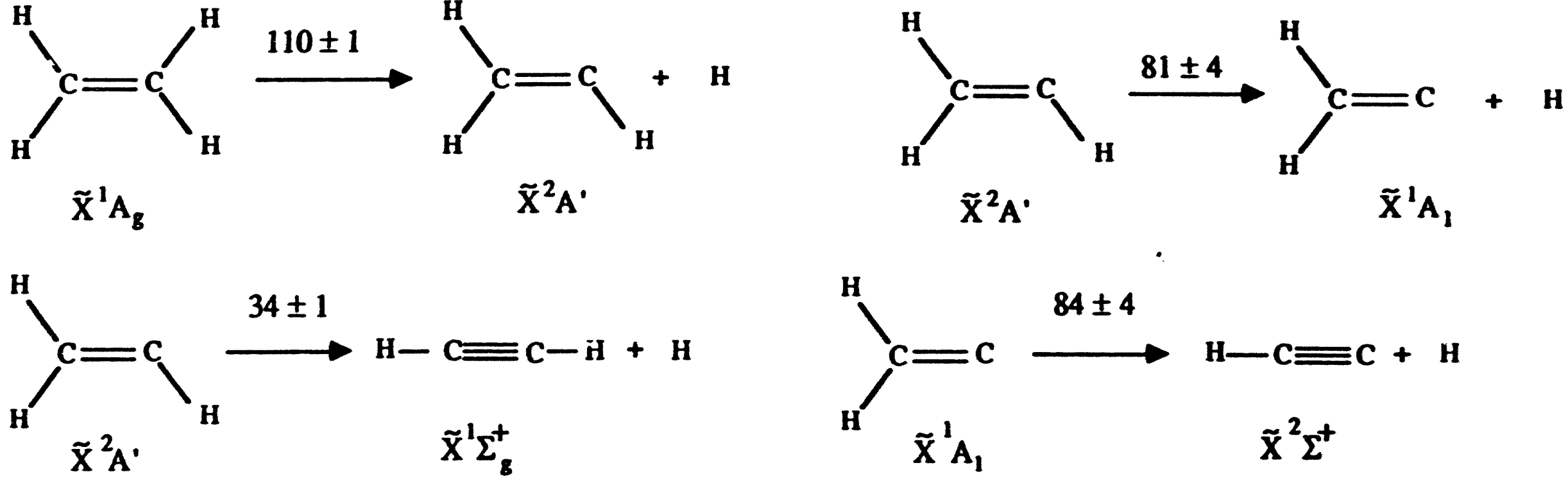

$131 \pm 1$

$$
\begin{gathered}
\mathrm{H}-\mathrm{C} \equiv \mathrm{C}-\mathrm{H} \\
\tilde{\mathrm{X}}^{1} \Sigma_{\mathrm{B}}^{+}
\end{gathered} \underset{\mathrm{H}-\mathrm{C} \equiv \mathrm{C}+\mathrm{H}}{\tilde{\mathrm{X}}^{2} \Sigma^{+}}
$$

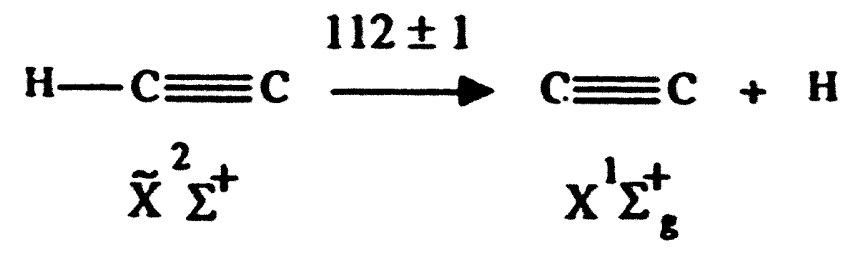


$88.1 \pm 0.4$

$$
\begin{array}{ll}
\mathrm{CH}_{3} \mathrm{CH}_{3} \stackrel{8}{\longrightarrow} \mathrm{CH}_{3}+\mathrm{CH}_{3} \\
\widetilde{\mathrm{X}}^{1} \mathrm{~A}_{1 \mathrm{~g}} & \widetilde{\mathrm{X}}^{2} \mathrm{~A}_{2}^{\prime \prime} \quad \widetilde{\mathrm{X}}^{2} \mathrm{~A}_{2}^{\prime \prime}
\end{array}
$$

$$
\begin{aligned}
& \mathrm{H}-\mathrm{C} \equiv \mathrm{C}-\mathrm{H} \stackrel{229 \pm 1}{\longrightarrow} \mathrm{H}-\mathrm{C}+\mathrm{C}-\mathrm{H} \\
& \tilde{X}^{1} \Sigma_{g}^{+} \\
& \mathrm{x}^{2} \Pi \quad \mathrm{x}^{2} \Pi
\end{aligned}
$$

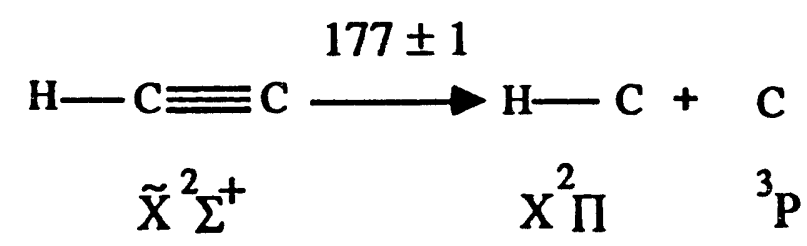

$145.2 \pm 0.5$

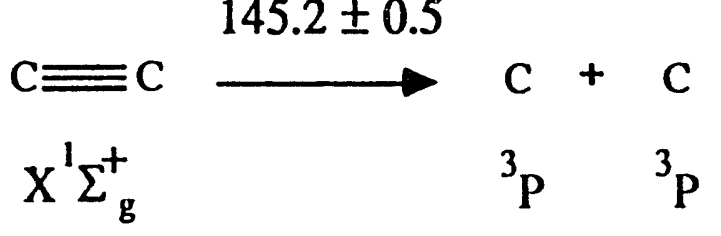

$$
\begin{array}{ll}
\mathrm{CH}_{3} \mathrm{CH}_{2} \stackrel{97 \pm 1}{\longrightarrow} \mathrm{CH}_{3}+\mathrm{CH}_{2} \\
\tilde{\mathrm{X}}^{2} \mathrm{~A}^{\prime} & \tilde{\mathrm{X}}^{2} \mathrm{~A}_{2}^{\prime \prime} \quad \widetilde{\mathrm{X}}^{3} \mathrm{~B}_{1}
\end{array}
$$

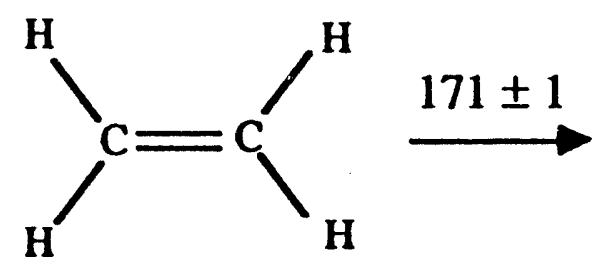

$\tilde{\mathrm{X}}^{1} \mathrm{~A}_{\mathrm{g}}$
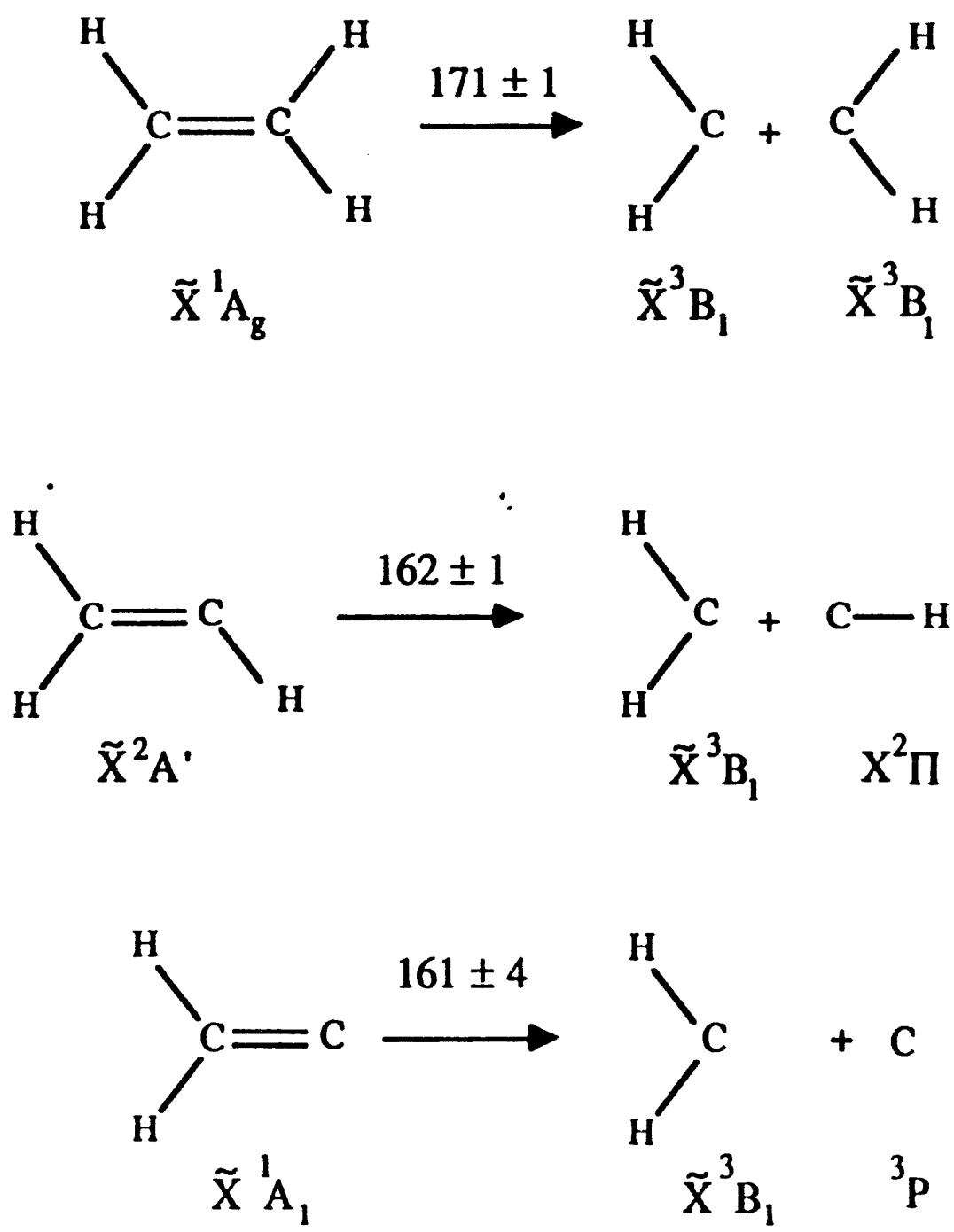


\section{Chart II}

\section{Acetaldehyde Experimental Bond Strengths $\left(D_{0}\right.$ in $\left.\mathrm{kcal} \mathrm{mol}^{-1}\right)$}

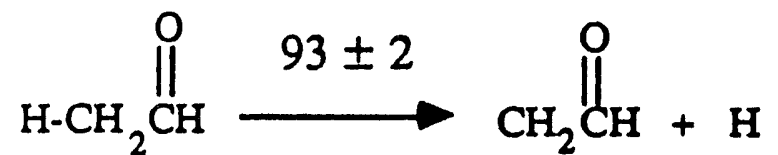

$\tilde{\mathrm{X}}^{1} \mathrm{~A}^{\prime}$
$\mathrm{CH}_{3} \mathrm{C}-\mathrm{O} \stackrel{87.9 \pm 0.5}{\longrightarrow}$

$\tilde{\mathrm{X}}^{1} \mathrm{~A}^{\prime}$
$\mathrm{CH}_{3} \stackrel{\mathrm{C}}{\mathrm{C}}+\mathrm{H}$

$\tilde{\mathrm{X}}^{2} \mathrm{~A}^{\prime}$
$\mathrm{CH}_{2} \mathrm{CH} \stackrel{\mathrm{C}}{\longrightarrow} \mathrm{CH}_{2}=\mathrm{C}=\mathrm{O}+\mathrm{H}$

$\tilde{\mathrm{X}}^{2} \mathrm{~A} "$

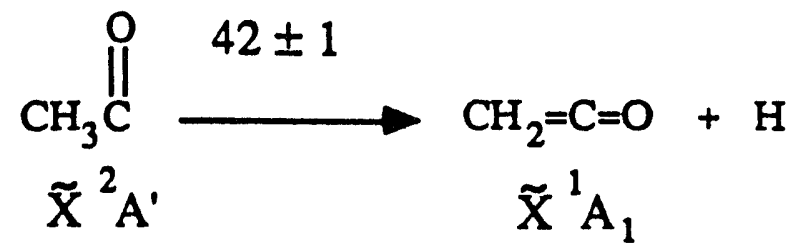

$\underset{\tilde{\mathrm{X}}_{3} \mathrm{~A}^{\prime}}{\stackrel{\mathrm{O} H}{82.7 \pm 0.3} \underset{\mathrm{A}_{3}}{\mathrm{CH}_{3}}+\underset{\mathrm{HCO}}{\tilde{\mathrm{X}}^{2} \mathrm{~A}_{2}^{\prime \prime}} \tilde{\mathrm{X}}^{2} \mathrm{~A}^{\prime}}$

$\mathrm{CH}_{2} \stackrel{\mathrm{CH}}{99 \pm 2} \longrightarrow \mathrm{CH}_{2}+\mathrm{HCO}$

$\tilde{\mathrm{X}}^{2} \mathrm{~A}^{\prime \prime}$

$\tilde{\mathrm{X}}^{3} \mathrm{~B}_{1} \quad \tilde{\mathrm{X}}^{2} \mathrm{~A}^{\prime}$

$\underset{\tilde{\mathrm{X}}_{3}^{2} \mathrm{~A}^{\prime}}{\stackrel{\mathrm{O}}{\mathrm{CH}^{\prime}} \stackrel{9.4 \pm 0.5}{\longrightarrow} \underset{\tilde{\mathrm{X}}^{2} \mathrm{~A}_{2}^{\prime \prime}}{\mathrm{CH}_{3}}+\mathrm{X}^{1} \Sigma^{+}}$ 
Methanol Experimental Bond Strengths $\left(D_{0}\right.$ in kcal mol-1)

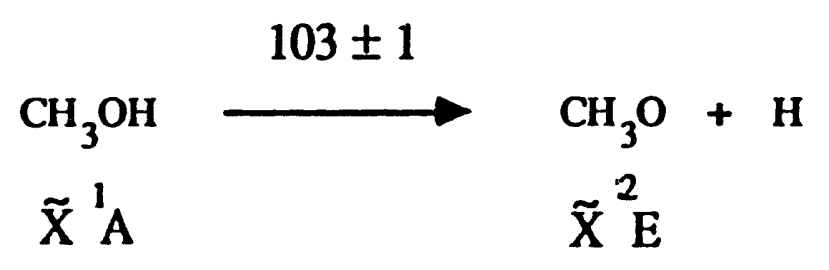

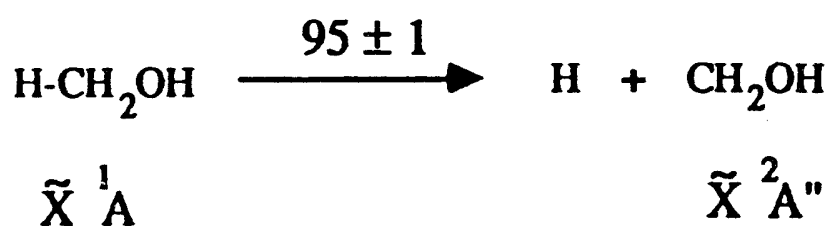

$\mathrm{CH}_{3} \mathrm{O} \stackrel{21 \pm 1}{\longrightarrow} \mathrm{CH}_{2} \mathrm{O}+\mathrm{H}$

$\tilde{\mathrm{X}}^{2} \mathrm{E} \quad \tilde{\mathrm{X}}^{1} \mathrm{~A}_{1}$

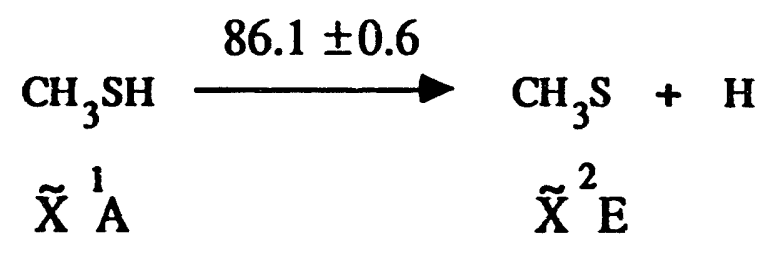

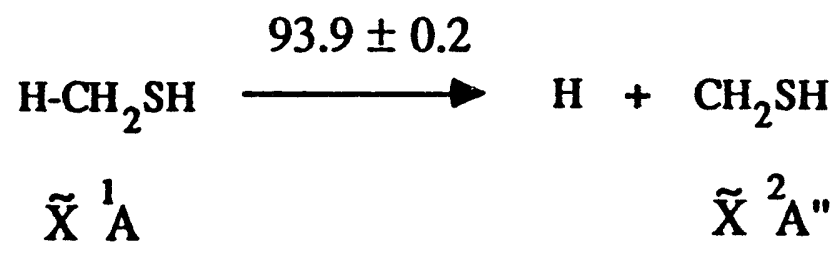

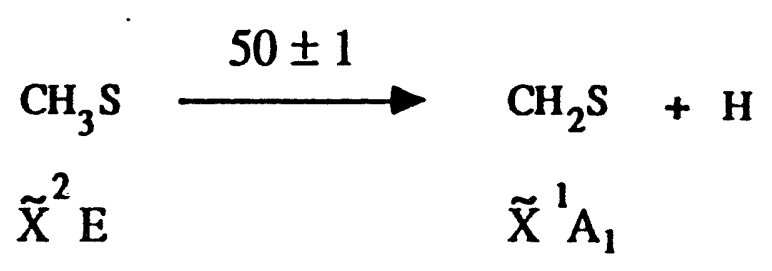




$$
\begin{aligned}
& \mathrm{CH}_{2} \mathrm{OH} \stackrel{29 \pm 1}{\longrightarrow} \mathrm{CH}_{2} \mathrm{O}+\mathrm{H} \\
& \tilde{\mathrm{X}}^{2} \mathrm{~A}^{\prime \prime} \quad \tilde{\mathrm{X}}^{1} \mathrm{~A}_{1}
\end{aligned}
$$

$$
\begin{array}{ll}
\mathrm{CH}_{3} \mathrm{OH} \stackrel{90.3 \pm 0.4}{\longrightarrow} & \mathrm{CH}_{3}+\mathrm{OH} \\
\tilde{\mathrm{X}}^{1} \mathrm{~A} & \tilde{\mathrm{X}}^{2} \mathrm{~A}_{2}^{\prime \prime} \quad \mathrm{X}^{2} \Pi
\end{array}
$$

$$
\begin{aligned}
& \mathrm{CH}_{3} \mathrm{O} \stackrel{89 \pm 1}{\longrightarrow} \mathrm{CH}_{3}+\mathrm{O} \\
& \tilde{\mathrm{X}}^{2} \mathrm{E} \quad \tilde{\mathrm{X}}^{2} \mathrm{~A}_{2}^{\prime \prime} \quad{ }^{3} \mathrm{P}
\end{aligned}
$$

$$
\begin{aligned}
& \mathrm{CH}_{2} \mathrm{OH} \stackrel{104 \pm 1}{\longrightarrow} \mathrm{CH}_{2}+\mathrm{OH} \\
& \tilde{\mathrm{X}}^{2} \mathrm{~A}^{\prime \prime} \quad \tilde{\mathrm{X}}^{3} \mathrm{~B}_{1} \quad \mathrm{X}^{2} \Pi
\end{aligned}
$$

$$
\begin{array}{ll}
\mathrm{CH}_{2} \mathrm{SH} \stackrel{42 \pm 1}{\longrightarrow} \mathrm{XH}_{2} \mathrm{~S}+\mathrm{H} \\
\tilde{\mathrm{X}}^{2} \mathrm{~A}^{\prime \prime} & \widetilde{\mathrm{X}}^{1} \mathrm{~A}_{1}
\end{array}
$$

$$
\begin{array}{ll}
\mathrm{CH}_{3} \mathrm{SH} \stackrel{73 \pm 1}{\longrightarrow} \underset{\mathrm{X}^{1} \mathrm{~A}}{\mathrm{CH}_{3}+\mathrm{SH}} \\
\tilde{\mathrm{X}}^{2} \mathrm{~A}_{2}^{\prime \prime} \cdot \mathrm{X}^{2} \Pi
\end{array}
$$

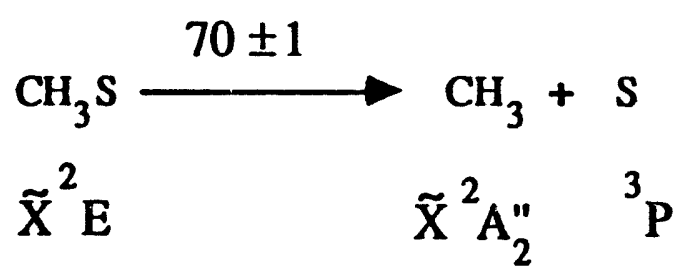

$$
\begin{array}{ll}
\mathrm{CH}_{2} \mathrm{SH} & \stackrel{88 \pm 1}{\longrightarrow} \\
\tilde{\mathrm{X}}^{2} \mathrm{~A}^{\prime \prime} & \mathrm{CH}_{2}+\mathrm{SH} \\
& \tilde{\mathrm{X}}^{3} \mathrm{~B}_{1} \quad \mathrm{X}^{2} \Pi
\end{array}
$$




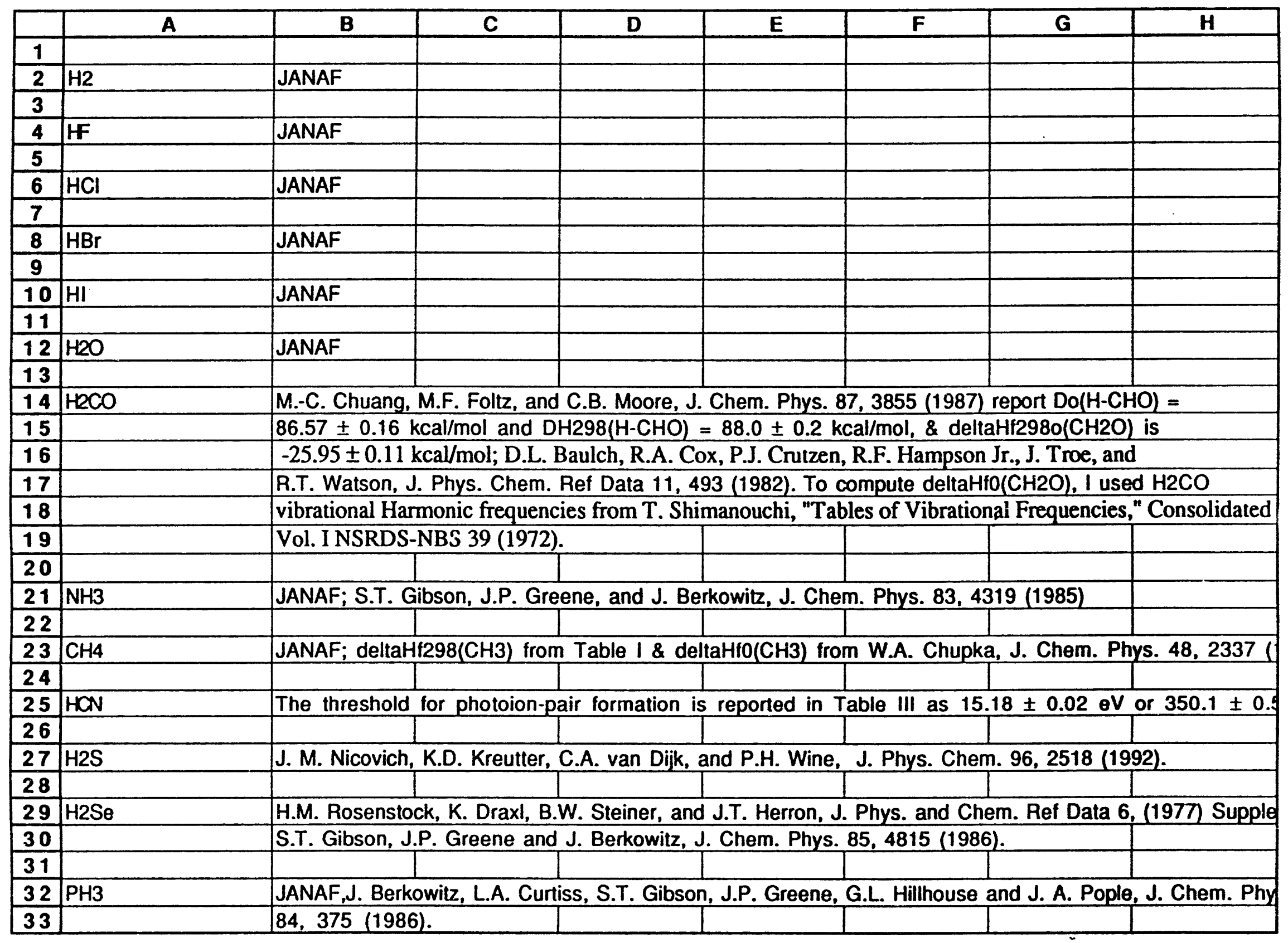




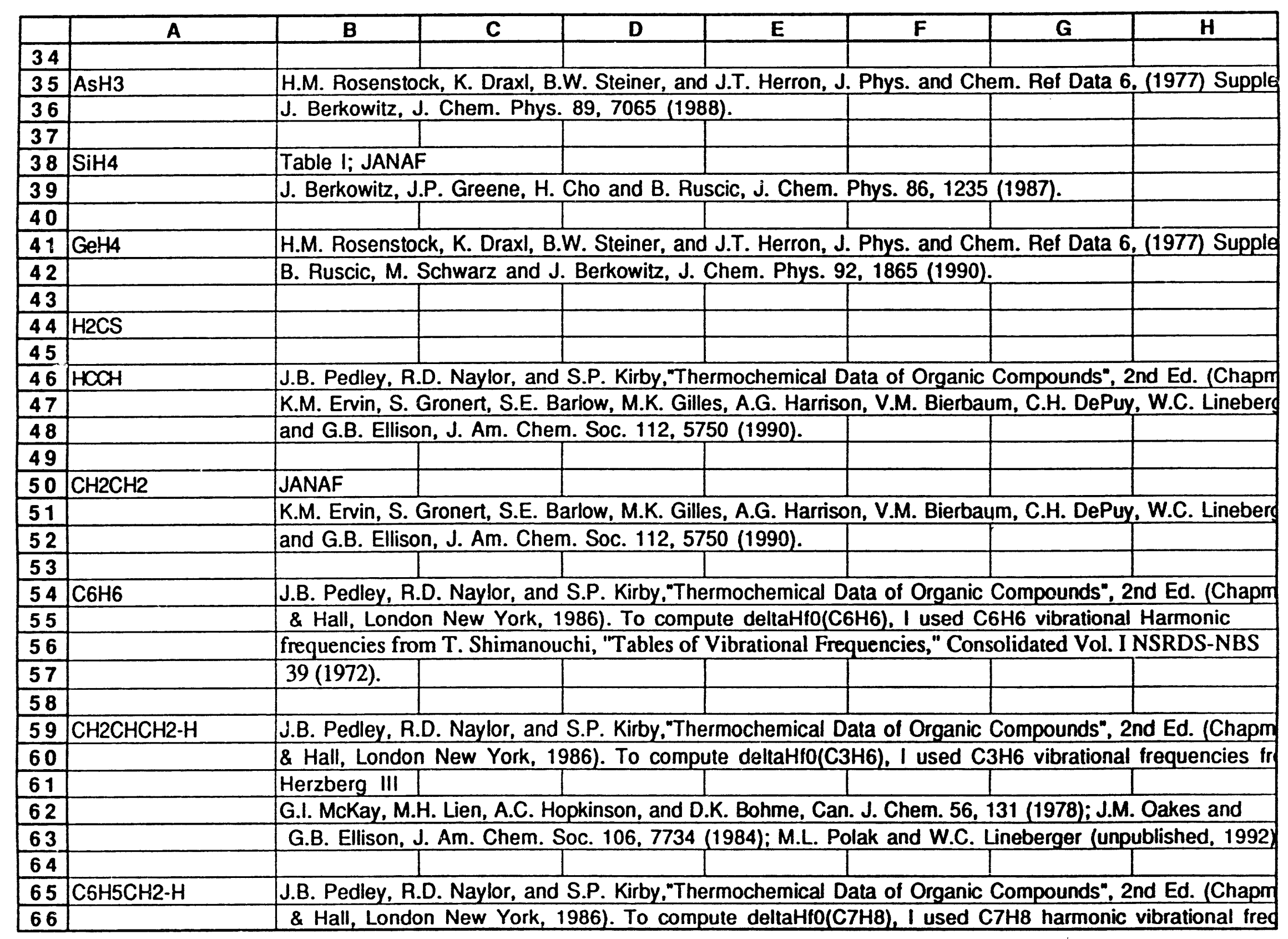




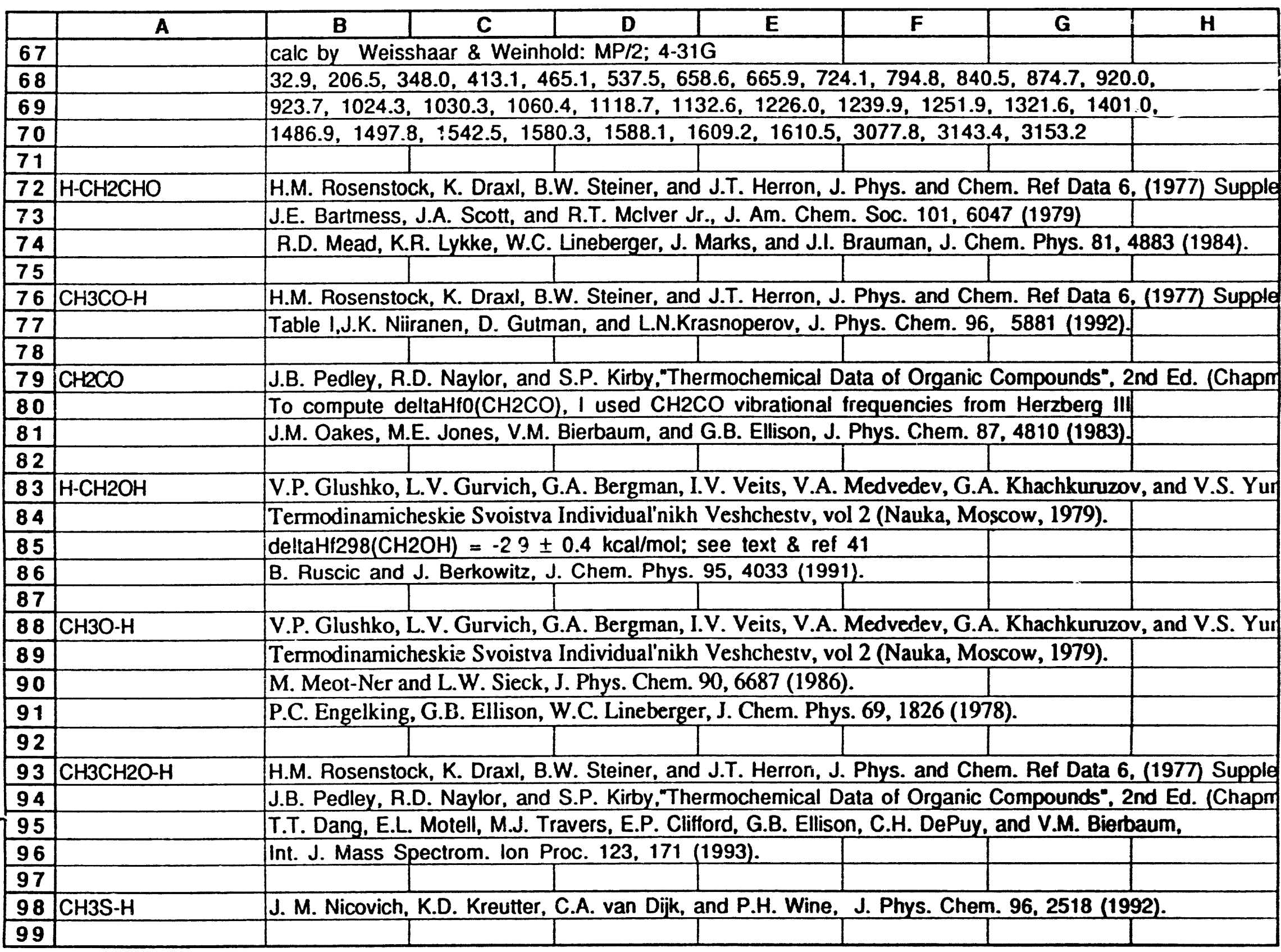




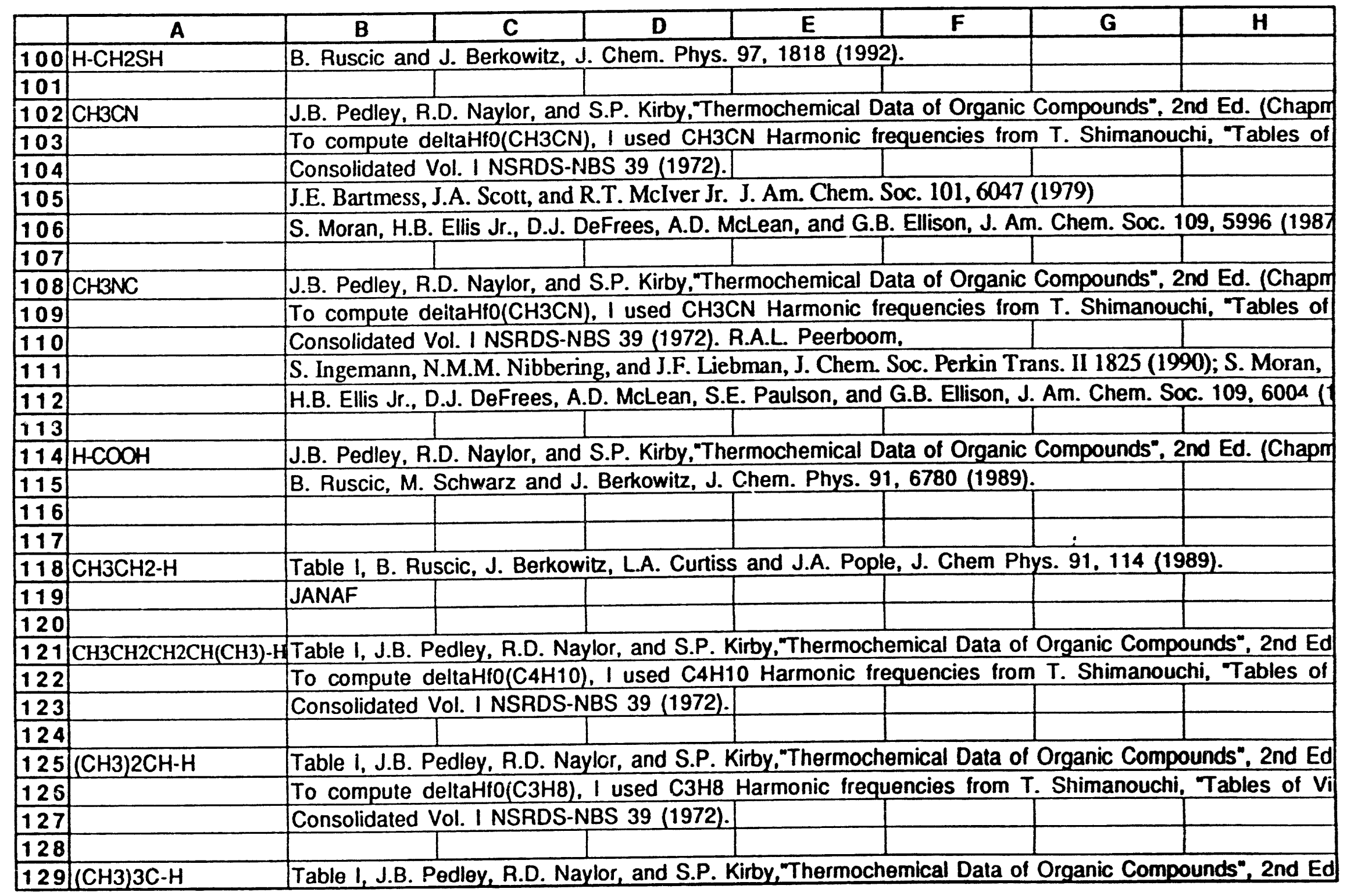




\begin{tabular}{|c|c|c|c|c|c|c|c|c|c|c|c|c|c|c|c|}
\hline & A & $\bar{B}$ & C & $\bar{D}$ & $\bar{E}$ & $\mathbf{F}$ & $\mathbf{G}$ & H & 1 & J & $\mathrm{K}$ & $L$ & $\mathbf{M}$ & $\bar{N}$ & $\mathbf{0}$ \\
\hline 1 & & Constants & from Coh & en \& Ta & ylor/1986 & & & & & & & & & & \\
\hline 2 & Temp $=$ & 298.15 & & so & 207.226 & $\mathrm{~cm}-1$ & & & & & & & & & \\
\hline 3 & $\mathbf{R}=$ & 1.987216 & $\mathrm{cal} / \mathrm{mol}$ & and & 0.59249 & $\mathrm{kcal} / \mathrm{mol}$ & & & & & & & & & \\
\hline 4 & $\mathbf{k}=$ & $1.38 \mathrm{E}-16$ & $\mathrm{erg} / \mathrm{K}$ & & & & & & & & & & & & \\
\hline 5 & $c=$ & $3 \mathrm{E}+10$ & $\mathrm{~cm} / \mathrm{sec}$ & & & & & & & & & & & & \\
\hline 6 & $h=$ & $6.63 \mathrm{E}-27$ & erg sec & so & 0.69504 & $\mathrm{~cm}-1 / \mathrm{K}$ & & & & & & & & & \\
\hline 7 & $1 \mathrm{~atm}=$ & 1013250 & dyne/cm & & & & & & & & & & & & \\
\hline 8 & Avogadro no. & $6.02 \mathrm{E}+23$ & atoms/m & 4.184 & & & & & & & & & & & \\
\hline 9 & H mass (amu) & 1.00783 & O mass & 15.99 & $\mathbf{F}$ mass $=$ & 18.998 & & & & & & & & & \\
\hline 10 & C mass (amu) & 12 & $\mathbf{N}$ mass & 14 & & & & & & & & & & & \\
\hline 11 & Cl mass (amu) & 34.96885 & $\operatorname{Br}(79)=$ & 78.92 & & & & & & & & & & & \\
\hline
\end{tabular}




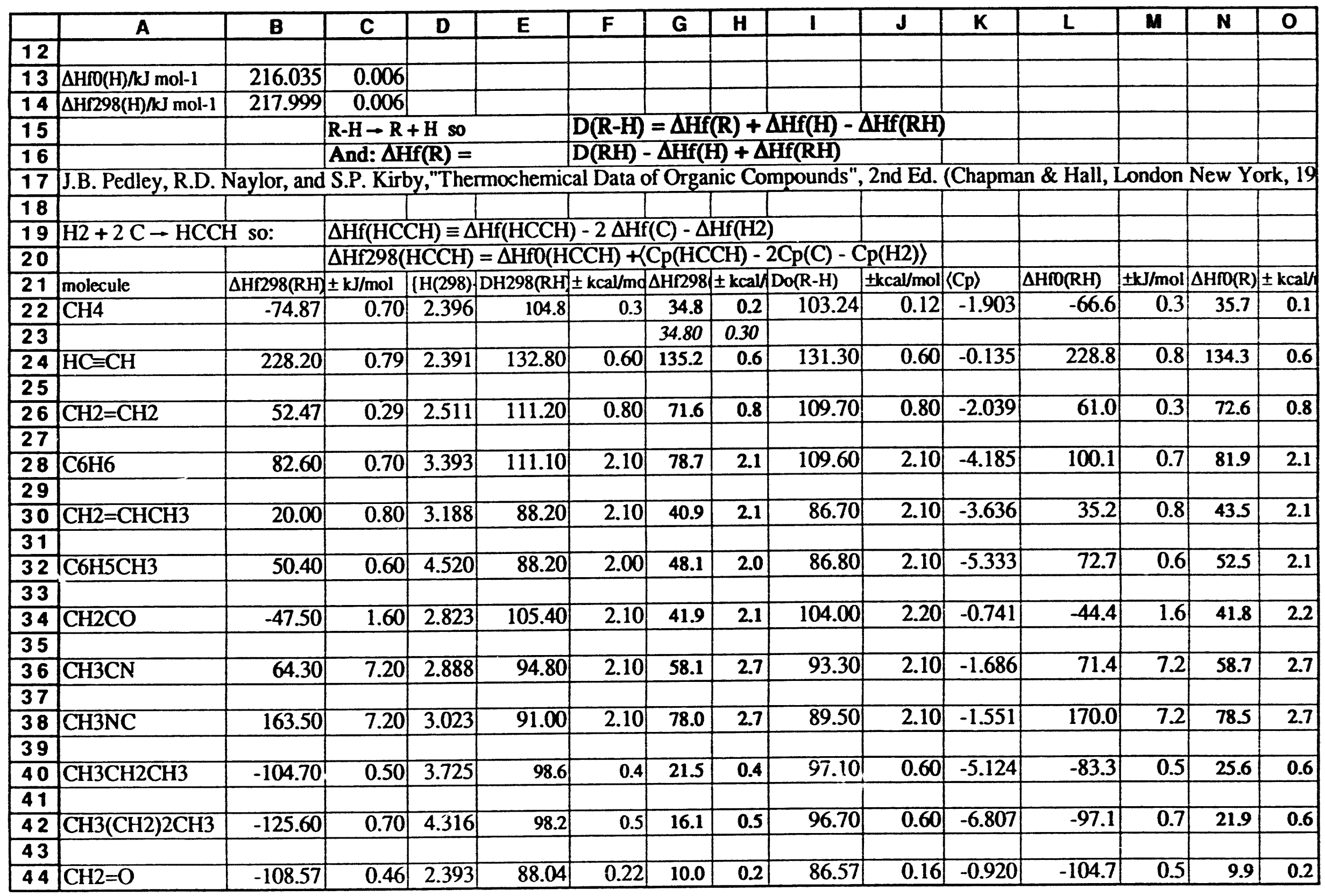




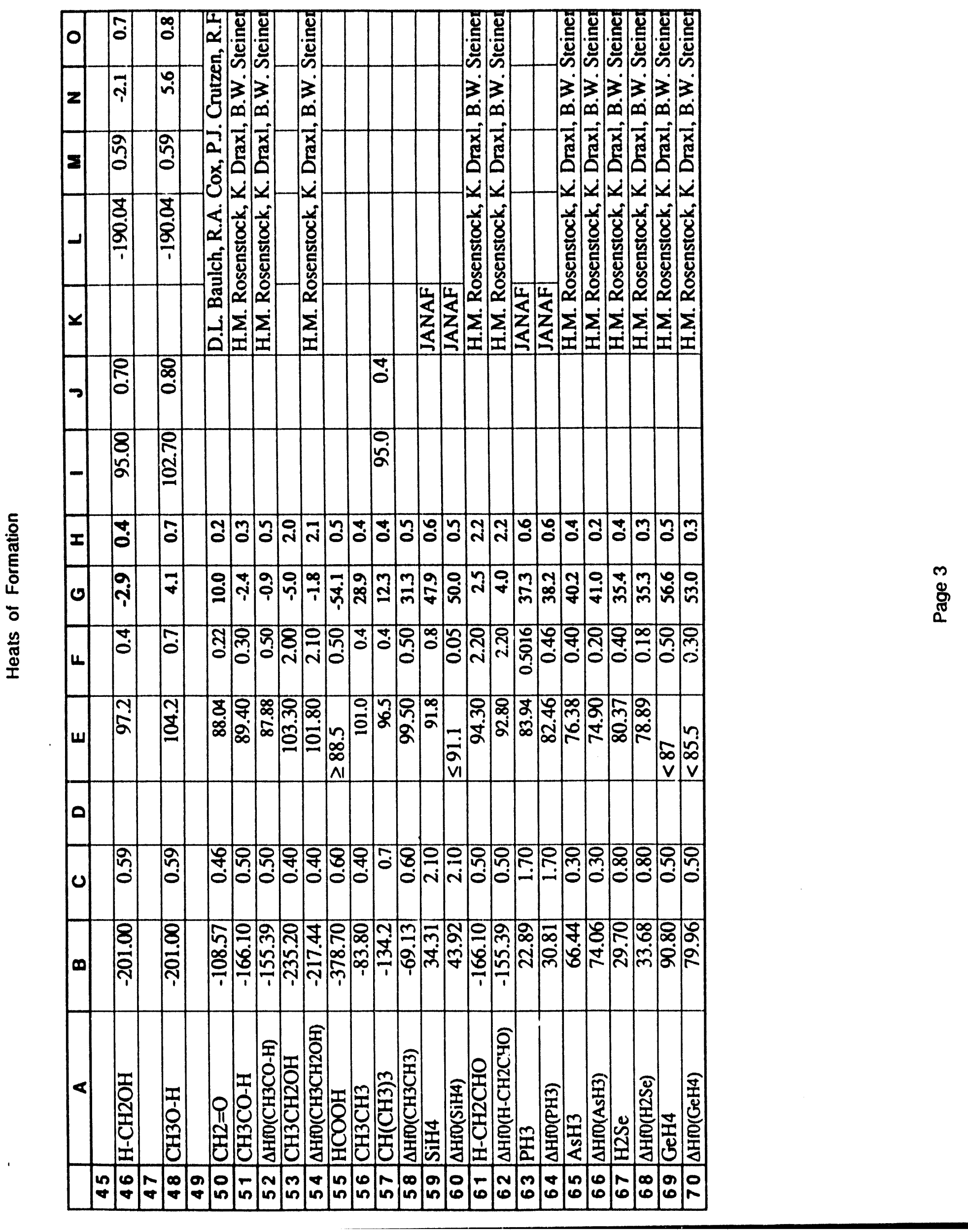




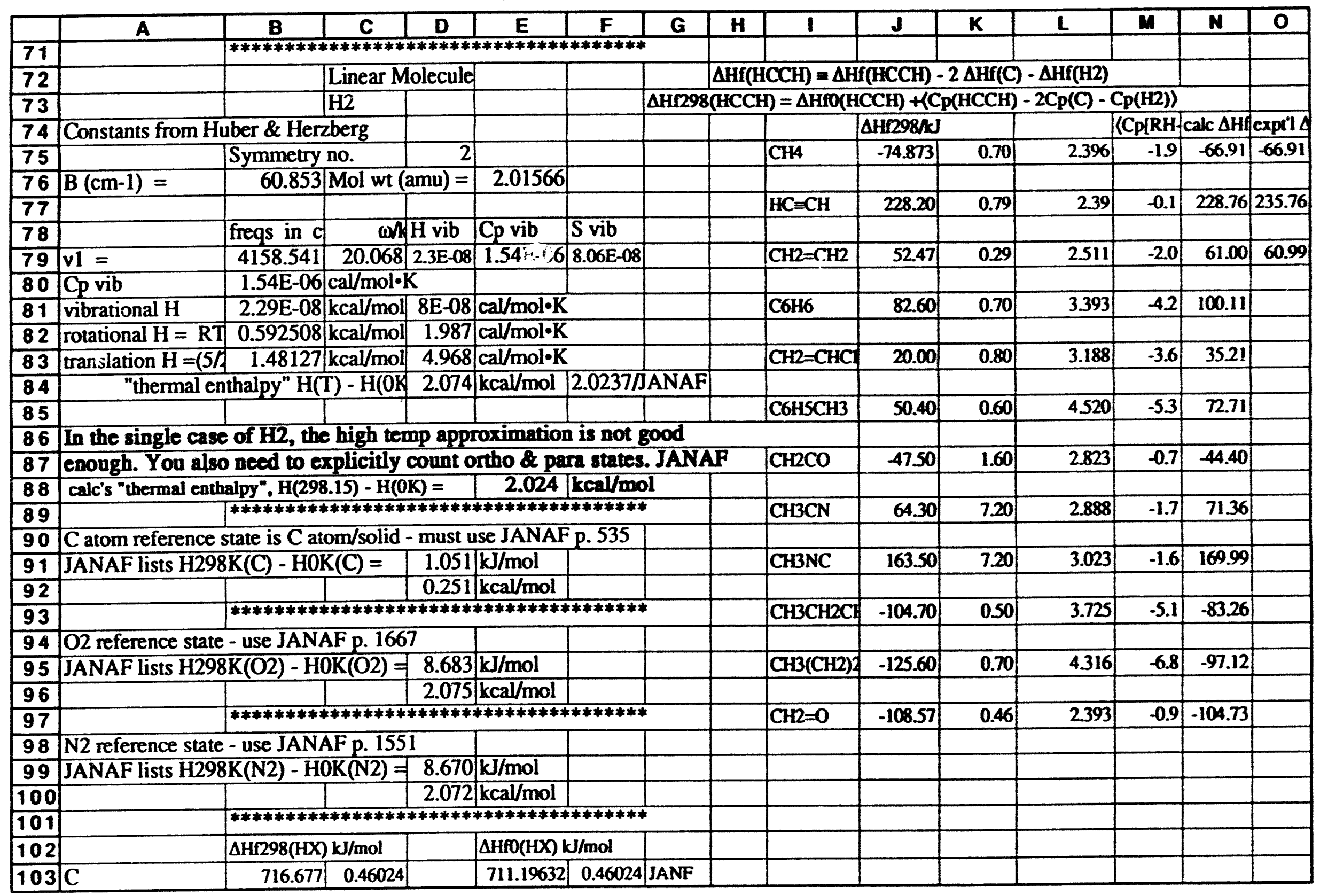




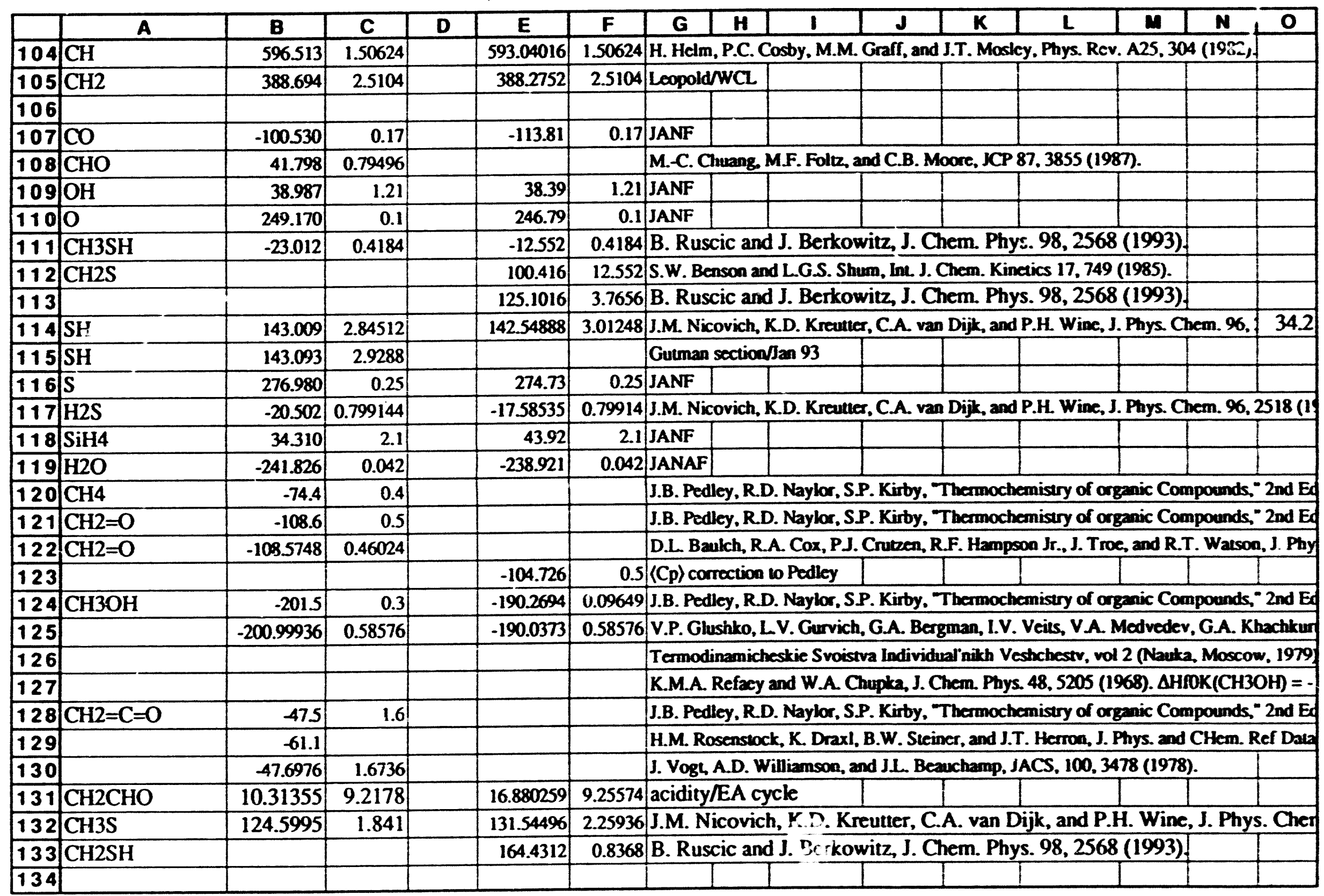




\begin{tabular}{|c|c|c|c|c|c|c|c|c|c|c|c|c|c|c|}
\hline & $\mathbf{B}$ & C & $\mathbf{D}$ & $\mathbf{E}$ & $\mathbf{F}$ & $\mathbf{G}$ & H & $I$ & J & $\mathbf{K}$ & $\mathbf{L}$ & $\mathbf{u}$ & $\mathbf{N}$ & 0 \\
\hline 135 & & & & DH298/kcal & $\mathrm{kal} / \mathrm{mol}$ & & & Dorkal & \pm kcallmol & & & & & \\
\hline 136 & $\mathrm{CH} 3 \mathrm{CHO} \rightarrow \mathrm{CH} 3 \mathrm{CO}+\mathrm{H}$ & & & 89.4 & 0.3 & & & 87.9 & 0.5 & & & & & \\
\hline 137 & $\mathrm{CH} 3 \mathrm{CHO} \rightarrow \mathrm{CH} 2 \mathrm{CHO}+\mathrm{H}$ & & & 94.3 & 2.2 & & & 92.8 & 2.2 & & & & & \\
\hline 138 & $\mathrm{CH} 3 \mathrm{CO} \rightarrow \mathrm{CH} 2 \mathrm{CO}+\mathrm{H}$ & & & 43.2 & 0.5 & & & 41.9 & 0.6 & & & & & \\
\hline 139 & $\mathrm{CH} 2 \mathrm{CHO} \rightarrow \mathrm{CH} 2 \mathrm{CO}+\mathrm{H}$ & & & 38.3 & 2.2 & & & 37.0 & 2.2 & & & & & \\
\hline 140 & $\mathrm{CH} 3 \mathrm{CHO} \rightarrow \mathrm{CH} 3+\mathrm{CHO}$ & & & 84.5 & 0.3 & & & 82.7 & 0.3 & & & & & \\
\hline 141 & $\mathrm{CH} 3 \mathrm{CO} \rightarrow \mathrm{CH} 3+\mathrm{CO}$ & & & 13.2 & 0.4 & & & 9.4 & 0.5 & & & & & \\
\hline 142 & $\mathrm{CH} 2 \mathrm{CHO} \rightarrow \mathrm{CH} 2+\mathrm{CHO}$ & & & 100.4 & 2.3 & & & 98.7 & 2.3 & & & & & \\
\hline 143 & & & & & & & & & & & & & & \\
\hline 144 & $\mathrm{CH} 3 \mathrm{OH} \rightarrow \mathrm{CH} 3 \mathrm{O}+\mathrm{H}$ & & & 104.2 & 0.7 & & & 102.7 & 0.8 & & & & & \\
\hline 145 & $\mathrm{CH} 3 \mathrm{OH} \rightarrow \mathrm{CH} 2 \mathrm{OH}+\overline{\mathrm{H}}$ & & & 97.2 & 0.4 & & & 95.0 & 0.7 & & & & & \\
\hline 146 & $\mathrm{CH} 3 \mathrm{O} \rightarrow \mathrm{CH} 2 \mathrm{O}+\mathrm{H}$ & & & 22.1 & 0.7 & & & 21.0 & 0.8 & & & & & \\
\hline 147 & $\mathrm{CH} 2 \mathrm{OH} \rightarrow \mathrm{CH} 2 \mathrm{O}+\mathrm{H}$ & & & 29.1 & 0.4 & & & 28.7 & 0.8 & & & & & \\
\hline 148 & $\mathrm{CH} 3 \mathrm{OH} \rightarrow \mathrm{CH} 3+\mathrm{OH}$ & & & 92.2 & 0.4 & & & $\begin{array}{l}90.3 \\
\end{array}$ & 0.4 & & & & & \\
\hline 149 & $\mathrm{CH} 3 \mathrm{O} \rightarrow \mathrm{CH} 3+\mathrm{O}$ & & & 90.3 & 0.7 & & & 89.0 & 0.8 & & & & & \\
\hline 150 & $\mathrm{CH} 2 \mathrm{OH} \rightarrow \mathrm{CH} 2+\mathrm{OH}$ & & & 105.1 & 0.8 & & & 104.0 & 1.0 & & & & & \\
\hline 151 & & & & & & & & & & & & & & \\
\hline 152 & $\mathrm{CH} 3 \mathrm{SH} \rightarrow \mathrm{CH} 3 \mathrm{~S}+\mathrm{H}$ & & & 87.4 & 0.5 & & & 86.1 & 0.5 & & & & & \\
\hline 153 & $\mathrm{CH} 3 \mathrm{SH} \rightarrow \mathrm{CH} 2 \mathrm{SH}+\mathrm{H}$ & & & & & & & 93.9] & 0.2 & & & & & \\
\hline 154 & $\mathrm{CH} 3 \mathrm{~S} \rightarrow \mathrm{CH} 2 \mathrm{~S}+\mathrm{H}$ & & & & & & & 50.1 & 1.0 & & & & & \\
\hline 155 & $\mathrm{CH} 2 \mathrm{SH} \rightarrow \mathrm{CH} 2 \mathrm{~S}+\mathrm{H}$ & & & & & & & 42.2 & 0.9 & & & & & \\
\hline 156 & $\mathrm{CH} 3 \mathrm{SH} \rightarrow \mathrm{CH} 3+\mathrm{SH}$ & & & 74.5 & 0.7 & & & 72.8 & 0.7 & & & & & \\
\hline 157 & $\mathrm{CH} 3 \mathrm{~S} \rightarrow \mathrm{CH} 3+\mathrm{S}$ & & & 71.2 & 0.6 & & & 69.9 & 0.6 & & & & & \\
\hline 158 & $\mathrm{CH} 2 \mathrm{SH} \rightarrow \mathrm{CH} 2+\mathrm{SH}$ & & & & & & & 87.6 & 1.0 & & & & & \\
\hline
\end{tabular}

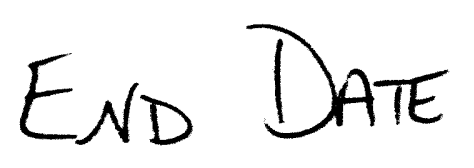

$1-14-94$ 